\title{
Storms and Jobs: The Effect of Hurricanes on Individuals' Employment and Earnings over the Long Term
}

by

\author{
Jeffrey A. Groen $\dagger$ \\ U.S. Bureau of Labor Statistics
}

Mark J. Kutzbach ${ }^{\oplus}$

U.S. Census Bureau

Anne E. Polivka:

U.S. Bureau of Labor Statistics

\section{CES 15-21 August, 2015}

The research program of the Center for Economic Studies (CES) produces a wide range of economic analyses to improve the statistical programs of the U.S. Census Bureau. Many of these analyses take the form of CES research papers. The papers have not undergone the review accorded Census Bureau publications and no endorsement should be inferred. Any opinions and conclusions expressed herein are those of the author(s) and do not necessarily represent the views of the U.S. Census Bureau. All results have been reviewed to ensure that no confidential information is disclosed. Republication in whole or part must be cleared with the authors.

To obtain information about the series, see www.census.gov/ces or contact Fariha Kamal, Editor, Discussion Papers, U.S. Census Bureau, Center for Economic Studies 2K132B, 4600 Silver Hill Road, Washington, DC 20233, CES.Papers.List@ census.gov. 


\begin{abstract}
We study the responsiveness of individuals' employment and earnings to the damages and disruption caused by Hurricanes Katrina and Rita, which struck the U.S. Gulf Coast in 2005. Our analysis is based on individual-level survey and administrative data that tracks workers over time, both in the immediate aftermath of the storm and over a seven-year period. For individuals who were employed at the time of the storm, we estimate models that compare the evolution of earnings for individuals who resided in storm-affected areas and individuals who resided in a set of control counties with pre-storm characteristics similar to those of the storm-affected areas prior to the storm. We find that, on average, the storms reduced the earnings of affected individuals during the first year after the storm. These losses reflect various aspects of the shortrun disruption caused by the hurricanes, including job separations, migration to other areas, and business contractions. Starting in the third year after the storms, however, we estimate that the storms increased the quarterly earnings of affected individuals. We provide evidence that the long-term earnings gains experienced by affected individuals were the result of differences in wage growth between the affected areas and the control areas, due to reduced labor supply and increased labor demand, especially in sectors related to rebuilding. Despite short-term earnings losses due to an increased rate of non-employment, we find a net increase in average quarterly earnings among affected individuals over the entire post-storm period. However, subgroups with large and persistent earnings losses after the storms had a net decrease in average quarterly earnings over the seven-year period due to the storms.
\end{abstract}

Keyword: Disaster, Hurricane, Employment, Earnings, Local Labor Markets, Katrina, Rita JEL Classification: J6, Q54, R23

\footnotetext{
* We have benefitted from the comments of participants at the Southern Regional Science Association annual meeting, the BLS-Census Research Workshop, the Urban Economics Association annual meeting, the American Economic Association annual meeting, the University of Maryland, the Population Association of America meeting, the Society of Labor Economists meeting, Penn State University, and the Federal Reserve Board. We are grateful to Ken Couch, Robert Dunn, Graton Gathright, Clark Gray, Jesse Gregory, Erika McEntarfer, and Till von Wachter for helpful discussions and detailed comments. We thank Ron Jarmin and Javier Miranda for providing the FEMA shape files used in their analysis and guidance on how to use those files. Any opinions and conclusions expressed herein are those of the authors and do not necessarily represent the views of the U.S. Bureau of Labor Statistics or the U.S. Census Bureau. All results have been reviewed to ensure that no confidential information is disclosed.

$\dagger$ U.S. Bureau of Labor Statistics. E-mail: Groen.Jeffrey@bls.gov.

${ }^{\oplus}$ U.S. Census Bureau. E-mail: Mark.J.Kutzbach@census.gov.

† U.S. Bureau of Labor Statistics. E-mail: Polivka.Anne@bls.gov.
} 


\section{Introduction}

The 2005 Atlantic hurricane season was one of the most active on record. It included two storms that reached Category 5 strength (the highest on the Saffir-Simpson Hurricane Wind Scale) and caused significant damage to the United States, primarily along the U.S. Gulf Coast (Nordhaus, 2010). Hurricane Katrina, which made landfall on the Gulf Coast on August 29, was the costliest and one of the deadliest hurricanes in U.S. history with more than 1,800 deaths (Knabb, Rhome, and Brown, 2005; Blake, Landsea, and Gibney, 2011). The massive hurricane caused catastrophic flooding in New Orleans and devastating damage along the Gulf coasts of Alabama, Mississippi, and Louisiana. Hurricane Rita made landfall on the Texas-Louisiana border on September 24, devastating coastal communities in southeastern Texas and southwestern Louisiana and causing additional flooding in New Orleans (Knabb, Rhome, and Brown, 2006).

These hurricanes caused massive disruptions to people's lives and their ability to be engaged in gainful employment. Katrina, in particular, caused one of the largest and most abrupt relocations of people in U.S. history, as approximately 1.5 million people aged 16 years and older evacuated from their homes (Groen and Polivka, 2008a). The number of mass-layoff events in Louisiana and Mississippi rose sharply in September 2005 following Katrina (Brown and Carey, 2006). In the two months following Katrina, payroll employment declined by 35 percent in the New Orleans metropolitan area and by 12 percent in the entire state of Louisiana (Kosanovich, 2006). In addition to the short-term disruptions, the effects of Hurricane Katrina have been long lasting and far-reaching, permanently reshaping some communities and even challenging the economic viability and sustainability of others (Cutter et al., 2006; Elliott and Pais, 2006; Groen and Polivka, 2010; Vigdor, 2008).

The sheer magnitude of the physical destruction and the scale of the evacuation make the effects of Katrina and Rita worth studying. In addition, analysis of the effects of these storms could provide a reference point for other natural and man-made disasters, because these hurricanes were among the most destructive in U.S. history. ${ }^{1}$ Moreover, analysis of the effects of Katrina and Rita on individuals' economic status, including their employment and earnings, could have particular relevance for the study of economic dislocation due to job displacement

\footnotetext{
${ }^{1}$ Annual U.S. hurricane damages and related government spending are expected to increase over time due to climate change and an increase in the population of coastal areas (Nordhaus, 2010).
} 
(e.g., Jacobson, LaLonde, and Sullivan, 1993), local or regional shocks (e.g., Blanchard and Katz, 1992), and mass destruction (e.g., Davis and Weinstein, 2002).

In this paper we estimate the impact of residing in an area affected by a major storm on the evolution of employment and earnings. In particular, we examine the effects of Katrina and Rita on individuals' employment and earnings both in the immediate aftermath of the storms and over a seven-year period. Our analysis combines Census Bureau household-survey data with longitudinal earnings from administrative data (from the Longitudinal Employer-Household Dynamics program). The earnings data, reported by employers, allow us to track workers over time, even if they move across state lines. Our approach is to compare the evolution of earnings before and after the storms of individuals who resided (at the time of the storms) in stormaffected areas and individuals who resided in suitable control counties. For our preferred control group, the control counties are chosen to have worker characteristics, earnings trends, and economic conditions similar to those of the storm-affected areas prior to the storm.

Our emphasis on the longer-term impacts of hurricanes on individuals' employment and earnings is distinctive. ${ }^{2}$ Most studies analyzing the effects of Katrina, Rita, and other hurricanes on the labor market have concentrated on the effects on particular geographic areas rather than on individuals (e.g., Belasen and Polachek, 2008, 2009; Brown, Mason, and Tiller, 2006; Clayton and Spletzer, 2006; Jarmin and Miranda, 2009; Strobl, 2011). The few studies that have examined the effects of Katrina on individuals' employment and earnings have examined the impact on labor-market outcomes only during the first year after the storm (Elliot and Pais, 2006; Groen and Polivka, 2008b; Vigdor, 2007; Zissimopoulos and Karoly, 2010).

An additional contribution of our paper is our approach to constructing a longitudinal dataset for analyzing the effects of a disaster on individuals. Other approaches use new surveys to collect post-disaster information from affected individuals (e.g., Paxson and Rouse, 2008; Sastry, 2009). Our approach, by using existing survey and administrative data, has the advantage of including post-disaster information with no respondent burden or recall bias. Our approach also provides a representative sample of the pre-disaster population.

Another paper that analyzes the long-term effect of Katrina on individuals' earnings is Deryugina, Kawano, and Levitt (2014). They use data from federal tax returns to investigate

\footnotetext{
${ }^{2}$ Analysis of the longer-term impacts of Hurricanes Katrina and Rita on other individual outcomes includes Sacerdote (2012) on schooling and Paxson et al. (2012) on mental health.
} 
effects on earnings, taxable income, and demographic outcomes. Although our paper is similar to Deryugina et al. (2014) in using administrative earnings data to address the long-term effects of Katrina, our paper has several advantages. First, our data and analysis are deeply rooted in the labor market, which allows us to identify the location and industry of pre-storm employment as well as use industry-specific estimates to shed light on the mechanism underlying our long-run earnings effects. Second, we employ detailed damage data (at the Census-block level) to assess how the storm impacts vary by the level of damage to workers' homes and workplaces and evaluate the roles of migration and job loss as channels. Third, the quarterly frequency of our earnings data enables us to track the immediate disruptive effect of the storms in greater detail and to apportion within-year earnings changes into effects due to shifts to non-employment and effects due to changes in earnings within employment. Fourth, by using local economic conditions in a propensity-score model for selecting a control area and by comparing labormarket indicators between the treatment and control areas before and after the storms, we explain the rise in earnings after the storm as being attributable to increased labor demand and decreased labor supply in the storm-affected areas.

The remainder of this paper is organized as follows. In Section 2, we describe potential mechanisms for how storm damage, labor-market shifts, and rebuilding could translate into changes in employment and earnings for affected workers. Section 3 describes the administrative data on employment and earnings as well as the data on storm damage that we use to examine worker outcomes. Section 4 explains the difference-in-differences methodology we use to estimate storm effects on earnings and introduces a decomposition that we use to analyze possible causes for earnings changes. Section 5 presents our main results comparing the evolution of worker outcomes in the treatment sample and the control sample. Section 6 gives our interpretation of how local labor-market shifts can explain long-run worker outcomes. Section 7 provides robustness checks and extensions of the main analysis. Section 8 concludes. The Data Appendix provides additional discussion of the data contributing to this analysis.

\section{Determinants of Effects on Employment and Earnings}

In this section, we outline how the storms may have disrupted jobs and some possible consequences for labor supply and labor demand in the affected areas. The effect of the storm on workers' employment and earnings will depend on the responses of workers, the responses of 
employers, and the interplay of these decisions within local labor markets. While having some common features across time, these effects may also differ depending on the length of time after the storm.

\subsection{Immediate Aftermath and Short-term Disruptions}

In the immediate aftermath of the storm, the effects on workers' earnings will be determined by the severe disruptions caused by the storm and by employers' and workers' reactions to these disruptions. Damage to facilities and infrastructure, as well as reduced demand due to evacuations and a lack of tourism, could force businesses to suspend or reduce operations and to lay off or furlough workers or reduce hours. Government statistics and news reports in the months following the storms noted numerous mass layoffs from both the private and public sectors (due both to short-term disruptions and anticipated reductions in tax revenue). ${ }^{3}$ Layoffs, furloughs, and reduced hours would decrease workers' earnings, with it being anticipated that the more severe the damage the greater would be the decline in workers' earnings.

Estimates indicate that reductions in employers' payrolls in the wake of the storm were substantial, with greater reductions in the most-damaged areas. Jarmin and Miranda (2009) found that in areas with catastrophic damage in Alabama, Louisiana, and Mississippi establishments' payrolls were 45 percent smaller in the fourth quarter of 2005 (the quarter after the storm hit) than they were in the same quarter a year earlier. Even among establishments that continued to report employment (thus excluding establishments that closed), Jarmin and Miranda found that payrolls of establishments in areas with catastrophic damage dropped 22 percent. In areas that were flooded, Jarmin and Miranda estimated that payrolls declined 49 percent overall and 15 percent among those that continued to report employment.

Independent of the response of employers, workers' own actions (especially their decision to evacuate) will also affect their earnings. Evacuees not afforded the opportunity to use paid leave (or without the ability to work remotely) would have a reduction in their earnings in the immediate aftermath of the storm. Activities related to being an evacuee such as finding temporary housing or obtaining aid combined with the psychological impact of being an evacuee also could reduce evacuees' desire and ability to work in the immediate aftermath of the storm.

\footnotetext{
${ }^{3}$ Bureau of Labor Statistics (October 25, 2005), "Mass Layoffs in September 2005." http://www.bls.gov/news.release/archives/mmls 10252005.pdf (accessed August 14, 2015). King, R. (October 26, 2005), "Katrina Blows Away 224,000 Local Jobs." The Times Picayune, p. A1. Varney, J. and Donze, F. (October 5, 2005), "N.O. Fires 3,000 City Workers.” The Times Picayune, p. A1.
} 
This reduction in the ability and desire to work would, correspondingly, reduce evacuees' earnings in the short term.

Workers remaining in the affected area could also have reduced desire and ability to work, being reflected in a higher reservation wage. Infrastructure damage and destroyed vehicles may prevent individuals from getting to or searching for work. Cleaning up after the storm, repairing damaged structures, and filing insurance forms could take precedence over working. The inability to get to work combined with the decreased marginal utility of working (compared to other activities necessitated by the storm) would decrease the earnings of those who did not evacuate. Similar to the effect of the storm on businesses' decisions to open, it is anticipated that in the short run the decrease in non-evacuees earnings would be greater the more damage an area suffered.

\subsection{Effects of Workers' Behavior on Earnings in the Medium and Longer Term}

Beyond the immediate disruptive effects of the storm, workers' earnings in the medium and longer term could be influenced by the consequences of involuntary job separations and changes in workers' budget constraints.

The literature on mass-displacement events (e.g., Jacobson et al., 1993) suggests that such separations, resulting in the loss of firm-specific human capital, can have long-run negative consequences on workers' earnings. Compounding these concerns, both evacuees and those who remain in storm-damaged areas may face higher job-search costs. Evacuees, who face uncertainty as to the degree of damage to their home or neighborhood, may be unsure whether the potential earnings of a temporary job justify the high cost of job search in a new location. They also may have difficulty accessing information about the local labor market and have higher search costs because of unfamiliarity with the market and lack of social networks in their new area. Those who remain in the affected area may face added complications in finding a job due to industry shifts in demand, damage to infrastructure and vehicles, and disruption to jobplacement services.

In the longer run, job losers amongst both those who evacuated and those who remained in storm-affected areas may experience higher wages than they would have otherwise. Migrants may experience wage gains if prior to the storm they were precluded from moving to the higherwage areas in which they settled by high moving costs (including the loss of social capital), information frictions, or their strong attachment to their pre-storm areas. Those separated from 
their pre-storm jobs who remained in storm-affected areas may have longer-term earnings gains if they are able to be easily absorbed by expanding sectors, retool quickly, or did not change jobs prior to the storm due to high job-search and job-transition costs.

Hurricanes Katrina and Rita resulted in $\$ 41.1$ billion and $\$ 5.2$ billion in insured property losses, respectively, with an additional $\$ 16.8$ billion payment from the National Flood Insurance Program. ${ }^{4}$ This large destruction of personal property, particularly if it was not completely insured, would decrease the wealth of many workers. In addition to the loss of wealth, the storm may have increased some workers' indebtedness as they attempted to rebuild or replace destroyed goods. Both a decrease in wealth and an increase in indebtedness would tightened the budget constraints of workers. Workers' budget constraints would be further tightened if the price of goods or housing increased after the storm or if the places to which individuals migrated had higher prices than storm-affected areas prior to the storm. ${ }^{5}$ Tighter budget constraints may induce workers to attempt to work more hours at their current jobs, take on extra jobs, or be employed more continuously in a given year. This increase in labor supply, in turn, would increase workers' earnings in the medium and long term. It should be noted, however, that the loss-of-wealth effect would be muted and offset by disaster-relief payments, government grants for rebuilding, and private-insurance payments.

\subsection{Effects of Employers' Behavior on Workers' Earnings in the Medium and Longer Term}

Although this study does not examine employer outcomes directly, storm damage, rebuilding strategies, and changes in demand for goods and services will have consequences for workers' earnings. First, damage from the storm could impose fixed costs to repair damaged facilities and inventories, which could be an obstacle for re-opening. Whether or not these fixed costs were a binding constraint and result in permanent closure might depend on access to insurance payments, rebuilding grants, and credit. One consequence of these fixed costs might be that only the employers that were more profitable and productive prior to the storm re-opened or continued operation. Increased prevalence of more-productive employers in the aftermath of

\footnotetext{
${ }^{4}$ Insured property losses (in 2005 dollars) reported by the Insurance Information Institute (Hartwig and Wilkinson, 2010); payment from the National Flood Insurance Program reported by FEMA ("Significant Flood Events (as of May 31, 2015)," http://www.fema.gov/significant-flood-events, accessed August 14, 2015).

${ }^{5}$ In particular, the price of housing in the storm-affected area may have increased because a large proportion of the area's housing stock was destroyed by the storm (Vigdor, 2008).
} 
the storm would be analogous to the "cleansing" effects of recessions (Caballero and Hammour, 1994; Basker and Miranda, 2014).

Second, employers may adopt more technologically advanced and less-labor-intensive means of production when they rebuild their businesses (Hallegatte and Dumas, 2008; Okuyama, 2003). For example, school districts may decide to consolidate some of their schools, retail stores may introduce self-checkout machines, casinos may introduce more-mechanized methods of gambling, and fishers could purchase more-mechanized boats.

Third, an employer's choice to continue operations, and at what scale, may be mediated by demand conditions in the affected area for an industry and whether that industry is tradable or non-tradable. In tradable sectors (e.g., agriculture, natural resources, and manufacturing), surviving businesses would be expected to return to pre-storm levels of output. In non-tradable sectors, demand would be negatively affected by the declines in population (due to evacuations and relocations), a reduction in purchasing power (of those who remain), decreases in tourism, and by the closure of other businesses. The exception would be construction, which would be expected to see high demand for rebuilding depending on the timing and distribution of disasterrelief payments, insurance payments, grants, and credit.

\subsection{Local Labor-Market Dynamics}

Local labor-market dynamics in storm-affected areas encompass the aggregate effects of both worker and employer responses. As discussed above, in the immediate aftermath of the storms, we anticipate reduced employment and earnings due to job disruption or separations. We anticipate that the closure or downsizing of businesses in the affected area would reduce labor demand in every industrial sector that is not directly related to rebuilding. The medium- and longer-term effects on labor demand in the storm-affected areas would vary across tradable and non-tradable sectors. Shifts in labor demand could also have spillover effects, with high-demand sectors crowding out other sectors and increasing wages. At the same time, labor supply could fall due to out-migration, higher search costs, higher reservation wages, and more home production. This drop would be mitigated by workers seeking more employment to finance home repair or if there is significant migration into the region of workers involved in reconstruction. In their analysis of hurricanes in Florida that incorporates both of these possible dynamics, Belasen and Polachek (2008) found that counties directly affected by a Category 4 or 
5 hurricane displayed a 4.8-percent reduction in employment and a 4.4-percent rise in earnings per worker in the quarter of impact. ${ }^{6}$

In tradable sectors, wages are typically determined by national factors due to cost equalization caused by trade. Consequently, wages for those who continue to work in the tradable sector would be expected to return to pre-storm levels (provided national demand did not change) unless local employers took the opportunity to modernize their production technology when they rebuilt. Even at the same pre-storm wage, workers in tradable sectors who remain in the storm-affected area may experience earnings gains if the reduction in local labor supply resulted in them obtaining more hours of work within a week or more steady employment across weeks.

In the construction industry and in other non-tradable sectors related to rebuilding, private and public reconstruction projects could boost both employment and wages. However, migration of construction workers into affected areas could limit the wage gains. Without sustained reconstruction funding, a lower population level might ultimately lead to fewer construction jobs.

In non-tradable sectors not related to rebuilding, after the initial short-term decline the effect on workers' wages and employment would depend on the relative magnitude of the shifts in labor supply (due to the decline in population) and labor demand along with the elasticities of labor supply and demand. The earnings of those who remain in storm-affected areas may remain depressed or rise above pre-storm levels depending on the outcome for the industry to which they are most attached.

The influence of local labor-market dynamics on workers who relocated to new areas are expected to be muted compared to the effect of local labor-market dynamics for those who did not migrate. Nevertheless, the influx of migrants to destination areas (e.g., Houston) may have reduced wages of some migrants working in non-tradable sectors due to an increase in labor supply (De Silva et al., 2010; McIntosh, 2008).

\footnotetext{
${ }^{6}$ Belasen and Polachek (2008) also found some industry variation, including a positive effect on construction and service-sector earnings and negative effects on earnings in manufacturing; trade, transportation, and utilities; and finance, insurance, and real estate.
} 


\section{Data}

We draw on a wide range of public-use and confidential data. In this section, we outline our worker and earnings data, damage data, and how the treatment and control groups are defined. See the Data Appendix for additional discussion of the worker and earnings data, assembly of the estimation sample, sample weights, and damage data.

\subsection{Worker Data}

To examine longitudinal outcomes for individuals in the treatment and control samples, we make use of restricted-access administrative and survey data brought together at the U.S. Census Bureau. The sample of individuals for our analysis is composed of respondents to the 2000 Census long-form and the American Community Survey (ACS) from January 2003 through July 2005, before Hurricane Katrina struck. The survey responses are limited to persons aged 25 to 59 in 2005 and provide information on demographics (age, sex, race, and ethnicity) and educational attainment. We determine a 2005 residential location (county and Census block) for each person using an annual address file based on federal administrative records. Because the majority of these records are sourced from the addresses on federal income-tax returns (which are typically filed in the first four months of the year), the locations are a good representation of pre-storm location.

We use unique person identifiers to match the survey records for this sample to earnings records from the Longitudinal Employer-Household Dynamics (LEHD) program for the two years prior to the storms (starting in 2003 quarter 3, or 2003:3) and seven years after the storms (through 2012 quarter 3, or 2012:3). LEHD is an employer-employee matched database of jobs, with each record consisting of the earnings by a worker at an employer in a quarter, reported to states for Unemployment Insurance (UI) coverage purposes. These job records are linked to employer workplace, industry, and size information in the Quarterly Census of Employment and Wages (QCEW) file for each state. LEHD data do not cover some sectors, including selfemployment, the federal government, the postal service, and the armed forces (Stevens, 2007). Unpaid family work, some agricultural jobs, and jobs at some non-profits also are not covered. Still, LEHD earnings records cover approximately 96 percent of private-sector, non-farm wageand-salary employment. The national collection of earnings records is crucial for our approach because it allows us to follow workers over time, even if they move across state lines. Our 
earnings data begin in 2003:3 because Mississippi first provided earnings records for that quarter.

Our primary sample from the survey and administrative records consists of workers with substantial ties to the labor market at the time of the storm; for this sample, we require that individuals had LEHD earnings for each of the nine quarters from 2003:3 to 2005:3 and that they had a job that spanned July 1, 2005 (the beginning of the quarter in which the storms occurred). For the job held on July 1, 2005 (or the highest-earning one in 2005:2 if a worker has multiple such jobs), we link to the employer's industry (NAICS code) and establishment location to examine differential effects of the storm on workers. ${ }^{7}$

\subsection{Damage Data}

We use two sources of damage data in the analysis. The first is a county-level measure. The second is a more spatially detailed measure that provides the degree of damage on streets and in neighborhoods. We use these measures to define a treatment area and assign a type of damage to individuals' residences and workplaces.

The U.S. Department of Housing and Urban Development (HUD) (2006) compiled the first measure, which tabulates the number of occupied housing units in counties of Texas, Louisiana, Mississippi, and Alabama with uninsured storm damage to real and personal property. The damage assessments for Katrina and Rita were based on direct inspection of housing units to determine eligibility for Federal Emergency Management Agency (FEMA) housing assistance. For our analysis, we use the share of units in a county with major (between $\$ 5,200$ and $\$ 29,999$ ) or severe $(\$ 30,000$ or higher) damage to define the treatment area (with shares based on the total number of occupied housing units according to the 2000 Census). Figure 1 maps this countylevel damage share for the set of 122 counties in these four states, with darker shading indicating counties with a greater share of damaged units. The darkest regions of the map are coastal areas in the vicinity of where Katrina (in eastern Louisiana and coastal Mississippi) and Rita (in western Louisiana) made landfall.

The second, more-detailed measure is based on Geographic Information Systems (GIS) shapefiles released by FEMA (2005) that indicate the degree and type of damage occurring in

\footnotetext{
${ }^{7}$ State UI earning records for multi-unit employers do not specify the establishment to which a worker is associated. For this study, we use the first establishment draw from a multiple-imputation model developed by the LEHD program to assign establishments to workers. The model uses establishment-size and commute-distance parameters estimated from data for Minnesota, which reports establishment assignments with its job records.
} 
sub-county areas defined by sets of latitude and longitude coordinates. Based on remote-sensing observations (satellite technology and airplane flyovers), FEMA designated areas as having Limited Damage, Moderate Damage, Extensive Damage, or Catastrophic Damage or being Flooded. For our analysis, we define "major damage" sub-county areas as comprising locations with Extensive or Catastrophic Damage as well as areas in and around New Orleans with flooding that persisted beyond September 10, 2005. We also define "minor damage" sub-county areas as comprising locations with Limited or Moderate Damage as well as areas with lesspersistent flooding (including New Orleans areas where flooding receded by September 10, 2005).

For illustrative purposes, Figure 2 displays maps of two affected areas by FEMA damage category, with red indicating major damage, dark blue indicating minor damage, and green indicating land areas with no specified damage. In addition to including areas with no damage, the green shading also includes sparsely populated areas that were not subject to structural damage (but may have had strong winds or flooding). Note that some nearby counties were not surveyed for damage by FEMA study; these counties had a relatively small share of damaged housing units as reported by HUD (2006). Panel A, which depicts the New Orleans area, shows mostly flooding damage, with minor damage in the areas where flooding receded quickly and major damage in the zones where it persisted. Panel B, which depicts the Gulf coast of Mississippi, shows mostly storm surge and wind damage, with catastrophic and extensive damage directly along the coast.

\subsection{Treatment Group}

In order to examine the effect of the storms on individuals' earnings, we define a treatment group and a control group. The treatment group is defined as individuals who resided, in 2005, in a county that experienced substantial damage from either Katrina or Rita.

Specifically, the treatment area is the set of 63 counties (or parishes) where at least 1 percent of the housing units sustained major or severe damage (according to the county-level estimates from HUD as described in the previous section). ${ }^{8}$ These counties (shown in Figure 3 in light shading), which stretch from Texas to Alabama, included 1.8 million occupied housing units, of which 278,957 (15.8 percent) had major or severe damage.

\footnotetext{
${ }^{8}$ Three of the 63 counties have less than 1 percent of housing units with major or severe damage; we included them in the treatment area because they are covered by the detailed sub-county damage data.
} 
Within the treatment area, we also identify the degree of damage occurring in neighborhoods and city blocks (as discussed in the previous section). We use this more-detailed classification both to characterize the range of damage for our sample and to examine whether a greater amount of local damage leads to larger effects on individuals. There are 22 counties with sub-county major and minor damage reported by FEMA (2005); these counties include all of the high-damage counties (as defined by HUD) as well as some of the moderate-damage and lowdamage counties. For these counties, we identify the set of Census blocks intersecting with either type of damage (major or minor) and assume that the most severe damage type applies to all addresses located within each block. ${ }^{9}$ We regard the remainder of blocks in these 22 surveyed counties as having no damage. For blocks in the remainder of the 63-county treatment area, damage is uncertain but likely to be of lower frequency and intensity.

\subsection{Propensity-Score Matched Control Group}

A key aspect of our empirical approach is the selection of control counties with pre-storm characteristics similar to those of the storm-affected areas. We use a propensity-score methodology to identify a set of control counties with worker characteristics, earnings trends, and economic conditions similar to those of the treatment counties prior to the storm. Our methodology follows the approach taken by Sommers, Long, and Baicker (2014) in their study of mortality after a state health-care reform. More generally, our approach is similar in spirit to a synthetic control group as in Abadie, Diamond, and Hainmueller (2010).

The primary source of the county-level characteristics for the propensity-score model is our matched survey-administrative worker data, including the requirement of employment during nine quarters from 2003:3 to 2005:3 and continuous employment at a job from 2005:2 to 2005:3. We use these data to construct county-level means of variables for demographic characteristics (shares by race/ethnicity and educational attainment), industry composition (based on the prestorm job), and average quarterly earnings for each of the eight quarters from 2003:3 to 2005:2. ${ }^{10}$ Given the cyclical dynamics of the 2000s, with a housing boom through 2006 and the Great

\footnotetext{
${ }^{9}$ We used ArcGIS to intersect the FEMA (2005) shapefiles with TIGER/Line shapefiles for Census 2000 tabulation blocks. See Figure A4 for maps overlaying the damage areas with boundaries of Census blocks.

${ }^{10}$ In calculating the means, we use person weights indicating the count of persons in 2005 represented by each record. Industry shares are based on the highest-earning 2005:2-to-2005:3 job. Although we combine agriculture and natural resources in a single industry category for the main analysis (due to the small share of employment in each), we use separate categories for the propensity-score model because trends in energy prices may affect local areas differently depending on their employment shares in natural resources (Marchand, 2012).
} 
Recession beginning in 2007, it is important that we match not only the population characteristics but also pre-storm economic conditions. Therefore, we include four additional county-level measures: (1) the percent of individuals who were highly attached to the labor force in the pre-storm period (defined using the same condition as our sample), (2) the unemployment rate in 2004 , (3) the change in housing prices from 2000:2 to 2005:2, and (4) the change in total population from July 1, 2000, to July 1, 2005. ${ }^{11}$ We restrict the set of counties to the 63 in the treatment area and to 2,393 other counties in the continental United States. ${ }^{12}$

For the propensity-score model, we estimate a logit model with a binary outcome, where counties in the treatment area have the indicator 1 and all other counties have the indicator 0 . This method estimates the association between county characteristics and the treatment area. ${ }^{13}$ To select the control sample, we use the parameter estimates to predict, within sample, the probability that each county might be a treatment county. We sort the control candidates by propensity score in descending order and select the top 5 percent of counties using population weights (so that counties representing 5 percent of the candidate county population are chosen). ${ }^{14}$ Our control area includes 286 counties in 26 states. $^{15}$ Figure 3 maps the control counties (in dark shading), which are concentrated in the coastal Southeast and Mid-Atlantic, Appalachia, and along the Mississippi river, with a scattering across northern Michigan, the Great Plains, and western mountain regions.

To examine the robustness of our main results, we also consider three alternative control groups, described in Section 7.1.

\footnotetext{
${ }^{11}$ See the Data Appendix for definitions and data sources for these measures.

${ }^{12}$ In defining the set of potential controls, we exclude all counties in Texas, Louisiana, Mississippi, and Alabama because these states include the treatment counties and we do not want our control group to capture geographic spillovers to areas adjacent to the treatment counties. We exclude all counties in Florida because it is adjacent to the treatment area and was affected by another 2005 hurricane, Hurricane Wilma. We exclude Alaska, Hawaii, Puerto Rico, and the Washington DC metropolitan area because we are concerned about issues of seasonality and data completeness in those areas (the LEHD data does not include federal workers). We also exclude 130 counties because they had less than 150 person records in the underlying survey data.

${ }^{13}$ In the logit model, we use the population weights so that counties with a larger sample population have a greater effect on the estimates. The coefficient estimates are reported in Table A1.

${ }^{14}$ Even for this top 5 percent, there is a wide degree of variation along any particular characteristic. Thus, each control county is not necessarily similar to the treatment area along all dimensions. Rather, a control county may be very similar in several dimensions but less similar on other dimensions.

${ }^{15}$ Each county includes at least 150 person records in the sample, with a median of approximately 600, and no state accounts for more than 23 percent of the control-sample records.
} 


\subsection{Summary Statistics}

For our sample of Census/ACS respondents linked to LEHD earnings records, Table 1 provides the resulting sample sizes and summary statistics (percentages and means) of variables prior to the storm describing worker characteristics, earnings, and local economic conditions for the treatment sample, potential control sample, and matched control sample. Our primary sample of high-attachment workers contains approximately 445,000 workers, including 110,000 workers in the treatment sample and 335,000 workers in the matched control sample. ${ }^{16}$ For comparison, we also include summary statistics for the potential control sample, which consists of the 6.7 million workers who resided in counties that were eligible for inclusion in the matched control sample.

While the treatment sample differs from the potential control sample in some notable ways, it is very similar to the matched control sample along a range of worker characteristics and local economic conditions (as we intended; see Table A4 for standardized differences). Prior research (e.g., Groen and Polivka, 2008a) documented that the storm-affected areas had a higher proportion of blacks, lower levels of educational attainment, and lower earnings than the rest of the country. Correspondingly, compared to the potential control sample, the treatment sample has more blacks, lower educational attainment, and lower earnings. In terms of industry (based on jobs held in the quarter before the storms), the treatment sample has greater concentrations in agriculture and natural resources (including mineral extraction), construction, leisure and accommodations, and healthcare. ${ }^{17}$ In contrast to differences between the potential control and treatment sample, once we use propensity-score matching to select control counties, our matched control sample is very similar to the treatment sample. For example, average quarterly earnings prior to the storm (2005:2) are $\$ 10,640$ for the treatment sample, $\$ 12,318$ for the potential control sample, and $\$ 10,833$ for the matched control sample. The matched control and treatment samples also align closely on local economic conditions, although the treatment sample has somewhat lower labor-force attachment and population growth prior to the storm.

\footnotetext{
${ }^{16}$ Observation counts are rounded to the nearest 1,000 persons.

${ }^{17}$ LEHD files provide industry, but the earnings records do not indicate the occupation of a worker. In comparisons using survey-reported industry (and occupation), we also find broad similarities between the treatment and control samples. We do not include survey-reported industry (or occupation) in the analysis because the responses may not apply to the job held in 2005 .
} 
Table 2 gives the distribution of damage types for the treatment sample, calculated by matching a worker's 2005 residence location and 2005:2 workplace location to the FEMA (2005) damage files. Workplace damage is slightly more common, with 24.8 percent having major or minor workplace damage and only 17.3 percent having major or minor residence damage. This imbalance is partially attributable to the concentration of employment in urban areas near the coast, with some workers commuting from further inland. The remainder have no damage or uncertain damage, with uncertainty due to either imprecision in residence or workplace location or a lack of detailed damage surveys in some counties. ${ }^{18}$ Most of the uncertain cases are due to a lack of detailed damage data in counties where storm intensity was lower.

Table 3 presents a summary statistic on migration and confirms the well-known movement of people away from storm-affected areas. Making use of the longitudinal place-ofresidence data, we measure residential mobility (or the migration rate) as the share of each sample (treatment and control) living in a different location (county, commuting zone, or state) relative to 2005. ${ }^{19}$ Prior to the storms, the matched control sample (of high-attachment workers) had a larger propensity to migrate, with 3.4 percent residing in a different commuting zone in 2004 and 2005, compared to 2.3 percent in the treatment sample. After the storms, migration was greater for the treatment sample. The share of the treatment sample that changed locations between 2005 and 2006 was over twice the share of the control sample that did so. However, after 2006, the relative excess in the migration rate for the treatment sample diminishes; this easing coincides with return migration among some of those in the treatment sample that moved away from their 2005 locations in the aftermath of the storms (Groen and Polivka, 2010) as well as a higher baseline migration rate (both in- and out-migration) in the control area.

Migration trends for the high-attachment sample may not represent trends for the population as a whole. The lower panel of Table 3 shows migration rates for a broader sample, with no employment restriction in the pre-storm period. Relative to the high-attachment sample, the migration rates for the broader sample are larger but the difference in migration rates

\footnotetext{
${ }^{18}$ Table A5 provides the detailed categories used to construct the classifications in Table 2.

${ }^{19}$ Commuting zones are sets of counties that are related by commuting ties. They encompass all metropolitan and nonmetropolitan areas in the United States, and they are sensible units for defining local labor markets (Tolbert and Sizer, 1996; Autor, Dorn, and Hanson, 2013). For Table 3, we limit the sample to workers with an observed residence location at the county level or better in each year from 2003 to 2010, which reduces the sample by about 10 percent.
} 
between the treatment and control samples follows a similar time pattern. Notably, the migration rates in the year after the storm suggest a somewhat larger migration response in the broader sample; however, by 2010 the difference in the migration rates of treatment and control samples is similar in the broader sample and high-attachment sample.

\section{Methodology}

We identify the effect of Katrina and Rita on earnings by comparing the evolution of earnings before and after the storms of individuals in the treatment sample with individuals in the control sample. Our econometric framework exploits the panel nature of our earnings data to control for both time effects and individual fixed effects. The latter control for permanent differences between workers related to observable and unobservable characteristics. Our econometric approach is based on the specification that is standard in the job-displacement literature (e.g., Jacobson et al., 1993), with storm-affected individuals playing the role of displaced workers.

Our primary outcome variable is quarterly earnings. For each quarter from 2003:3 to 2012:3, we either observe earnings from one or more jobs for a worker in our sample or interpret zero earnings as the absence of any job in the quarter. The LEHD data express earnings in current dollars, and we convert the amounts into constant dollars as of 2005:2 using the Consumer Price Index. Including observations with zero earnings allows us to consistently use a balanced panel for our analysis, which means that we follow cohorts (defined by 2005 residence county) of workers over time before and after the storm. It also means that the earnings changes we capture are due to both (1) shifts between employment and non-employment and (2) changes in earnings within employment.

Our baseline specification is:

$$
Y_{i t}=\alpha_{i}+\gamma_{t}+\sum_{k} D_{i k} \delta_{k}+\varepsilon_{i t}
$$

The dependent variable $Y_{i t}$ is earnings of individual $i$ in quarter $t$. The term $\alpha_{i}$ is an individual fixed effect. The $\gamma_{t}$ terms are the coefficients on a set of quarterly dummy variables that capture the general time pattern of average earnings for the entire sample. The dummy variables $D_{i k}$ are equal to 1 if individual $i$ is in the treatment sample and the quarter is $k$ quarters before or after 2005:3, when the storms struck. (That is, $k=0$ for 2005:3, $k<0$ for quarters before 2005:3, and $k>0$ for quarters after 2005:3.) The coefficients on these variables, $\delta_{k}$, capture the 
difference between individuals in the treatment and control samples as of the $k$ th quarter before/after the storm, relative to this difference in the first quarter before the storm (2005:2). The estimation runs from 2003:3 $(k=-8)$ through 2012:3 $(k=28)$.

In order to obtain appropriate standard errors for our estimates of $\delta_{k}$, we aggregate the microdata into cells defined by 2005 residence county and calendar quarter. This aggregation leads to appropriate standard errors in this context because the values of the $D_{i k}$ variables are identical for all individuals within a county-quarter cell (Angrist and Pischke, 2009). The earnings variable at the cell level is average earnings in the county-quarter cell, weighted using sample weights. With average earnings as the dependent variable, we estimate the analogue to Equation (1) at the cell level, weighting by group size (the sum of the sample weights). In this regression, the person fixed effects in Equation (1) are replaced by county fixed effects based on individuals' 2005 county of residence. The county fixed effects fulfill the same purpose as the person fixed effects, but each county fixed effect represents an effect for a cohort of individuals rather than for a given individual. The estimates of $\delta_{k}$ that we obtain from the regression at the cell level are identical to those we obtain from estimating the individual-level model.

We define two additional earnings variables in order to decompose the effects identified from the baseline specification into effects due to shifts to non-employment and effects due to changes in earnings within employment. Note that our main earnings variable, $Y_{i t}$, includes zeros for person-quarter observations after the storm in which individuals do not have an earnings record. The first new variable, $Y_{i t}^{e}$, replaces any zeros in the post-storm period with the individual's earnings in the reference quarter, 2005:2 (denoted $\left.Y_{i *}\right)$; otherwise, $Y_{i t}^{e}=Y_{i t}$. This variable isolates changes in earnings within employment. The second new variable is the difference between the other two earnings variables: $Y_{i t}^{n}=Y_{i t}-Y_{i t}^{e}$. This variable, which is $-Y_{i *}$ for quarters in which $Y_{i t}=0$ and zero otherwise, isolates earnings losses due to shifts from employment to non-employment. ${ }^{20}$ We estimate our earnings model separately for each dependent variable $\left(Y_{i t}, Y_{i t}^{e}, Y_{i t}^{n}\right)$ on the full sample and obtain coefficients of interest $\left(\delta_{k}\right.$, $\left.\delta_{k}^{e}, \delta_{k}^{n}\right)$. Because $Y_{i t}=Y_{i t}^{e}+Y_{i t}^{n}$, it can be shown that $\delta_{k}=\delta_{k}^{e}+\delta_{k}^{n}$; that is, the overall effect

\footnotetext{
${ }^{20}$ As an example, consider a worker who earned $\$ 10,000$ in 2005:2, zero in 2005:3, and $\$ 15,000$ in 2005:4. These values would yield: $Y_{i 2005: 3}=0, Y_{i 2005: 3}^{e}=10,000, Y_{i 2005: 3}^{n}=-10,000, Y_{i 2005: 4}=15,000, Y_{i 2005: 4}^{e}=15,000$, and $Y_{i 2005: 4}^{n}=0$. In each quarter, $Y_{i t}=Y_{i t}^{e}+Y_{i t}^{n}$.
} 
of the storm on earnings is decomposed into (1) a part from earnings changes within employment and (2) a part from earnings losses due to shifts from employment to non-employment.

To estimate how storm effects vary across different groups of individuals according to demographic or workplace characteristics, we estimate a version of Equation (1) separately for each subgroup (e.g., college graduates). To estimate these regressions at the cell level, we use the microdata to select the relevant sample of individuals (e.g., college graduates), collapse the resulting data to the cell level, and estimate the analogue of Equation (1) at the cell level. In this specification, to facilitate discussion of the results, instead of producing estimates of storm effects for each quarter we produce estimates for three time periods after the storm: 2005:42006:3 (“short term"), 2007:4-2008:3 (“medium term"), and 2011:4-2012:3 (“long term"). These time periods are useful for describing the various effects of the storm in the short, medium, and long run, as outlined in Section 2. We also estimate a specification that produces average quarterly effects over the entire post-storm period (2005:4-2012:3) in order to assess aggregate impacts of the storm on individuals' earnings. This effect combines the short-run and long-run effects (which may diverge) into a total effect.

To examine how storm effects vary with the extent of hurricane damage, we distinguish individuals in the treatment sample by the damage category of their 2005 residence or workplace and compare individuals in a given damage category to the entire control sample. This analysis reflects the reality that the "treatment" of the storm varied across individuals in relation to the amount of storm damage they experienced. The specification we use for residence damage is: $Y_{i t}=\alpha_{i}+\gamma_{t}+\sum_{k} D_{i k}\left(\beta_{k}^{\text {maj }}\right.$ major $_{i}+\beta_{k}^{\text {min }}$ minor $_{i}+\beta_{k}^{u n c} u n c_{i}+\beta_{k}^{\text {none }}$ none $\left._{i}\right)+\varepsilon_{i t}$,

where major $_{i}$ is an indicator for residing in a Census block with major damage and $\beta_{k}^{m a j}$ is the estimated storm effect in quarter $k$ for individuals with major damage. The other damage variables and associated coefficients correspond to the other categories of residence damage: minor damage, uncertain damage, and no damage. The specification for damage to an individual's workplace is identical to Equation (2) except that it accounts for an additional category of damage: being employed outside the treatment area at the time of the storms (and thus, not subject to damage).

In order to estimate the damage specifications at the cell level, we modify the cell structure. Instead of defining cells by county and quarter, we define them by county/damage and quarter. We use the interaction of 2005 county of residence and damage category: for a given 
quarter, each treatment county may have multiple county/damage cells, one for each damage category observed among individuals whose 2005 residence was in that county. Because there is no damage in control counties, each control county has only one cell for a given quarter. With the cells defined this way, damage category is constant within cells and we can estimate the analogue to Equation (2) at the cell level.

\section{Main Results}

Average earnings (without any controls) for the treatment sample and matched control sample before and after the storm are shown in Figure $4 .^{21}$ Before the storm, average earnings is somewhat lower for the treatment sample than the control sample, but the difference in average earnings is fairly stable across quarters. In the aftermath of the storm, average earnings for the treatment sample fell relative to the control sample. However, the gap in average earnings between the treatment and control samples closed over time, and by the fifth quarter after the storm (2006:4) average earnings is larger in the treatment sample than in the control sample. Average earnings continued to be larger in the treatment sample for each quarter thereafter (through the end of our sample period), and the difference in average earnings widened over time. By 2012 (7 years after the storm), average quarterly earnings is higher in the treatment sample by an average of $\$ 575$ (2011:4-2012:3). ${ }^{22}$

\subsection{Effects on Earnings and Employment}

The general pattern in the plot of average earnings is reflected in our difference-indifferences results. Figure 5 presents estimates of storm effects on earnings, from our baseline specification. The estimates of $\delta_{k}$ for the pre-storm period demonstrate that the treatment and control samples had broadly similar trends in earnings prior to the storm, with no significant deviations from zero. The top panel of Table 4 shows the effect of the storm on earnings in the short, medium, and long term as well as over the entire post-storm period aggregated. In the first year after the storm, we find that the storms reduced the earnings of affected individuals. The effect during these four quarters $(\mathrm{k}=1-4)$ is a loss of $\$ 238$ per quarter, which is $2.2 \%$ of average

\footnotetext{
${ }^{21}$ Henceforth, when presenting the results we use the term "control sample" to refer to the matched control sample.

${ }^{22}$ The long-run decline in average earnings for both samples is due to requiring that the sample members be employed in before the storm but not requiring that they be employed after the storm. When we consider a broader sample (i.e., one without the restriction on pre-storm employment), average earnings does not decline after the storm. The regression model compares differences in changes across the treatment and control samples relative to the baseline quarter, so the long-run decline is absorbed in the quarter effects.
} 
pre-storm earnings in the treatment sample $(\$ 10,640)$. The largest estimated earnings loss in a quarter was $\$ 375$ (3.5\%), which occurred in the second quarter after the storm (2006:1).

By the second year after the storm, our estimates indicate that average earnings in the treatment sample had recovered from the losses experienced in the aftermath of the storm. In second year after the storm $(\mathrm{k}=5-8)$, our estimates are positive but generally not statistically different from zero. Subsequent to the second year, affected individuals continued to experience earnings gains relative to the control sample. Starting in the eighth quarter after the storm (2007:3) - 2 years after the storm — and continuing through the seventh year after the storm, our estimates are positive and statistically different from zero. The average effect for time periods subsequent to the second year after the storm is $\$ 437$ per quarter $(4.1 \%)$ during quarters $\mathrm{k}=8-18$ ( 2 to $4 \frac{1}{2}$ years after the storm) and $\$ 681$ per quarter (6.4\%) during quarters $\mathrm{k}=20-28$ (5 to 7 years after the storm). Over the entire post-storm period including the first and second year after the storm $(\mathrm{k}=1-28)$, we find that the storm led to a net increase in earnings of affected individuals of $\$ 392$ per quarter $(3.7 \%)$.

Figure 6 decomposes the overall effect on earnings in each quarter into two parts: (1) a part from earnings changes within employment and (2) a part from earnings losses due to shifts from employment to non-employment. The estimates indicate that the short-term losses in earnings over the first year after the storm are primarily the result of reductions in earnings due to shifts between employment and non-employment. This source accounts for 63 percent of the overall (negative) effect on earnings in the first full quarter after the storm $(2005: 4$, which is quarter 1 in Figure 6) and 96 percent in the second quarter after the storm. ${ }^{23}$ The estimated earnings losses due to shifts to non-employment are largest in the first through fourth quarters after the storm. In the third and fourth quarters after the storm, the estimated effect due to shifts between employment and non-employment remains negative whereas the estimated effect due to earnings changes within employment becomes positive. ${ }^{24}$

\footnotetext{
${ }^{23}$ Because our sample requires a job spanning 2005:2 and 2005:3, our decomposition is not sensitive to earnings losses due to non-employment in the quarter of the storms (2005:3, which is quarter 0 in Figure 6).

${ }^{24}$ As a check on our decomposition, we estimate a variant of our baseline model, replacing earnings as the dependent variable with an indicator for having a job in the quarter (i.e., having positive earnings). In this variant, the time pattern of the estimated storm effects is similar to the pattern of the estimated earnings losses due to shifts to non-employment; the largest negative effects on the probability of employment are about 4 percentage points (during the second and fourth quarters after the storm).
} 
The estimated earnings losses due to shifts to non-employment continue through the fourth year after the storm, but starting in the second year after the storm these earnings losses are eclipsed by the estimated earnings gains due to earnings changes within employment. As a result, the overall effect on earnings is positive starting in the second year after the storm and the effect is driven primarily by increased earnings within employment. In the fifth, sixth, and seventh years after the storm $(\mathrm{k}=17-28)$, the estimated earnings losses due to shifts to nonemployment are close to zero and the overall effect on earnings comes entirely from increased earnings within employment.

These results imply that starting in the second year after the storm those who were employed were already experiencing earnings gains. Earnings changes within employment may result from changes in wages, changes in hours worked (over the quarter, at all jobs), or both. We explore this issue in Section 6, but first we examine effects for subsets of our sample as anticipated by the discussion in Section 2 .

\subsection{Effects by Damage Type}

When we estimate storm effects separately by type of residence damage, there is a monotonic relationship between the severity of damage and the negative effects of the storm on earnings (Figure 7 and Table 4). Individuals that experienced major damage had the largest negative effects. These earnings losses are primarily in the short term, though they lasted for approximately two years after the storm. Specifically, those with major damage had an average quarterly earnings loss of $\$ 1,696(-15.9 \%)$ during the first year after the storm. Individuals who experienced minor damage also experienced short-term earnings losses, though these losses were smaller in magnitude and less persistent than the losses for those with major damage. Generally, the dispersion in effects by damage type is much greater in the short term than in the long term. After the initial negative shock, average earnings of individuals in each damage type improved relative to the control group. In the long term, our estimates of storm effects are positive and statistically significant for individuals in each damage type.

Although affected individuals with each type of residence damage experienced increases in average earnings relative to the control group in the long term, the net effect of the short-term earnings losses and long-term earnings gains depends crucially on damage type. For those with major damage, the storm led to a net decrease in earnings of $\$ 345$ per quarter $(-3.2 \%)$ over the seven-year period. By contrast, those with minor damage or no damage experienced a net 
increase in earnings. Specifically, those with minor damage had a net increase of $\$ 200$ per quarter (1.9\%), and those with no damage had a net increase of $\$ 414$ per quarter (3.9\%).

When we measure damage according to workplace rather than residence, the general pattern is similar. ${ }^{25}$ Notably, the negative short-term effects for those with major workplace damage $(\$ 1,531$, or $14.4 \%)$ are about the same as those with major residence damage. In addition, the long-term effect on earnings is positive for all categories of workplace damage, as it is for residence damage. Two differences between the results for workplace damage and those for residence damage: (1) the short-term earnings losses for those with minor workplace damage are somewhat larger than for those with minor residence damage and (2) the longer-term earnings gains for those with major workplace damage materialize four quarters earlier than the earnings gains for those with major residence damage. On average over the entire post-storm period, those with major workplace damage experienced a net decrease in earnings of \$118 per quarter $(-1.1 \%)$, while those with minor workplace damage or no workplace damage experienced a net increase in earnings (of $\$ 176$ per quarter [1.7\%] or $\$ 305$ per quarter [2.9\%], respectively).

\subsection{Effects by Subgroup}

In Tables 5 and 6, we examine storm effects on earnings by subgroup according to workplace and demographic characteristics, respectively. The estimated effects by industry sector (based on pre-storm employer) are consistent with shifts in the demand for tradable and non-tradable goods associated with the immediate impact of the storms and the subsequent recovery. Dolfman, Wasser, and Bergman (2007) found substantial heterogeneity in how industry sectors in New Orleans responded to the storm (after a short-term drop in all sectors), with tourism employment falling by half, professional services recovering, and construction employment rising by a third. As reported in Table 5, we find that short-term earnings losses are largest for individuals employed in leisure and accommodations (-8.7\%) and healthcare ($8.3 \%$ ) - both non-traded sectors unrelated to construction. A decrease in tourism in the affected areas after the storms hurt leisure-and-accommodations workers. A decrease in the demand for local services due to the evacuation and migration of a portion of the resident population hurt healthcare workers' earnings. For those in healthcare, the earnings losses moderated but

\footnotetext{
${ }^{25}$ In a specification (results not presented here) including both residence damage and workplace damage, we find that both factors appear to have independent and additive effects on earnings in the short run. In other words, there is no special interactive effect of having both residence and workplace damage.
} 
persisted in the long term (seventh year after the storm), at $-1.3 \%$ of pre-storm earnings. For individuals in leisure and accommodations, we estimate that the effect of the storm on earnings in the long term was essentially zero $(-0.3 \%)$.

The effects by industry are most positive for individuals in construction and in agriculture and natural resources. Those in construction experienced an earnings gain even in the short term (5.3\%), and in the long term they experienced strong earnings gains $(20.9 \%)$; these gains are presumably tied to the increased demand for construction services related to post-storm cleanup and rebuilding.

In the long term, our estimates indicate that workers experienced earnings gains in every industry except health care and leisure and accommodations. In addition to construction, the long-term gains were large for agriculture and natural resources (12.3\%), trade, transportation, and utilities (8.6\%) and professional services $(8.3 \%)$.

In terms of differences by demographic groups (Table 6), our estimates of short-term losses in earnings are larger for those who had college degrees (-4.4\%) than for those who had less education (close to zero for those with high school or less). Those with less education also had stronger earnings gains in the medium and long term. For instance, workers with less than a high school education at the time of the storm experienced a long-term earnings gain of 13.0 percent. The pattern of larger gains for those with less education could reflect that these workers were more likely to be employed in construction and/or were more able to work in recovery tasks requiring physical strength.

Our estimates by gender suggest that the earnings effects of the storm were worse for women than men. In particular, short-term earnings losses were larger for women $(-4.5 \%$, compared to $-1.0 \%$ for men) and long-term earnings gains were smaller for women $(4.0 \%$, compared to $9.2 \%$ for men). Again, these differences could reflect in part differences by industry and skill. Our estimates by race suggest that the earnings effects of the storm were worse for blacks than whites, especially in the short term. The short-term effects were $-6.5 \%$ blacks and $-1.2 \%$ for whites. Further, although blacks did experience earnings gains in the medium and long term, whites gained more. Specifically, the long-term effects were $7.9 \%$ for whites and $5.3 \%$ for blacks. The differences by race could reflect the differences by type of residence damage, because prior research on Katrina has documented that, among those living in 
New Orleans before the storm, blacks experienced greater residence damage (Fussell, Sastry, and VanLandingham, 2010; Groen and Polivka, 2010).

Although our discussion of Table 6 has emphasized differences across demographic groups in the short-term and long-term earnings effects of the storm, an important takeaway from these results is that the long-term earnings gains are widespread: affected individuals in all demographic groups have increased earnings (relative to the control group) by the seventh year after the storm.

\subsection{Role of Migration and Job Separations}

In the spirit of our subgroup analysis, we investigate how the earnings effects of the storm vary with migration status over the first year after the storm. Conceptually, examining earnings effects by migration status is potentially more complicated than examining earnings effects by demographic characteristics because migration itself can be considered a response to the disaster (Hunter, 2005). Rather than examining migration and earnings jointly over the time period of our study, in this section we keep our focus on earnings as the outcome of interest and define migration based on the initial response to the storm. Specifically, we measure migration for individuals in the treatment sample (7 percent of the sample; see Table 3 ) as an indicator for residential location being in a different commuting zone in 2005 and 2006 We use commuting zones to define migration because they are the best proxy for local labor markets that is available in our data.

With this measure of migration, we split the treatment sample into movers and nonmovers and estimate earnings effects by comparing each group to the control sample as a whole (analogous to our approach for estimating effects by damage type). (Note that the non-mover group contains individuals who may have moved away from their 2005 location after the storms, perhaps for several months, but returned as of 2006.) Our estimates of earnings effects, shown in the top panel of Figure 8 and panel A of Table 7, indicate that movers experienced much larger earnings losses in the short term. This is consistent with prior research on Katrina evacuees that compared those who relocated over the first year after the storm with those who did not (Groen and Polivka, 2008b; Vigdor, 2007). In the long term, we estimate that both movers and nonmovers experienced earnings gains. However, over the entire post-storm period aggregated, movers experienced a net decrease in earnings (-\$126/quarter [-1.2\%]) whereas non-movers experienced a net increase (\$442/quarter [4.2\%]). 
Over the first year after the storm, the estimated earnings losses for movers are about $\$ 1,699$ per quarter $(16.0 \%)$, similar to the short-term earnings losses for those with major residence damage. Given the similarity of these two effects, we investigate whether the earnings losses for movers are due to residence damage rather than to moving per se. First, in results reported in in the first three columns of Table 8, we examine the relationship between damage type and migration in the treatment sample using a linear probability model with the migration indicator as the dependent variable, indicators for damage type as independent variables, and demographic characteristics as control variables. We find that those who experienced greater residence damage were more likely to move between 2005 and 2006, whether we control for type of workplace damage (column 3) or not (column 1). Controlling for type of workplace damage (column 3), those who experienced major residence damage were 21 percentage points more likely to move between 2005 and 2006 than were those who experienced no residence damage. Although major residence damage has a very large effect on migration, minor residence damage has almost no effect (workplace damage has a moderate effect).

Second, we estimate another set of earnings effects for movers and non-movers; instead of using the entire treatment sample, we control for residence damage by limiting the treatment sample to those with major residence damage. The estimates, shown in the panel B of Table 7, indicate that, even among those with major residence damage, movers do much worse than nonmovers - in both the short term and the long term. In fact, the difference in earnings effects between movers and non-movers increases when we limit the sample to those with major residence damage. Why do movers do so much worse than non-movers? One potential reason (as discussed in Section 2) is that movers had difficulty adjusting to their new areas. The larger earnings losses of movers could also be partially due to unmeasured differences in the severity of residence damage among those with major damage (with the movers having more severe damage). If there are unobserved differences in damage and movers have less ability to repair or rebuild houses (regardless of the severity of damage) because they have lower wealth, these differences could be reflected in the difference in earnings effects between movers and nonmovers.

Analogous to our method for examining migration together with earnings and damage, we investigate how the earnings effects of the storm vary with short-term job separations and how these effects are related to damage. Recall that the short-term losses in earnings over the 
first year after the storm are primarily the result of reductions in earnings due to shifts between employment and non-employment. Therefore, we investigate specifically the earnings effects for those who separated from their pre-storm employer. For individuals in the treatment sample, we define a job separation as the loss of earnings from one's main, pre-storm employer for at least the first four quarters after the storm (though one could have earnings from other secondary or new jobs). ${ }^{26}$

When we split the treatment sample into separators and non-separators and estimate earnings effects relative to the control sample, we find that separators experienced much larger earnings losses in the short term (bottom panel of Figure 8 and panel $\mathrm{C}$ of Table 7). The estimated earnings losses for the separators lasted until the fourth year after the storm, but by the seventh year after the storm the separators experienced earnings gains that are similar to those of the non-separators. Next, in the last three columns of Table 8, we again use a linear probability model and find that those who experienced greater workplace damage were more likely to separate from their pre-storm employers (columns 5 and 6). Controlling for type of residence damage (column 6), those who experienced major workplace damage were 9 percentage points more likely to separate than were those who experienced no workplace damage. Our finding that damage is associated with separations is consistent with Jarmin and Miranda (2009), who found that the decline in payroll was greater in areas with more workplace damage and that this decline was largely explained by business closures.

In our earnings model, we find that limiting the treatment sample to those with major workplace damage does not reduce the difference in the estimated earnings effects between separators and non-separators (Table 7, panel D). Even among those with major workplace damage, separators do much worse than non-separators in the short term and the medium term. ${ }^{27}$ Separators do worse than non-separators presumably for many of the same reasons that displaced workers experience persistent earnings losses, such as loss of specific skills and difficulty finding new employment (Fallick, 1996; Jacobson et al., 1993). ${ }^{28}$ Differences in earnings effects between separators and non-separators may also reflect unmeasured differences in the severity of

\footnotetext{
${ }^{26}$ The four-quarter requirement avoids counting near-term recalls and seasonal jobs as separations. The separation rate in the treatment sample was 8.3 percent, compared to 5.2 percent in the control sample.

${ }^{27}$ The negative short-term effect on the earnings of non-separators at employers with major workplace damage may be evidence of firms reducing employees' hours while rebuilding but retaining those workers once they re-opened.

${ }^{28}$ Concerns of unobserved differences between separated workers and those who remain on the job are much alleviated in the case of mass-displacement events where job cuts are widespread.
} 
workplace damage among those with major damage, with the separators having more severe damage.

\subsection{Discussion}

Our results indicate that in the immediate aftermath of the storm and for the first year after the storm, affected individuals experienced an earnings loss. Compared to individuals in the control group, affected individuals lost an average of $\$ 238$ per quarter $(2.2 \%$ of average prestorm earnings) during the first year after the storm. Our results indicate that storm-affected workers earned less in the first year after the storm primarily because they were less likely to have a job.

The increase in shifts to non-employment in the immediate aftermath of the storm is consistent with various factors in the short-term disruption, as outlined in Section 2 (e.g., migration, displacement, and industry-specific effects). The short-term earnings results by subgroups support each of these explanations. Individuals whose residence or workplace suffered major damage experienced larger earnings losses in the short term than did those who experienced minor damage or no damage. Individuals who moved to a different area (commuting zone) also experienced greater earnings losses than did those who remained in their pre-storm area. Individuals who were separated from their pre-storm jobs experienced large earnings losses in the short term, and the separators experienced earnings losses until the fourth year after the storm. Finally, short-term earnings losses were greatest among those individuals in sectors most closely tied to tourism (leisure and accommodations) or the size of the local population (healthcare, public, and education).

In the medium and longer term, our results indicate that those affected by the storm earned comparatively more than those not affected. Our findings of a long-term increase in earnings are consistent with the findings of Deryugina et al. (2014) using a different source of earnings data (federal tax returns). Our earnings decomposition indicates that the earnings gains were due to higher earnings among those employed rather than increases in the share employed. Higher earnings for storm-affected individuals who were employed could arise because their wages were higher, their hours were higher, or both. We discuss these mechanisms below.

The pattern of estimated storm effects by type of residence damage does not support the explanation that workers with larger wealth losses increased their labor supply, or hours of work. Notably, the long-term positive effect of the storm on earnings is no larger for those who 
suffered major damage than for those who suffered no damage. This suggests that if workers' hours are greater it would be due to an increase in labor demand.

Through the mechanisms outlined in Section 2, wages of affected individuals could increase due to productivity changes, industry switching, or shifts in labor supply and labor demand. First, wages in the storm-affected areas could increase because of a productivity increase driven by either the adoption of new technology when rebuilding (Hallegatte and Dumas, 2008) or selection in the survival of damaged establishments (Basker and Miranda, 2014). These explanations do not seem to fit our results because we find earnings gains for individuals who came from areas with no damage. Second, average wages of affected individuals could increase because of changes in the composition and size of employers and industries. In our individual-level data, we find that individuals in the treatment sample became somewhat more concentrated over time (relative to the change over time for the control sample) in sectors that experienced earnings gains; however, the magnitude of these shifts does not appear large enough to explain the long-term earnings gains in the aggregate (Table A2).

A third potential reason that wages of affected individuals could increase over time (relative to the control sample) is differences between treatment areas and control areas in local labor-market dynamics, namely different shifts in labor supply and labor demand that could affect workers' wages. Contemporary reporting on the storm-affected areas noted labor shortages and boosts in wages, especially for skilled positions in manufacturing and construction. In the months immediately following the storms (at the height of the evacuations), employers reported offering multiples of pre-storm wages. During the recession, rebuilding helped to insulate those two sectors and the local economy from national trends. ${ }^{29}$ We evaluate this potential explanation in the next section by incorporating area-level data on population, employment, and wages.

\section{Local Labor-Market Dynamics}

In order to compare the evolution of employment and wages in treatment and control areas, in this section, we shift the focus of our data and analysis from micro data on individuals

\footnotetext{
${ }^{29}$ Rivlin, G. (November 11, 2005), "Wooing Workers for New Orleans.” The New York Times. Quillen, K. (August 31, 2008), "Labor Shortages Persist in the Metro New Orleans Area." The Times Picayune. Quillen, K. (November 29, 2008), "As Labor Markets Crash Nationwide, New Orleans is Holding onto its Jobs." The Times Picayune.
} 
to macro data on areas. Our primary goal is to determine whether changes in average wages in treatment and control areas over time can explain the long-term increases in earnings of individuals in the treatment sample relative to the control sample. ${ }^{30}$

\subsection{Measuring Labor-Market Characteristics}

To understand the treatment-area labor market, we need to characterize labor supply, labor demand, employment, and wages in both the short run and long run. We describe the labor market in the aggregate and for specific industries highly affected by the storms. Our general approach to producing area-level estimates for the treatment area as a whole and the control area as a whole is to aggregate county-level estimates or metropolitan-area estimates that proxy for aspects of the labor market.

We use population estimates over time as an indicator of trends in labor supply. Figure 9 shows the population of the treatment and control areas from 2000 to 2012 as a percent of 2005 population. $^{31}$ Between $_{2000}$ and 2005, population growth in the treatment and control areas was nearly identical. From 2005 to 2006 , the population fell by 6.8 percent in the treatment area and increased by 1.5 percent in the control area, a difference of 8.3 percentage points. After 2006, the treatment area grew at a slightly faster rate than the control area, but not enough to make up for the storm-related drop in population. By 2012, population as a percent of the pre-storm level was 100.8 in the treatment area and 107.1 in the control area, a difference of 6.3 percentage points. Essentially, three-fourths of the population loss in the first year after the storm persisted until 2012. ${ }^{32}$

We construct estimates of beginning-of-quarter employment (overall and by industry sector) in the treatment and control areas from the LEHD Infrastructure Files. ${ }^{33}$ As shown in Figure 9, employment (as a percent of pre-storm employment) in the treatment area fell sharply

\footnotetext{
${ }^{30}$ Although individuals in the treatment sample did not necessarily reside in the treatment area in the long run (and similarly for the control sample and the control area), a large majority of the treatment sample resided in the treatment area (93 percent), as evidenced by the migration statistics in Table 3. As a result, the labor-market dynamics in the treatment and control areas are likely to have first-order effects on the average earnings of the treatment sample relative to the control sample.

${ }^{31}$ We use Census Bureau population estimates at the county level on an annual basis with a reference date of July 1.

${ }^{32}$ We note that propensity to migrate away was modestly lower for our high-attachment sample than for the adult population as a whole. Table 3 shows that in the year after the storms, the migration rate (relative to the control) was higher in the broader sample than in the high-attachment sample. While this differential may have deepened the short-term drop in labor supply, the migration rates converged in later years.

${ }^{33}$ As explained in the Data Appendix, we construct employment estimates from LEHD data using the aggregation and confidentiality-protection measures employed in the Quarterly Workforce Indicators, a public-use data product from the Census Bureau.
} 
in the aftermath of the storm and remained well below employment in the control areas until early 2009. After that point, employment growth was somewhat greater in the treatment area than in the control area; by the end of 2012, employment as a percent of the pre-storm level was greater in the treatment area (100.4) than in the control area (98.1).

Employment trends in four sectors are also shown in Figure 9. In construction, employment in the treatment area fell after the storm for only one quarter; after that, employment grew sharply through early 2008. Construction employment in the treatment area declined during the Great Recession, though not by as much as construction employment in the control area; by 2012, construction employment in the treatment area was above its pre-storm level while construction employment in the control area was well below its pre-storm level. ${ }^{34}$ Relative to the control area, manufacturing employment grew in the treatment area between 2005 and 2012, though both areas experienced an absolute decline by 2009 .

In contrast to the picture in construction and manufacturing, the negative effects of the storm on employment were quite severe and prolonged in non-tradable services, including healthcare and leisure and accommodations. In leisure and accommodations, employment in the treatment area fell by over 25 percent in the aftermath of the storm, and not until 2012 had it had recovered to its pre-storm level. In healthcare, the short-run decline in employment was not as severe; however, it was not until the second half of 2011 that employment in healthcare was consistently above its pre-storm level. For most of the seven years after the storm, employment in the healthcare sector as a percent of its pre-storm level was lower in the treatment area than in the control area. A comparison of the charts for population and healthcare employment suggests that the population decline in the treatment area was a key factor in the decline in healthcare employment. ${ }^{35}$

\footnotetext{
${ }^{34}$ One indicator of demand for construction work is the issuance of residential building permits. From 1995 to 2004 (including the core years of the housing boom), both the treatment and control areas experienced almost a 60percent increase in annual permits for new or renovated units. From 2004 to 2005, permits rose by 10 percent in the control area and stayed constant in the treatment area, consistent with disruptive effects of the storm. From 2005 to 2006, permits (as a percent of 2004 permits) rose by 20 percentage points in the treatment area and fell by 7 percentage points in the control area, consistent with rebuilding after the storm. After 2006, the number of permits issued fell in both the treatment and control areas (consistent with the nationwide decline in housing demand), but the treatment area maintained an advantage in permits (permits in 2012 as a percent of 2004 permits were about 20 percentage points higher in the treatment area). See Data Appendix.

${ }^{35}$ Another indicator of local demand for services is the number of students enrolled in public elementary and secondary schools, which fell by over 10 percent in the treatment area from 2004 to 2005 (whereas enrollment increased slightly in the control area). Enrollment at schools in the treatment area gradually recovered after 2005,
} 
Our estimates of average hourly wages in the treatment and control areas over time are derived from the Occupational Employment Statistics (OES) survey. As explained in the Data Appendix, we use the OES public-use estimates of average wages by occupation and metropolitan area for May 2005, May 2008, and May 2012 along with the OES national estimates of employment by industry and occupation for each of the three time periods to construct estimates of average wages by industry for the treatment and control areas over time. Table 9 presents the estimates of average wages in the treatment and control areas (in all industries combined) over time. Prior to storm, average wages were lower in the treatment area by $\$ 1.68 /$ hour. After the storm, wage growth was greater in the treatment area than in the control area. Over the medium term (from 2005 to 2008), wage growth was 2.5 percent in the treatment area and -1.1 percent in the control area, a difference of 3.6 percentage points. The difference in wage growth was even greater over the long term: wage growth from 2005 to 2012 was 6.9 percent in the treatment area and 0.4 percent in the control area, a difference of 6.5 percentage points.

\subsection{Labor-Market Illustration}

Figure 10 illustrates shifts in labor supply and labor demand over the long term (2005 to 2012) in treatment and control areas that are consistent with the observed trends in employment and average wages. In keeping with our "difference-in-differences"-type estimates for employment and average wages, the shift in a given schedule is intended to represent a net change over time in the treatment area relative to the control area. For instance, a shift out in the labor-demand curve means that labor demand increased by more in the treatment area than in the control area. Equilibrium is represented by a wage ratio (treatment relative to control) and an employment ratio.

The top panel of Figure 10 illustrates the long-term situation for all industries combined - that is, for the treatment and control areas as a whole. Given the population changes, labor supply decreases (from $\mathrm{S}_{0}$ to $\mathrm{S}_{1}$ ) in the treatment area relative to the control area. Given the supply change and the observed employment changes, labor demand must have increased (from $\mathrm{D}_{0}$ to $\mathrm{D}_{1}$ ) in the treatment area relative to the control area, and the increase in labor demand must be sufficient such that any decrease in labor supply did not reduce long-run 
employment. The magnitude of the shift in labor demand could reflect several factors, including post-storm reconstruction activity in the treatment area; the fact that some of the affected areas, particularly New Orleans, were economically depressed prior to the storm (Vigdor, 2008); and less of a negative effect of the Great Recession in the treatment area than the control area.

The middle and bottom panels of Figure 10 illustrate the differences across sectors in demand and supply shifts. In construction, a non-tradable sector tied to the reconstruction, labor supply does not change (due to the in-migration of low-skilled labor offsetting the out-migration of affected individuals) and labor demand increases, leading to an increase in both relative wages and relative employment in the treatment area. ${ }^{36}$ By contrast, in healthcare (a non-tradable sector tied to the local population), labor supply and labor demand both decrease, with shifts sufficient to increase relative wages in the treatment area but decrease relative employment.

\subsection{Interpretation of Labor-Market Evidence}

With this illustrative framework and the empirical evidence on the changes in average wages by sector, we are now prepared to evaluate whether local labor-market dynamics are responsible for the long-run increase in earnings for the treatment sample relative to the control sample. At the aggregate level (across all sectors), the time pattern and magnitude of the OES estimates of average wages in treatment and control areas provide strong evidence that an increase in relative wages in the affected areas was an important factor behind the long-term earnings gains experienced by affected individuals (in the LEHD sample). Over the medium term (2005 to 2008), wage growth was higher in the treatment area by 3.6 percentage points (Table 9) and affected individuals experienced an earnings gain of 3.2 percent of pre-storm earnings (Table 5). Over the long term (2005 to 2012): wage growth was higher in the treatment area by 6.5 percentage points (Table 9 ) and affected individuals experienced an earnings gain of 7.2 percent of pre-storm earnings (Table 5). Further, wage gains being the primary cause of higher earnings among workers in our treatment sample is consistent with our decomposition estimates (presented in Figure 6), which illustrate that earning gains are caused primarily by within-employment shifts.

In addition to the aggregate evidence, variation by industry sector supports this explanation. Figure 11 plots wage growth in the treatment area (relative to the control area) and

\footnotetext{
${ }^{36}$ Other research has documented the in-migration of immigrants, especially Hispanics, to work in construction in New Orleans during the Katrina recovery (e.g., Sisk and Bankston, 2014).
} 
earnings growth in the treatment sample (relative to the control sample) from 2005 to 2012, by industry sector. Across sectors, the magnitude of wage growth (from OES estimates) is positively correlated with the magnitude of long-term effects of the storm on earnings. ${ }^{37}$ Said another way, the sectors with stronger growth in relative wages tend to be the sectors with stronger earnings gains in our individual-level analysis. These sectors include construction, manufacturing, and agriculture/natural resources. By contrast, healthcare and public/education had weaker growth in relative wages in the treatment area and weaker earnings gains in our individual-level analysis.

\section{Robustness Checks and Extensions}

\subsection{Alternate Control Samples}

Although the propensity-score matched control sample is very similar to the treatment sample in terms of worker characteristics and local economic conditions before the storm, we consider alternate control samples to gauge the robustness of our main results. The alternate control samples have some desirable features, though they are less similar to the treatment sample (along those dimensions) than is the matched control sample. Each of the three alternate control samples is composed of individuals who resided in particular geographic areas in 2005 and meet our other sample requirements from the main analysis (namely, having earnings in the nine pre-storm quarters and having a job that spanned July 1, 2005). The geographic areas used to define the three alternate control samples are shown in Figure A1. Tables A3 and A4 provide summary statistics on the alternate control samples and measures of divergence between each control sample and the treatment sample.

Our first alternate control sample is defined using a region along the Atlantic Coastal Plain (see Figure A1). We use a definition of coastal counties developed by the National Oceanic and Atmospheric Administration (2013) to designate a region of 117 counties (or county equivalents) in the Atlantic watershed in Virginia, North Carolina, Georgia, South Carolina, and Florida. A desirable attribute of the Coastal Plain, as a control area, is its susceptibility to

\footnotetext{
${ }^{37}$ This relationship also holds over the medium term (2005 to 2008).
} 
hurricanes (though it experienced no major storms during our analysis period). ${ }^{38}$ Being in the South and consisting of low-lying coastal plains, the area also has demographic and economic characteristics that are broadly similar to those of the treatment area. The Coastal Plain sample includes 179,000 workers.

The second alternate control sample we construct is formed by individuals whose 2005 residence was in Oklahoma, Arkansas, and Tennessee, which together form a region adjacent to the states that contain the treatment areas (see Figure A1). We refer to this control sample as the "Upland South" sample, following the term for the geographical region that includes these three states. The Upland South is used as an alternative control group because being adjacent to states that contain the treatment area it is anticipated that this region would have a relatively similar economy. The Upland South sample includes 367,000 workers.

The third alternate control sample is based on a set of economically weak metropolitan areas identified in a Brookings Institution report (Vey, 2007). These metropolitan areas consist mostly of older industrial cities that had low performance on a set of eight economic indicators (including employment growth from 1990 to 2000 and per-capita income in 2000). The Brookings report separated 65 "weak cities" into three groups according to whether their metropolitan areas were weak, moderate, or strong. The Weak Cities list includes two areas that were affected by Katrina or Rita: New Orleans and Beaumont-Port Arthur, Texas. ${ }^{39}$ Use of a Weak City control sample will reflect economies that presumably were on a similar trajectory as these two metropolitan areas in the treatment area.

When forming this control sample, we first exclude these two metropolitan areas and then refine the list by excluding areas in any of the states used to define our treatment sample or other alternate control samples. The list used to define this alternate control sample contains 95 counties that include 30 weak cities. As shown in Figure A1, these counties are primarily in the Midwest and Northeast. The Weak Cities sample includes 936,000 workers.

According to the summary statistics in Table A3, each alternate control sample is similar to the treatment sample in terms of some characteristics, but overall the alternate control samples

\footnotetext{
${ }^{38}$ Notable hurricanes that struck the southern Atlantic coast during the 2003-2012 analysis period were Isabel (2003), Charley (2004), Irene (2009), and Sandy (2012). For the Gulf Coast, notable hurricanes that struck the areas affected by Katrina and Rita were Ivan (2004), Dennis (2005), Gustav (2008), Ike (2008), and Isaac (2012).

${ }^{39}$ The Brookings list of "weak city" metropolitan areas was used as a basis of comparison for New Orleans in terms of its post-Katrina trends on a number of economic and social indicators by the New Orleans Community Data Center (Plyer et al., 2013).
} 
are not as close to the treatment sample as is the matched control sample (see Data Appendix and Table A4). Figure A2 shows estimates of effects on earnings using the alternate control samples; for comparison, the figure also includes estimates using the matched control sample (from Figure 5). The time pattern of estimates we obtain with the alternate control samples is qualitatively similar to pattern obtained with the matched control sample. With the alternative controls, the estimates of short-term earnings losses are in the range of $\$ 200-\$ 300$ per quarter (relative to a loss of $\$ 238$ for the matched control sample, from Table 4) and the estimates of long-term earnings gains are in the range of $\$ 450-\$ 850$ per quarter (relative to a gain of $\$ 768$ for the matched control sample).

\subsection{Broader Sample of Individuals without Regard for Pre-Storm Employment}

Our main analysis relies on workers who were highly attached to the labor force before the 2005 storms. In order to be chosen for the sample, individuals had to have positive earnings for nine consecutive quarters (the quarter of the storm and the previous eight quarters). We relax this restriction in defining a broader sample of individuals without regard for earnings during those nine quarters. Our broader sample consists of all individuals in our survey sample, regardless of whether they had LEHD earnings records at the time of the storm or during the prestorm period covered by our analysis.

The broader sample, with no employment restrictions, contains approximately 1,070,000 individuals, including 275,000 individuals in the treatment sample and 795,000 individuals in the control sample. The broader sample differs from the high-attachment sample in that educational attainment and average earnings are lower, only half are employed on July 1, 2005, and the population has less residential stability (Table A3). Within the broader sample, the treatment and (matched) control samples are again highly comparable. For example, average quarterly earnings prior to the storm $(2005: 2)$ were $\$ 5,483$ for the treatment sample and $\$ 5,709$ for the control sample.

Figure A3 shows estimates of effects on earnings using the broader sample. The time pattern of these estimates - with short-term earnings losses and long-term gains - is similar to the pattern of estimates from the restricted sample. In terms of magnitude, the estimated effects obtained from the broader sample are somewhat muted relative those obtained from the highattachment sample, but that is to be expected given that some individuals in the broader sample 
may have been permanently out of the labor force. For these individuals, the storm would have no effect on their earnings.

\section{Conclusions}

This study contributes to our knowledge of mass disasters by examining how the employment and earnings of individuals affected by Hurricanes Katrina and Rita respond in the short term and long term. We examine how the evolution of individuals' earnings responded to Hurricanes Katrina and Rita, which struck the U.S. Gulf Coast in 2005. Our analysis is based on individuals who were employed at the time of the storms and had positive earnings in each of the eight quarters prior to the storms. We find that these disasters reduced the earnings of affected individuals in the immediate aftermath of the storms and over the first year after the storms. The earnings losses over the first year are moderate (2.2 percent of average pre-storm earnings) and primarily reflect that affected individuals were less likely to be employed after the storm (relative to the control sample).

The increase in shifts to non-employment reflects various aspects of the short-run disruption caused by the hurricanes. One aspect was that the physical damages brought about by the storms caused some affected individuals to take up temporary residence in other areas, causing them to take leave from or separate from their pre-storm jobs. Another aspect was that many businesses closed or reduced their operations in the aftermath of the storm, either due to storm damage or reductions in demand for their output. Our results indicate that individuals whose residence or workplace suffered major damage experienced larger earnings losses in the short term than did those who experienced minor damage or no damage. Short-term earnings losses were also more severe for those who moved to a different area during the first year and for those who separated from their pre-storm jobs. In addition, short-term earnings losses by industrial sector were greatest among those individuals who were employed in sectors closely tied to tourism (leisure and accommodations) or the size of the local population (healthcare, public, and education).

Although the hurricanes caused earnings losses in the short term, they led to earnings gains in the medium term and long term. Starting in the third year after the storms, we estimate that the storms increased the earnings of affected individuals. The estimated earnings gains in 2008 represent 3.2 percent of pre-storm earnings. In the long term, the estimated earnings gains 
are even larger: by 2012, the estimated gains represent 7.2 percent of pre-storm earnings. The gains in earnings over the medium and long term are primarily the result of increases in earnings within employment rather than increases in the share who were employed.

We provide evidence that the long-term earnings gains experienced by affected individuals were the result of differences in local labor-market dynamics between the affected areas and the control areas. Area-level data on population, employment, and average wages suggest that labor supply in the treatment area decreased from 2005 to 2012 (relative to the change in the control area) and aggregate labor demand increased in the treatment area over this period (relative to the change in the control area). The combined effect of these shifts was a small increase in relative employment and a large increase in relative wages in the treatment area. Between 2005 and 2012, the average wage increased by 6.9 percent in the treatment area and 0.4 percent in the control area, a difference of 6.5 percentage points. The magnitude of this difference is comparable to the magnitude of the gain in earnings over the long term that we estimate in our individual-level analysis.

In addition to the aggregate evidence, variation by industry sector supports this explanation for the long-term earnings gains in our individual-level analysis. Across sectors, wage growth in the treatment area (relative to the control area) over the long term (2005 to 2012) is positively correlated with the long-term effects of the storm on earnings. In other words, the sectors with stronger growth in relative wages tend to be the sectors with stronger earnings gains in our individual-level analysis. These sectors include construction, manufacturing, and agriculture/natural resources. By contrast, healthcare and public/education had weaker growth in relative wages in the treatment area and weaker earnings gains in our individual-level analysis.

In the aftermath of Hurricanes Katrina and Rita, the long-term earnings gains were widespread (because they were tied to market-wide increases in wages) but the short-term earnings losses were concentrated in particular subgroups. On average over the entire post-storm period (when both short-term losses and long-term gains are considered), we find that the storm led to a net increase in the average quarterly earnings of affected individuals of 3.7 percent of pre-storm earnings. However, for some subgroups the storm led to a net decrease in average quarterly earnings over the seven-year period: those who relocated during the first year after the storm, those who separated from their pre-storm employer during the first year after the storm, those whose residence or workplace experienced major damage, and those who worked in 
sectors closely tied to tourism or the size of the local population all suffered a net loss. For these subgroups, the earnings losses they experienced in the aftermath of the storms were more severe and persistent than for other affected individuals.

More generally, our study demonstrates that disasters may have both direct and indirect effects on individuals. Direct effects include the damages to residences and workplaces as well as impacts on individuals' physical and mental health. Indirect effects include changes in wages and prices that are caused by disasters through changes in labor, product, and housing markets. Although the direct effects are more obvious in the immediate aftermath of a disaster, the indirect effects may be more important. 


\section{References}

Abadie, A., A. Diamond, and J. Hainmueller. 2010. "Synthetic Control Methods for Comparative Case Studies: Estimating the Effect of California's Tobacco Control Program." Journal of the American Statistical Association 105(490): 493-505.

Abowd, J.M., B. Stephens, L. Vilhuber, F. Andersson, K. McKinney, M. Roemer, and S. Woodcock. 2009. "The LEHD Infrastructure Files and the Creation of the Quarterly Workforce Indicators," in T. Dunne, J.B. Jensen, and M.J. Roberts, eds., Producer Dynamics: New Evidence from Micro Data. Chicago: University of Chicago Press for the National Bureau of Economic Research, pp. 149-230.

Angist, J.D., and J.S. Pischke. 2009. Mostly Harmless Econometrics: An Empiricist's Companion. Princeton, NJ: Princeton University Press.

Austin, P.C. 2009. "Balance Diagnostics for Comparing the Distribution of Baseline Covariates between Treatment Groups in Propensity Score Matched Samples." Statistics in Medicine 28(25): 3083-3107.

Autor, D.H., D. Dorn, and G.H. Hanson. 2013. "The China Syndrome: Local Labor Market Effects of Import Competition in the United States." American Economic Review 103(6): 21212168.

Basker, E., and J. Miranda. 2014. "Taken by Storm: Business Survival in the Aftermath of Hurricane Katrina.” Working Paper CES 14-20. Washington, DC: Center for Economic Studies, U.S. Census Bureau.

Belasen, A.R., and S.W. Polachek. 2008. "How Hurricanes Affect Wages and Employment in Local Labor Markets." American Economic Review 98(2): 49-53.

Belasen, A.R., and S.W. Polachek. 2009. "How Disasters Affect Local Labor Markets: The Effects of Hurricanes in Florida." Journal of Human Resources 44(1): 251-276.

Blake, E.S., C.W. Landsea, and E.J. Gibney. 2011. The Deadliest, Costliest, and Most Intense United States Tropical Cyclones from 1851 to 2010. Miami, FL: National Hurricane Center.

Blanchard, O.J., and L.F. Katz. 1992. "Regional Evolutions.” Brookings Papers on Economic Activity 1:1-61.

Brown, S.P., and P. Carey. 2006. "Mass Layoff Statistics Program: Response and Findings." Monthly Labor Review 129(8): 70-75.

Brown, S.P., S.L. Mason, and R.B. Tiller. 2006. “The Effect of Hurricane Katrina on Employment and Unemployment.” Monthly Labor Review 129(8): 52-69. 
Caballero, R.J., and M.L. Hammour. 1994. "The Cleansing Effect of Recessions.” American Economic Review 84(5): 1350-1368.

Clayton, R.L. and J.R. Spletzer. 2006. "Worker Mobility Before and After Hurricane Katrina." Monthly Labor Review 129(8): 11-21.

Cutter, S.L., C.T. Emrich, J.T. Mitchell, B.J. Boruff, M. Gall, M.C. Schmidtlein, C.G. Burton, and G. Melton. 2006. "The Long Road Home: Race, Class, and Recovery from Hurricane Katrina." Environment 48(2): 8-20.

Davis, D.R., and D.E. Weinstein. 2002. "Bones, Bombs, and Break Points: The Geography of Economic Activity." American Economic Review 92(5): 1269-1289.

Deryugina, T., L. Kawano, and S. Levitt. 2014. "The Economic Impact of Hurricane Katrina on its Victims: Evidence from Individual Tax Returns.” Working Paper 20713. Cambridge, MA: National Bureau of Economic Research.

De Silva, D.G., R.P. McComb, Y. Moh, A. Schiller, and A.J. Vargas. 2010. "The Effect of Migration on Wages: Evidence from a Natural Experiment." American Economic Review 100(2): 321-326.

Dolfman, M.L., S.F. Wasser, and B. Bergman. 2007. "The Effects of Hurricane Katrina on the New Orleans Economy." Monthly Labor Review 130(3): 3-18.

Elliott, J.R. and J. Pais. 2006. "Race, Class, and Hurricane Katrina: Social Differences in Human Response to Disaster." Social Science Research 35(2): 295-321.

Fallick, B.C. 1996. "A Review of the Recent Empirical Literature on Displaced Workers." Industrial and Labor Relations Review 50(1): 5-16.

Federal Emergency Management Agency [FEMA]. 2005. "FEMA Mapping and Analysis, Hurricane Katrina, Remote Sensing Data from National Geospatial-Intelligence Agency."

Fussell, E., N. Sastry, and M. VanLandingham. 2010. "Race, Socioeconomic Status, and Return Migration to New Orleans after Hurricane Katrina." Population and Environment 31(1-3): 2042 .

Groen, J.A., and A.E. Polivka. 2008a. "Hurricane Katrina Evacuees: Who They Are, Where They Are, and How They Are Faring." Monthly Labor Review 131(3): 32-51.

Groen, J.A., and A.E. Polivka. 2008b. "The Effect of Hurricane Katrina on the Labor Market Outcomes of Evacuees.” American Economic Review 98(2): 43-48.

Groen, J.A., and A.E. Polivka. 2010. "Going Home after Hurricane Katrina: Determinants of Return Migration and Changes in Affected Areas.” Demography 47(4): 821-844. 
Hallegatte, S., and P. Dumas. 2008. "Can Natural Disasters Have Positive Consequences? Investigating the Role of Embodied Technical Change." Ecological Economics 68(3): 777-786.

Hartwig, R.P., and C. Wilkinson. 2010. "Hurricane Katrina: The Five Year Anniversary." Insurance Information Institute. http://www.iii.org/sites/default/files/docs/pdf/1007Katrina5Anniversary.pdf (accessed August 14, 2015).

Hunter, L.M. 2005. "Migration and Environmental Hazards." Population and Environment 26(4): 273-302.

Jarmin, R.S., and J. Miranda. 2009. "The Impact of Hurricanes Katrina, Rita, and Wilma on Business Establishments." Journal of Business Valuation and Economic Loss Analysis 4(2): Article 7.

Jacobson, L.S., R.J. LaLonde, and D.G. Sullivan. 1993. "Earnings Losses of Displaced Workers.” American Economic Review 84(4): 685-709.

Knabb, R.D., J.R. Rhome, and D.P. Brown. 2005. Tropical Cyclone Report: Hurricane Katrina. Miami, FL: National Hurricane Center.

Knabb, R.D., D.P. Brown, and J.R. Rhome. 2006. Tropical Cyclone Report: Hurricane Rita. Miami, FL: National Hurricane Center.

Kosanovich, K. 2006. "The Labor Market Impact of Hurricane Katrina: An Overview." Monthly Labor Review 129(8): 3-10.

Marchand, J. 2012. "Local Labor Market Impacts of Energy Boom-Bust-Boom in Western Canada." Journal of Urban Economics 71(1): 165-174.

McIntosh, M.F. 2008. "Measuring the Labor Market Impacts of Hurricane Katrina Migration: Evidence from Houston, Texas." American Economic Review 98(2): 54-57.

National Oceanic and Atmospheric Administration. 2013. NOAA's List of Coastal Counties for the Bureau of the Census Statistical Abstract Series.

https://www.census.gov/geo/landview/lv6help/coastal_cty.pdf (accessed May 24, 2013).

Nordhaus, W.D. 2010. "The Economics of Hurricanes and Implications of Global Warming." Climate Change Economics 1(1): 1-20.

Okuyama, Y. 2003. "Economics of Natural Disasters: A Critical Review.” Research Paper 200312. West Virginia University, Regional Research Institute.

Paxson, C., E. Fussell, J. Rhodes, and M. Waters. 2012. "Five Years Later: Recovery from Post Traumatic Stress and Psychological Distress among Low-Income Mothers Affected by Hurricane Katrina." Social Science and Medicine 74(2): 150-157. 
Paxson, C., and C.E. Rouse. 2008. "Returning to New Orleans after Hurricane Katrina." American Economic Review 98(2): 38-42.

Plyer, A., E. Ortiz, B. Horwitz, and G. Hobor. 2013. The New Orleans Index at Eight: Measuring Greater New Orleans' Progress toward Prosperity. New Orleans, LA: New Orleans Community Data Center.

Sacerdote, B. 2012. "When the Saints Go Marching Out: Long-Term Outcomes for Student Evacuees from Hurricanes Katrina and Rita." American Economic Journal: Applied Economics 4(1): 109-135.

Sastry, N. 2009. "Tracing the Effects of Hurricane Katrina on the Population of New Orleans: The Displaced New Orleans Residents Pilot Study." Sociological Methods and Research 38(1): 171-196.

Sisk, B., and C.L. Bankston III. 2014. "Hurricane Katrina, a Construction Boom, and a New Labor Force: Latino Immigrants and the New Orleans Construction Industry, 2000 and 20062010.” Population Research and Policy Review 33(3): 309-334.

Sommers, B.D., S.K. Long, and K. Baicker. 2014. "Changes in Mortality after Massachusetts Health Care Reform: A Quasi-experimental Study." Annals of Internal Medicine 160(9): 585593.

Stevens, D. 2007. "Employment That Is Not Covered By State Unemployment Insurance Laws." Longitudinal Employer-Household Dynamics Technical Paper No. TP-2007-04.

Strobl, E. 2011. "The Economic Growth Impact of Hurricanes: Evidence from U.S. Coastal Counties." Review of Economics and Statistics 93(2): 575-589.

Tolbert, C.M., and M. Sizer. 1996. "U.S. Commuting Zones and Labor Market Areas: A 1990 Update.” Economic Research Service Staff Paper No. 9614.

U.S. Department of Housing and Urban Development [HUD]. 2006. Current Housing Unit Damage Estimates: Hurricanes Katrina, Rita, and Wilma. Washington, DC: U.S. Department of Housing and Urban Development, Office of Policy Development and Research.

Vey, J.S. 2007. Restoring Prosperity: The State Role in Revitalizing America's Older Industrial Cities. Washington, DC: Brookings Institution.

Vigdor, J.L. 2007. "The Katrina Effect: Was There a Bright Side to the Evacuation of Greater New Orleans?” B.E. Journal of Economic Analysis and Policy, Advances, 7(1): Article 64.

Vigdor, J. 2008. "The Economic Aftermath of Hurricane Katrina.” Journal of Economic Perspectives 22(4): 135-154. 
Womble, J.A., S. Ghosh, B.J. Adams, and C.J. Friedland. 2006. Advanced Damage Detection for Hurricane Katrina: Integrated Remote Sensing and VIEWS Field Reconnaissance. Buffalo, NY: Multidisciplinary Center for Earthquake Engineering Research.

Zissimopoulos, J. and L.A. Karoly. 2010. "Employment and Self-employment in the Wake of Hurricane Katrina." Demography 47(2): 345-367. 
Table 1. Summary Statistics for Treatment and Control Samples

\begin{tabular}{|c|c|c|c|}
\hline Variable & Treatment & $\begin{array}{r}\text { Potential } \\
\text { Control }\end{array}$ & $\begin{array}{r}\text { Matched } \\
\text { Control }\end{array}$ \\
\hline Male & 50.2 & 51.3 & 49.1 \\
\hline Female & 49.8 & 48.8 & 50.9 \\
\hline $25 \leq$ Age $<30$ & 11.4 & 13.0 & 11.5 \\
\hline $30 \leq$ Age $<40$ & 28.9 & 28.6 & 29.5 \\
\hline $40 \leq$ Age $<50$ & 34.5 & 33.4 & 33.7 \\
\hline $50 \leq \mathrm{Age}<60$ & 25.2 & 25.0 & 25.3 \\
\hline White, not Hispanic & 65.3 & 73.6 & 65.4 \\
\hline Black, not Hispanic & 26.8 & 9.4 & 26.6 \\
\hline Hispanic & 5.3 & 10.6 & 5.2 \\
\hline Other race, not Hispanic & 2.6 & 6.3 & 2.8 \\
\hline Less than high school & 11.4 & 8.7 & 10.2 \\
\hline High school & 32.0 & 27.3 & 30.1 \\
\hline Some college & 33.2 & 32.9 & 33.0 \\
\hline College & 23.4 & 31.0 & 26.7 \\
\hline Annual earnings $<\$ 28.5 \mathrm{~K}$ & 38.7 & 30.8 & 37.8 \\
\hline$\$ 28.5 \mathrm{~K} \leq$ Annual earnings $<\$ 50 \mathrm{~K}$ & 34.5 & 36.0 & 36.4 \\
\hline Annual earnings $\geq \$ 50 \mathrm{~K}$ & 26.8 & 33.1 & 25.8 \\
\hline Agriculture and resources & 3.0 & 1.1 & 1.9 \\
\hline Construction & 6.1 & 4.7 & 5.1 \\
\hline Manufacturing & 13.8 & 16.3 & 14.6 \\
\hline Leisure, Accommodations & 6.8 & 4.7 & 5.3 \\
\hline Healthcare & 14.8 & 13.4 & 14.5 \\
\hline Professional services & 12.7 & 17.5 & 13.8 \\
\hline Local services & 15.5 & 15.1 & 15.9 \\
\hline Trade, Transport, Utilities & 9.8 & 10.0 & 10.5 \\
\hline Public, Education & 17.5 & 17.2 & 18.5 \\
\hline Same county last year & 94.5 & 94.9 & 93.5 \\
\hline Other county last year & 5.5 & 5.1 & 6.6 \\
\hline Earnings 2003:3 & 9,970 & 11,471 & 10,228 \\
\hline Earnings 2003:4 & 10,799 & 12,684 & 11,095 \\
\hline Earnings 2004:1 & 10,405 & 12,371 & 10,734 \\
\hline Earnings 2004:2 & 10,255 & 11,994 & 10,503 \\
\hline Earnings 2004:3 & 10,315 & 11,967 & 10,606 \\
\hline Earnings 2004:4 & 11,234 & 13,290 & 11,555 \\
\hline Earnings 2005:1 & 10,646 & 12,579 & 10,918 \\
\hline Earnings 2005:2 & 10,640 & 12,318 & 10,833 \\
\hline Percent highly attached & 40.0 & 47.6 & 42.4 \\
\hline Unemployment rate, 2004 & 6.2 & 5.6 & 6.1 \\
\hline Housing-price change, 2000:2-2005:2 & 23.7 & 37.3 & 23.4 \\
\hline Population change, $2000-2005$ & 3.7 & 3.7 & 4.1 \\
\hline Observations & 110,000 & $6,722,000$ & 335,000 \\
\hline
\end{tabular}

Notes: Person records are drawn from the 2000 Census and ACS microdata and matched to LEHD quarterly earnings records. Demographic variables including sex, age (in 2005), race, ethnicity, and educational attainment are derived from the survey data. Earnings (in 2005:2 dollars) and industry variables are derived from LEHD earnings and employer records. Annual earnings are based on the eight quarters before the storm, 2003:3-2005:2. Residential stability is derived from the CPR address records. See the Data Appendix for industry definitions. 
Table 2. Damage Incidence by Residence and Workplace (in percent)

\begin{tabular}{lrr}
\hline \hline Type of Damage & Residence & Workplace \\
\hline Major & 5.4 & 6.6 \\
Minor & 11.9 & 18.2 \\
Uncertain & 40.9 & 23.0 \\
None & 41.9 & 29.2 \\
Outside treatment area & N.A. & 23.0 \\
\hline \hline
\end{tabular}

Notes: Residence and workplace determined by 2005 locations. Residence location is from linked CPR address.

Workplace location is from the Employer Characteristics File, linked to the earnings record at the time of the storm in the Employment History File.

Table 3. Migration Outcomes (percent in different location than 2005)

\begin{tabular}{|c|c|c|c|c|c|c|c|c|c|}
\hline \multirow[b]{2}{*}{ Year } & \multicolumn{3}{|c|}{ County } & \multicolumn{3}{|c|}{ Commuting Zone } & \multicolumn{3}{|c|}{ State } \\
\hline & $\mathrm{T}$ & $\mathrm{C}$ & $\mathrm{T}-\mathrm{C}$ & $\mathrm{T}$ & $\mathrm{C}$ & $\mathrm{T}-\mathrm{C}$ & $\mathrm{T}$ & $\mathrm{C}$ & $\mathrm{T}-\mathrm{C}$ \\
\hline \multicolumn{10}{|c|}{ High-attachment Sample } \\
\hline 2004 & 5.0 & 6.2 & -1.2 & 2.3 & 3.4 & -1.1 & 1.2 & 2.1 & -0.9 \\
\hline 2005 & 0 & 0 & 0 & 0 & 0 & 0 & 0 & 0 & 0 \\
\hline 2006 & 10.2 & 5.6 & 4.6 & 7.0 & 2.9 & 4.1 & 4.9 & 1.8 & 3.1 \\
\hline 2008 & 14.7 & 12.6 & 2.1 & 9.4 & 7.2 & 2.2 & 6.2 & 4.6 & 1.6 \\
\hline 2010 & 16.9 & 16.2 & 0.7 & 10.6 & 9.7 & 0.9 & 6.8 & 6.2 & 0.6 \\
\hline \multicolumn{10}{|c|}{ Broader Sample } \\
\hline 2004 & 6.8 & 8.1 & -1.3 & 3.8 & 5.2 & -1.4 & 2.4 & 3.6 & -1.2 \\
\hline 2005 & 0 & 0 & 0 & 0 & 0 & 0 & 0 & 0 & 0 \\
\hline 2006 & 12.7 & 7.5 & 5.2 & 9.3 & 4.7 & 4.6 & 6.7 & 3.2 & 3.5 \\
\hline 2008 & 17.5 & 15.3 & 2.2 & 12.1 & 9.9 & 2.2 & 8.4 & 6.8 & 1.6 \\
\hline 2010 & 20.2 & 19.3 & 0.9 & 13.7 & 12.7 & 1.0 & 9.3 & 8.7 & 0.6 \\
\hline
\end{tabular}

Notes: $\mathrm{T}=$ treatment sample, $\mathrm{C}=$ control sample. Migration is defined as having a residence (per the $\mathrm{CPR}$ address) in a different location (county, commuting zone, or state) in the given year than in 2005. Sample is limited to records with a linked residence location of at least county-level precision for all years 2003-2010 (high-attachment sample: $\mathrm{N}=100,000$ for treatment, $\mathrm{N}=300,000$ for control; broader sample: $\mathrm{N}=229,000$ for treatment, $\mathrm{N}=665,000$ for control). 
Table 4. Effects on Earnings, Overall and by Damage Type

All

Effects by Time Period after the Storm

\begin{tabular}{|c|c|c|c|c|}
\hline All & $\begin{array}{c}-238.2 * \\
(71.6) \\
{[-2.2]}\end{array}$ & $\begin{array}{c}336.9 * \\
(71.6) \\
{[3.2]}\end{array}$ & $\begin{array}{c}767.9 * \\
(71.6) \\
{[7.2]}\end{array}$ & $\begin{array}{c}392.2 * \\
(67.0) \\
{[3.7]}\end{array}$ \\
\hline \multicolumn{5}{|l|}{ Residence Damage } \\
\hline Major & $\begin{array}{c}-1,696.0^{*} \\
(253.7) \\
{[-15.9]}\end{array}$ & $\begin{array}{c}-352.3 \\
(253.7) \\
{[-3.3]}\end{array}$ & $\begin{array}{c}481.4 \\
(253.7) \\
{[4.5]}\end{array}$ & $\begin{array}{c}-344.5 \\
(237.8) \\
{[-3.2]}\end{array}$ \\
\hline Minor & $\begin{array}{c}-598.5 * \\
(172.3) \\
{[-5.6]}\end{array}$ & $\begin{array}{c}241.8 \\
(172.3) \\
{[2.3]}\end{array}$ & $\begin{array}{c}672.2 * \\
(172.3) \\
{[6.3]}\end{array}$ & $\begin{array}{c}200.3 \\
(161.5) \\
{[1.9]}\end{array}$ \\
\hline Uncertain & $\begin{array}{c}5.2 \\
(97.0) \\
{[0.0]}\end{array}$ & $\begin{array}{c}446.7 * \\
(97.0) \\
{[4.2]}\end{array}$ & $\begin{array}{c}830.7 * \\
(97.0) \\
{[7.8]}\end{array}$ & $\begin{array}{c}522.5 * \\
(90.9) \\
{[4.9]}\end{array}$ \\
\hline None & $\begin{array}{l}-187.3 \\
(95.9) \\
{[-1.8]}\end{array}$ & $\begin{array}{c}344.9 * \\
(95.9) \\
{[3.2]}\end{array}$ & $\begin{array}{c}770.5^{*} \\
(95.9) \\
{[7.2]}\end{array}$ & $\begin{array}{c}413.6 * \\
(89.9) \\
{[3.9]}\end{array}$ \\
\hline Workplace Damage & & & & \\
\hline Major & $\begin{array}{c}-1,531.2 * \\
(201.6) \\
{[-14.4]}\end{array}$ & $\begin{array}{c}-148.4 \\
(201.6) \\
{[-1.4]}\end{array}$ & $\begin{array}{c}725.4 * \\
(201.6) \\
{[6.8]}\end{array}$ & $\begin{array}{c}-117.8 \\
(189.3) \\
{[-1.1]}\end{array}$ \\
\hline Minor & $\begin{array}{c}-737.4^{*} \\
(123.7) \\
{[-6.9]}\end{array}$ & $\begin{array}{c}257.9 * \\
(123.7) \\
{[2.4]}\end{array}$ & $\begin{array}{c}667.3 * \\
(123.7) \\
{[6.3]}\end{array}$ & $\begin{array}{c}175.9 \\
(116.2) \\
{[1.7]}\end{array}$ \\
\hline Uncertain & $\begin{array}{c}26.9 \\
(110.7) \\
{[0.3]}\end{array}$ & $\begin{array}{c}442.7 * \\
(110.7) \\
{[4.2]}\end{array}$ & $\begin{array}{c}937.5^{*} \\
(110.7) \\
{[8.8]}\end{array}$ & $\begin{array}{c}583.9 * \\
(104.0) \\
{[5.5]}\end{array}$ \\
\hline None & $\begin{array}{c}-143.6 \\
(99.3) \\
{[-1.3]}\end{array}$ & $\begin{array}{c}213.8 * \\
(99.3) \\
{[2.0]}\end{array}$ & $\begin{array}{c}610.0 * \\
(99.3) \\
{[5.7]}\end{array}$ & $\begin{array}{c}304.9 * \\
(93.3) \\
{[2.9]}\end{array}$ \\
\hline Outside treatment area & $\begin{array}{c}141.4 \\
(110.7) \\
{[1.3]} \\
\end{array}$ & $\begin{array}{c}588.6 * \\
(110.7) \\
{[5.5]}\end{array}$ & $\begin{array}{c}890.1 * \\
(110.7) \\
{[8.4]}\end{array}$ & $\begin{array}{c}627.8 * \\
(104.0) \\
{[5.9]} \\
\end{array}$ \\
\hline
\end{tabular}

Notes: The estimates for residence damage and workplace damage are based on separate regressions. Standard errors are in parentheses. Numbers in brackets are effects as a percent of average earnings in 2005:2 for the treatment sample as a whole. Short term is 2005:4-2006:3 ( $\mathrm{k}=1-4)$, medium term is 2007:4-2008:3 ( $\mathrm{k}=9-12)$, long term is 2011:4-2012:3 ( $\mathrm{k}=25-28)$, and full is 2005:4-2012:3 ( $\mathrm{k}=1-28)$.

$* \mathrm{p}<0.05$. 
Table 5. Effects on Earnings by Subgroup based on Workplace Characteristics

\begin{tabular}{|c|c|c|c|c|c|c|}
\hline \multirow[b]{2}{*}{ Dimension } & \multirow[b]{2}{*}{ Category } & \multirow{2}{*}{$\begin{array}{r}\text { Pre-storm } \\
\text { earnings }\end{array}$} & \multicolumn{4}{|c|}{ Effects by Time Period after the Storm } \\
\hline & & & Short & Medium & Long & Full \\
\hline \multirow{12}{*}{$\begin{array}{l}\text { Annual } \\
\text { earnings }\end{array}$} & \multirow[t]{3}{*}{ All } & \multirow[t]{3}{*}{10,640} & $-238.2 *$ & $336.9 *$ & $767.9 *$ & $392.2 *$ \\
\hline & & & $(71.6)$ & $(71.6)$ & $(71.6)$ & $(67.0)$ \\
\hline & & & {$[-2.2]$} & {$[3.2]$} & {$[7.2]$} & {$[3.7]$} \\
\hline & \multirow[t]{3}{*}{ Earnings $<\$ 28.5 \mathrm{~K}$} & \multirow[t]{3}{*}{4,804} & $-138.1 *$ & $217.0^{*}$ & $355.0 *$ & $218.8 *$ \\
\hline & & & $(33.7)$ & $(33.7)$ & $(33.7)$ & $(31.7)$ \\
\hline & & & {$[-2.9]$} & {$[4.5]$} & {$[7.4]$} & {$[4.6]$} \\
\hline & \multirow[t]{3}{*}{$\$ 28.5 \mathrm{~K} \leq$ Earnings $<\$ 50 \mathrm{~K}$} & \multirow[t]{3}{*}{9,774} & $-141.9^{*}$ & $352.1^{*}$ & $719.7^{*}$ & $450.0^{*}$ \\
\hline & & & $(63.2)$ & $(63.2)$ & $(63.2)$ & $(59.6)$ \\
\hline & & & {$[-1.5]$} & {$[3.6]$} & {$[7.4]$} & {$[4.6]$} \\
\hline & \multirow[t]{3}{*}{ Earnings $\geq \$ 50 \mathrm{~K}$} & \multirow[t]{3}{*}{20,192} & $-541.9^{*}$ & $472.5^{*}$ & $1,436.5^{*}$ & $557.2 *$ \\
\hline & & & (173.5) & (173.5) & $(173.5)$ & (160.8) \\
\hline & & & {$[-2.7]$} & [2.3] & [7.1] & [2.8] \\
\hline \multirow[t]{27}{*}{ Industry } & \multirow[t]{3}{*}{ Agriculture and resources } & \multirow[t]{3}{*}{15,527} & 537.5 & $1,806.3 *$ & $1,917.1 *$ & $1,402.5 *$ \\
\hline & & & $(281.0)$ & $(281.0)$ & $(281.0)$ & $(257.1)$ \\
\hline & & & [3.5] & [11.6] & [12.3] & [9.0] \\
\hline & \multirow[t]{3}{*}{ Construction } & \multirow[t]{3}{*}{11,340} & $597.8^{*}$ & $1,515.9^{*}$ & $2,372.9^{*}$ & $1,754.3^{*}$ \\
\hline & & & $(166.0)$ & $(166.0)$ & $(166.0)$ & (154.8) \\
\hline & & & [5.3] & [13.4] & [20.9] & {$[15.5]$} \\
\hline & \multirow[t]{3}{*}{ Manufacturing } & \multirow[t]{3}{*}{13,920} & -76.0 & $890.3^{*}$ & $1,085.7 *$ & $806.4^{*}$ \\
\hline & & & $(144.0)$ & (144.0) & $(144.0)$ & (132.8) \\
\hline & & & {$[-0.5]$} & [6.4] & [7.8] & [5.8] \\
\hline & \multirow[t]{3}{*}{ Leisure, accommodations } & \multirow[t]{3}{*}{6,612} & $-572.8^{*}$ & $-187.2^{*}$ & -21.1 & -152.8 \\
\hline & & & $(86.3)$ & $(86.3)$ & $(86.3)$ & $(79.1)$ \\
\hline & & & {$[-8.7]$} & {$[-2.8]$} & {$[-0.3]$} & {$[-2.3]$} \\
\hline & \multirow[t]{3}{*}{ Healthcare } & \multirow[t]{3}{*}{9,821} & $-814.7 *$ & $-260.5^{*}$ & -123.2 & $-367.3^{*}$ \\
\hline & & & $(120.0)$ & (120.0) & (120.0) & (109.9) \\
\hline & & & {$[-8.3]$} & {$[-2.7]$} & {$[-1.3]$} & {$[-3.7]$} \\
\hline & \multirow[t]{3}{*}{ Professional services } & 12,246 & $-620.2 *$ & -125.8 & $1,018.7^{*}$ & 166.6 \\
\hline & & & (181.5) & (181.5) & (181.5) & (168.7) \\
\hline & & & {$[-5.1]$} & {$[-1.0]$} & [8.3] & [1.4] \\
\hline & Local services & 8,167 & 34.3 & $334.5^{*}$ & $535.1^{*}$ & $361.6^{*}$ \\
\hline & & & $(67.6)$ & $(67.6)$ & $(67.6)$ & $(62.1)$ \\
\hline & & & {$[0.4]$} & [4.1] & [6.6] & [4.4] \\
\hline & Trade, Transport, Utilities & 12,644 & -152.7 & $698.6^{*}$ & $1,092.5^{*}$ & $699.3^{*}$ \\
\hline & & & $(129.6)$ & $(129.6)$ & $(129.6)$ & (119.7) \\
\hline & & & {$[-1.2]$} & {$[5.5]$} & [8.6] & {$[5.5]$} \\
\hline & Public, Education & 9,163 & -175.8 & 27.3 & $580.2^{*}$ & $248.2 *$ \\
\hline & & & $(105.1)$ & $(105.1)$ & $(105.1)$ & $(97.5)$ \\
\hline & & & {$[-1.9]$} & {$[0.3]$} & [6.3] & {$[2.7]$} \\
\hline
\end{tabular}

Notes: The estimates in each row are based on a separate regression. Standard errors are in parentheses. Pre-storm earnings are average earnings in 2005:2 for the treatment sample. Numbers in brackets are effects as a percent of average pre-storm earnings. For the earnings categories, annual earnings are based on the eight quarters before the storm, 2003:3-2005:2. Short term is 2005:4-2006:3 $(\mathrm{k}=1-4)$, medium term is 2007:4-2008:3 ( $\mathrm{k}=9-12)$, long term is 2011:4-2012:3 ( $\mathrm{k}=25-28)$, and full is 2005:4-2012:3 ( $\mathrm{k}=1-28)$.

$* \mathrm{p}<0.05$. 
Table 6. Effects on Earnings by Subgroup based on Demographic Characteristics

\begin{tabular}{|c|c|c|c|c|c|c|}
\hline \multirow[b]{2}{*}{ Dimension } & \multirow[b]{2}{*}{ Category } & \multirow{2}{*}{$\begin{array}{r}\text { Pre-storm } \\
\text { earnings }\end{array}$} & \multicolumn{4}{|c|}{ Effects by Time Period after the Storm } \\
\hline & & & Short & Medium & Long & Full \\
\hline & All & 10,640 & $-238.2 *$ & $336.9^{*}$ & $767.9^{*}$ & $392.2 *$ \\
\hline & & & (71.6) & $(71.6)$ & $(71.6)$ & $(67.0)$ \\
\hline & & & {$[-2.2]$} & {$[3.2]$} & {$[7.2]$} & {$[3.7]$} \\
\hline \multirow[t]{12}{*}{ Education } & Less than high school & 7,510 & -31.0 & $755.0^{*}$ & $974.8 *$ & $702.4^{*}$ \\
\hline & & & $(72.2)$ & $(72.2)$ & $(72.2)$ & $(67.8)$ \\
\hline & & & {$[-0.4]$} & {$[10.1]$} & {$[13.0]$} & {$[9.4]$} \\
\hline & High school & 8,836 & 4.3 & $614.9^{*}$ & $825.0^{*}$ & $601.9 *$ \\
\hline & & & $(57.0)$ & $(57.0)$ & $(57.0)$ & $(53.8)$ \\
\hline & & & {$[0.0]$} & {$[7.0]$} & {$[9.3]$} & {$[6.8]$} \\
\hline & Some college & 10,139 & $-186.3 *$ & $309.7 *$ & $710.0^{*}$ & $374.7^{*}$ \\
\hline & & & $(59.5)$ & $(59.5)$ & $(59.5)$ & $(55.9)$ \\
\hline & & & {$[-1.8]$} & {$[3.1]$} & {$[7.0]$} & {$[3.7]$} \\
\hline & College & 15,330 & $-667.7^{*}$ & -106.3 & $773.9^{*}$ & 86.5 \\
\hline & & & $(164.5)$ & $(164.5)$ & $(164.5)$ & (151.9) \\
\hline & & & {$[-4.4]$} & {$[-0.7]$} & {$[5.0]$} & {$[0.6]$} \\
\hline \multirow{12}{*}{$\begin{array}{l}\text { Age in } \\
2005\end{array}$} & $25 \leq$ Age $<30$ & 8,106 & -76.7 & -54.6 & 260.5 & 74.6 \\
\hline & & & $(168.0)$ & $(168.0)$ & $(168.0)$ & $(153.0)$ \\
\hline & & & {$[-0.9]$} & {$[-0.7]$} & {$[3.2]$} & {$[0.9]$} \\
\hline & $30 \leq$ Age $<40$ & 10,030 & $-185.9^{*}$ & $502.8^{*}$ & $851.6^{*}$ & $526.9 *$ \\
\hline & & & $(75.6)$ & $(75.6)$ & $(75.6)$ & $(71.1)$ \\
\hline & & & {$[-1.9]$} & {$[5.0]$} & {$[8.5]$} & {$[5.3]$} \\
\hline & $40 \leq$ Age $<50$ & 11,209 & $-310.6^{*}$ & $410.1 *$ & $843.6^{*}$ & $427.9^{*}$ \\
\hline & & & $(90.9)$ & $(90.9)$ & $(90.9)$ & $(84.5)$ \\
\hline & & & {$[-2.8]$} & {$[3.7]$} & {$[7.5]$} & {$[3.8]$} \\
\hline & $50 \leq$ Age $\leq 59$ & 11,702 & $-273.7^{*}$ & $232.5^{*}$ & $830.3^{*}$ & $346.6^{*}$ \\
\hline & & & $(101.4)$ & (101.4) & (101.4) & $(93.8)$ \\
\hline & & & {$[-2.3]$} & {$[2.0]$} & {$[7.1]$} & {$[3.0]$} \\
\hline \multirow[t]{6}{*}{ Sex } & Female & 8,034 & $-359.8^{*}$ & 41.6 & $322.7 *$ & $104.0 *$ \\
\hline & & & $(53.8)$ & $(53.8)$ & $(53.8)$ & $(50.4)$ \\
\hline & & & {$[-4.5]$} & {$[0.5]$} & {$[4.0]$} & {$[1.3]$} \\
\hline & Male & 13,224 & -126.6 & $624.8^{*}$ & $1,214.1 *$ & $677.7^{*}$ \\
\hline & & & $(105.5)$ & $(105.5)$ & $(105.5)$ & $(98.1)$ \\
\hline & & & {$[-1.0]$} & {$[4.7]$} & {$[9.2]$} & {$[5.1]$} \\
\hline \multirow{9}{*}{$\begin{array}{l}\text { Race/ } \\
\text { Ethnicity }\end{array}$} & White, not Hispanic & 11,893 & -140.2 & $415.5^{*}$ & $941.7^{*}$ & $492.3^{*}$ \\
\hline & & & $(94.6)$ & $(94.6)$ & $(94.6)$ & $(87.7)$ \\
\hline & & & {$[-1.2]$} & {$[3.5]$} & [7.9] & {$[4.1]$} \\
\hline & Black, not Hispanic & 7,661 & $-496.6^{*}$ & 140.0 & $404.2 *$ & $150.3^{*}$ \\
\hline & & & $(72.6)$ & $(72.6)$ & $(72.6)$ & $(67.8)$ \\
\hline & & & {$[-6.5]$} & {$[1.8]$} & {$[5.3]$} & {$[2.0]$} \\
\hline & Hispanic + Other race/NH & 10,387 & -168.6 & $362.8^{*}$ & $576.7^{*}$ & $393.0 *$ \\
\hline & & & $(144.0)$ & $(144.0)$ & $(144.0)$ & (131.7) \\
\hline & & & {$[-1.6]$} & {$[3.5]$} & {$[5.6]$} & {$[3.8]$} \\
\hline
\end{tabular}

Notes: The estimates in each row are based on a separate regression. Standard errors are in parentheses. Pre-storm earnings are average earnings in 2005:2 for the treatment sample. Numbers in brackets are effects as a percent of average pre-storm earnings. Short term is 2005:4-2006:3 $(\mathrm{k}=1-4)$, medium term is 2007:4-2008:3 ( $\mathrm{k}=9-12)$, long term is 2011:4-2012:3 ( $\mathrm{k}=25-28)$, and full is 2005:4-2012:3 $(\mathrm{k}=1-28)$.

$* \mathrm{p}<0.05$. 
Table 7. Effects on Earnings by Subgroups based on Migration or Job Separation

Effects by Time Period after the Storm

Migration

\begin{tabular}{cccc}
\hline Short & Medium & Long & Full \\
& & & \\
& & & \\
$-245.4^{*}$ & $354.4^{*}$ & $775.8^{*}$ & $402.0^{*}$ \\
$(73.8)$ & $(73.8)$ & $(73.8)$ & $(69.0)$ \\
{$[-2.3]$} & {$[3.3]$} & {$[7.3]$} & {$[3.8]$} \\
$-1,698.8^{*}$ & -59.3 & $704.4^{*}$ & -126.3 \\
$(229.7)$ & $(229.7)$ & $(229.7)$ & $(215.5)$ \\
{$[-16.0]$} & {$[-0.6]$} & {$[6.6]$} & {$[-1.2]$} \\
-136.0 & $385.5^{*}$ & $781.1^{*}$ & $441.8^{*}$ \\
$(71.2)$ & $(71.2)$ & $(71.2)$ & $(66.8)$ \\
{$[-1.3]$} & {$[3.6]$} & {$[7.3]$} & {$[4.2]$} \\
& & & \\
$-1,635.8^{*}$ & -283.1 & $554.5^{*}$ & -275.0 \\
$(262.3)$ & $(262.3)$ & $(262.3)$ & $(245.5)$ \\
{$[-15.4]$} & {$[-2.7]$} & {$[5.2]$} & {$[-2.6]$} \\
$-2,818.4^{*}$ & -909.7 & -304.0 & $-1,153.9^{*}$ \\
$(490.7)$ & $(490.7)$ & $(490.7)$ & $(450.2)$ \\
{$[-26.5]$} & {$[-8.6]$} & {$[-2.9]$} & {$[-10.8]$} \\
$-1,095.7^{*}$ & 3.0 & $946.6^{*}$ & 126.3 \\
$(332.7)$ & $(332.7)$ & $(332.7)$ & $(305.2)$ \\
{$[-10.3]$} & {$[0.0]$} & {$[8.9]$} & {$[1.2]$}
\end{tabular}

Job Separations

A. All Damage Types

Total

Movers

Non-movers

B. Residence Damage: Major

Total

Movers

Non-movers

C. All Damage Types

Total

$\begin{array}{llll}-238.2 * & 336.9 * & 767.9 * & * \\ & * & & \end{array}$

$\begin{array}{llll}(71.6) & (71.6) \quad(71.6)\end{array}$

$[-2.2] \quad[3.2] \quad[7.2] \quad[3.7]$

Separators

$-2,460.2 *-470.1 *$

(194.2)

(194.2)

$603.9 *$

$-429.5 *$

Non-separators

$[-23.1]$

$(194.2)$

$(184.4)$

$-15.2$

[-4.4]

[5.7]

[-4.0]

(69.1)

417.9*

784.4*

474.6*

[-0.1]

(69.1)

(69.1)

(65.6)

D. Workplace Damage: Major

Total

$\begin{array}{cccc}-1,531.2 * & -148.4 & 725.4 * & -117.8 \\ (201.6) & (201.6) & (201.6) & (189.3) \\ {[-14.4]} & {[-1.4]} & {[6.8]} & {[-1.1]} \\ -3,445.9 * & -905.5 & 337.2 & -834.7 \\ (499.8) & (499.8) & (499.8) & (461.6) \\ {[-32.4]} & {[-8.5]} & {[3.2]} & {[-7.8]} \\ -1,069.3 * & 34.3 & 819.0 * & 55.1 \\ (247.1) & (247.1) & (247.1) & (228.2) \\ {[-10.1]} & {[0.3]} & {[7.7]} & {[0.5]}\end{array}$

Notes: See notes to Figure 8 for definitions of subgroups based on migration or job separation. Standard errors are in parentheses. Numbers in brackets are effects as a percent of average earnings in 2005:2 for the treatment sample as a whole. Short term is 2005:4-2006:3 ( $\mathrm{k}=1-4)$, medium term is 2007:4-2008:3 ( $\mathrm{k}=9-12)$, long term is 2011:4$2012: 3(\mathrm{k}=25-28)$, and full is $2005: 4-2012: 3(\mathrm{k}=1-28)$.

$* \mathrm{p}<0.05$. 
Table 8. Effect of Damage Type on Migration and Job Separations

\begin{tabular}{|c|c|c|c|c|c|c|}
\hline \multirow{4}{*}{$\begin{array}{l}\text { Residence Damage } \\
\text { Major }\end{array}$} & \multicolumn{3}{|c|}{ Migration } & \multicolumn{3}{|c|}{ Job Separations } \\
\hline & (1) & (2) & (3) & (4) & (5) & (6) \\
\hline & & & & & & \\
\hline & $\begin{array}{l}0.2355^{*} \\
(0.0112)\end{array}$ & & $\begin{array}{l}0.2064 * \\
(0.0115)\end{array}$ & $\begin{array}{l}0.1243 * \\
(0.0092)\end{array}$ & & $\begin{array}{l}0.0906^{*} \\
(0.0094)\end{array}$ \\
\hline Minor & $\begin{array}{l}0.0293^{*} \\
(0.0057)\end{array}$ & & $\begin{array}{l}0.0127^{*} \\
(0.0060)\end{array}$ & $\begin{array}{c}0.03370^{*} \\
(0.0059)\end{array}$ & & $\begin{array}{l}0.0123^{*} \\
(0.0058)\end{array}$ \\
\hline Uncertain & $\begin{array}{l}-0.0239^{*} \\
(0.0045)\end{array}$ & & $\begin{array}{l}-0.0153^{*} \\
(0.0049)\end{array}$ & $\begin{array}{l}-0.0181^{*} \\
(0.0036)\end{array}$ & & $\begin{array}{l}-0.0040 \\
(0.0037)\end{array}$ \\
\hline None & -- & & -- & -- & & -- \\
\hline Workplace Damage & & & & & & \\
\hline Major & & $\begin{array}{c}0.1297 * \\
(0.0123)\end{array}$ & $\begin{array}{l}0.0852 * \\
(0.0077)\end{array}$ & & $\begin{array}{c}0.1116^{*} \\
(0.0208)\end{array}$ & $\begin{array}{l}0.0919 * \\
(0.0079)\end{array}$ \\
\hline Minor & & $\begin{array}{l}0.0874 * \\
(0.0127)\end{array}$ & $\begin{array}{l}0.0647^{*} \\
(0.0054)\end{array}$ & & $\begin{array}{l}0.0786^{*} \\
(0.0349)\end{array}$ & $\begin{array}{l}0.0678^{*} \\
(0.0051)\end{array}$ \\
\hline Uncertain & & $\begin{array}{l}-0.0087 \\
(0.0046)\end{array}$ & $\begin{array}{c}0.0035 \\
(0.0045)\end{array}$ & & $\begin{array}{l}-0.0128^{*} \\
(0.0049)\end{array}$ & $\begin{array}{c}-0.0083^{*} \\
(0.0044)\end{array}$ \\
\hline None & & -- & -- & & -- & -- \\
\hline Outside treatment area & & $\begin{array}{l}0.0286^{*} \\
(0.0043)\end{array}$ & $\begin{array}{c}0.0334^{*} \\
(0.0043)\end{array}$ & & $\begin{array}{c}0.0046 \\
(0.0049)\end{array}$ & $\begin{array}{c}0.0063 \\
(0.0040)\end{array}$ \\
\hline Demographic controls & $\mathrm{X}$ & $\mathrm{X}$ & $\mathrm{X}$ & $\mathrm{X}$ & $\mathrm{X}$ & $\mathrm{X}$ \\
\hline Job controls & & & & X & X & X \\
\hline Individuals & 100,000 & 100,000 & 100,000 & 110,000 & 110,000 & 110,000 \\
\hline R-squared & 0.0733 & 0.0531 & 0.0844 & 0.0624 & 0.0681 & 0.0727 \\
\hline Mean of Dep. Var. & 0.0700 & 0.0700 & 0.0700 & 0.0912 & 0.0912 & 0.0912 \\
\hline
\end{tabular}

Notes: Estimation sample is individuals in the treatment sample. Each column comes from a separate regression. Dependent variable for columns 1-3 is an indicator for living in a different commuting zone in 2005 and 2006; dependent variable for columns 4-6 is an indicator for not working for the pre-storm employer in the first four quarters after the storm. Standard errors, in parentheses, account for clustering by residence block (columns 1, 3, 4, and 6) or workplace block (columns 2 and 5). Demographic controls: age, sex, and race/ethnicity. Job controls: industry, employer size, and employee tenure. The sample size for columns 1-3 is smaller than the sample size for columns $4-6$ because the sample for the migration regressions is limited to records with a linked residence location of at least county-level precision for all years 2003-2010.

$* \mathrm{p}<0.05$. 
Table 9. Average Wages in Treatment and Control Areas, 2005-2012

\begin{tabular}{lrrr}
\hline & Treatment & Control & $\begin{array}{r}\text { Treatment } \\
- \text { Control }\end{array}$ \\
\hline Levels (\$) & & & \\
May 2005 & 15.68 & 17.36 & -1.68 \\
May 2008 & 16.08 & 17.18 & -1.10 \\
May 2012 & 16.76 & 17.43 & -0.67 \\
Changes (\%) & & & \\
2005 to 2008 & 2.53 & -1.07 & 3.60 \\
2005 to 2012 & 6.91 & 0.40 & 6.52 \\
\hline \hline
\end{tabular}

Note: Estimates of average wages are in \$2005:2.

Source: Occupational Employment Statistics (authors' calculations; see Data Appendix). 
Figure 1. County-level Damage

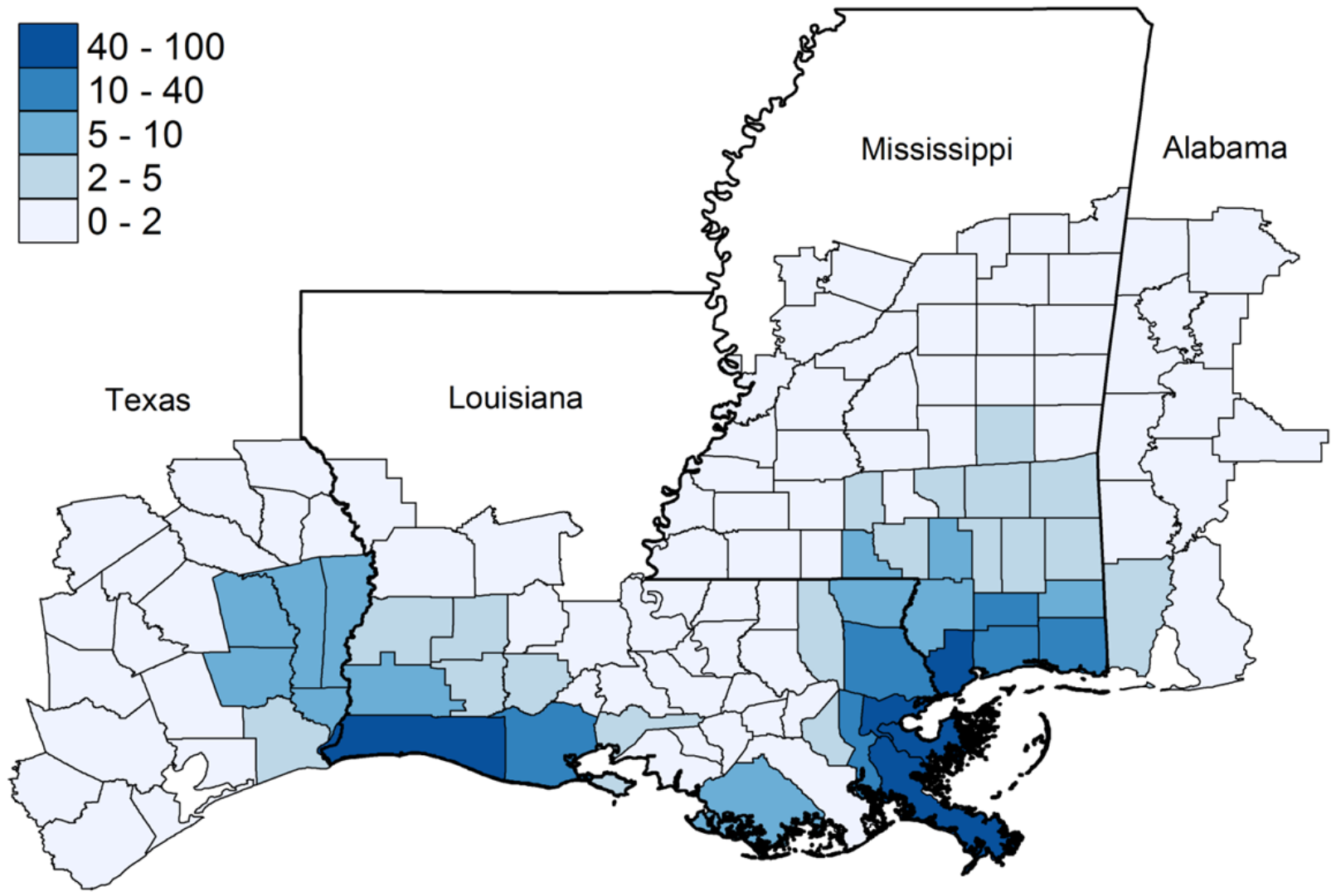

Source: FEMA damage data provided by HUD (2006).

Notes: Legend shows the share of housing units in a county with severe or major damage. The map shows 122 counties in Texas, Louisiana, Mississippi, and Alabama. 
Figure 2. Major and Minor Damage

Panel A. New Orleans, Louisiana (and surrounding areas)

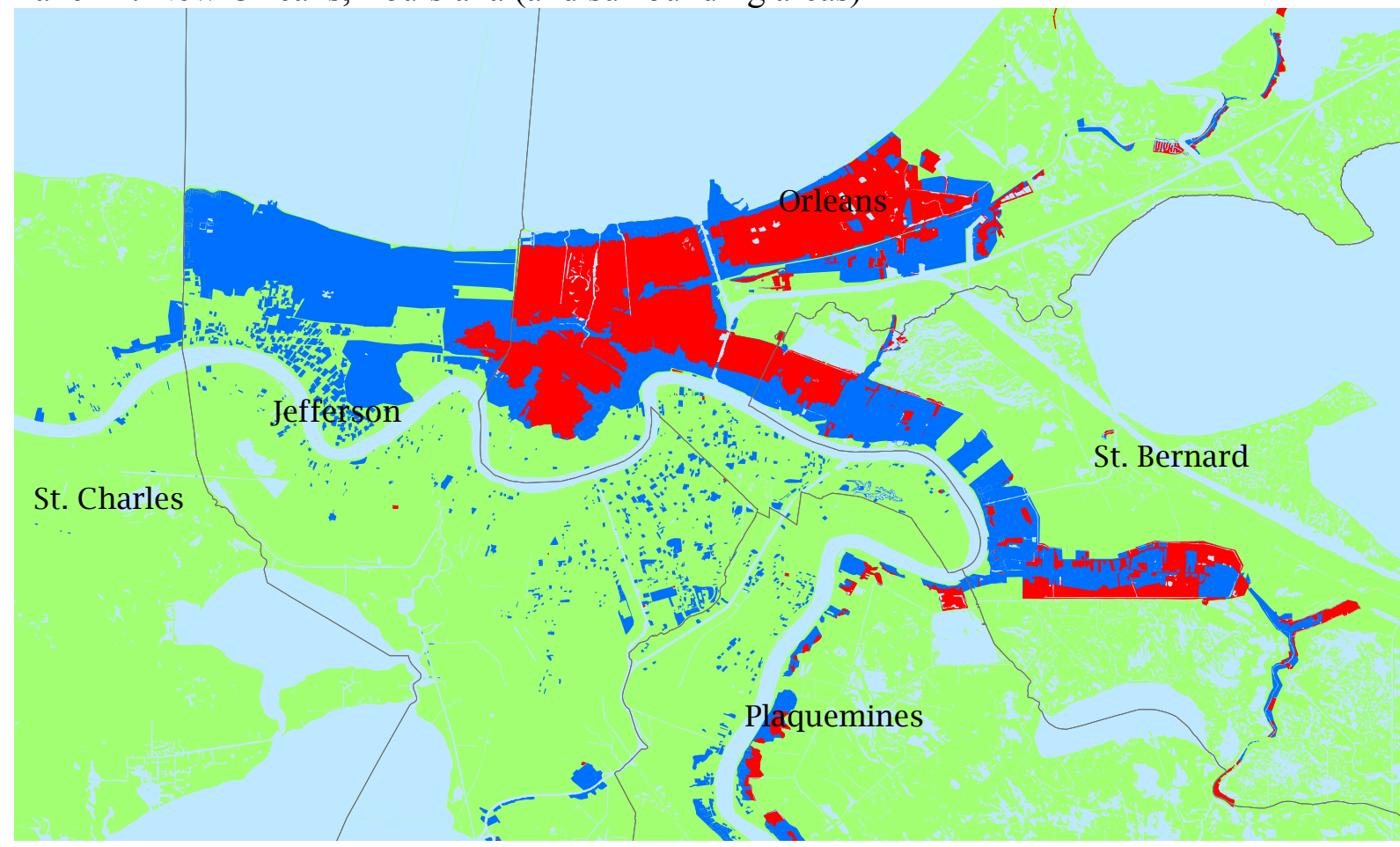

\section{Panel B. Gulf Coast of Mississippi}

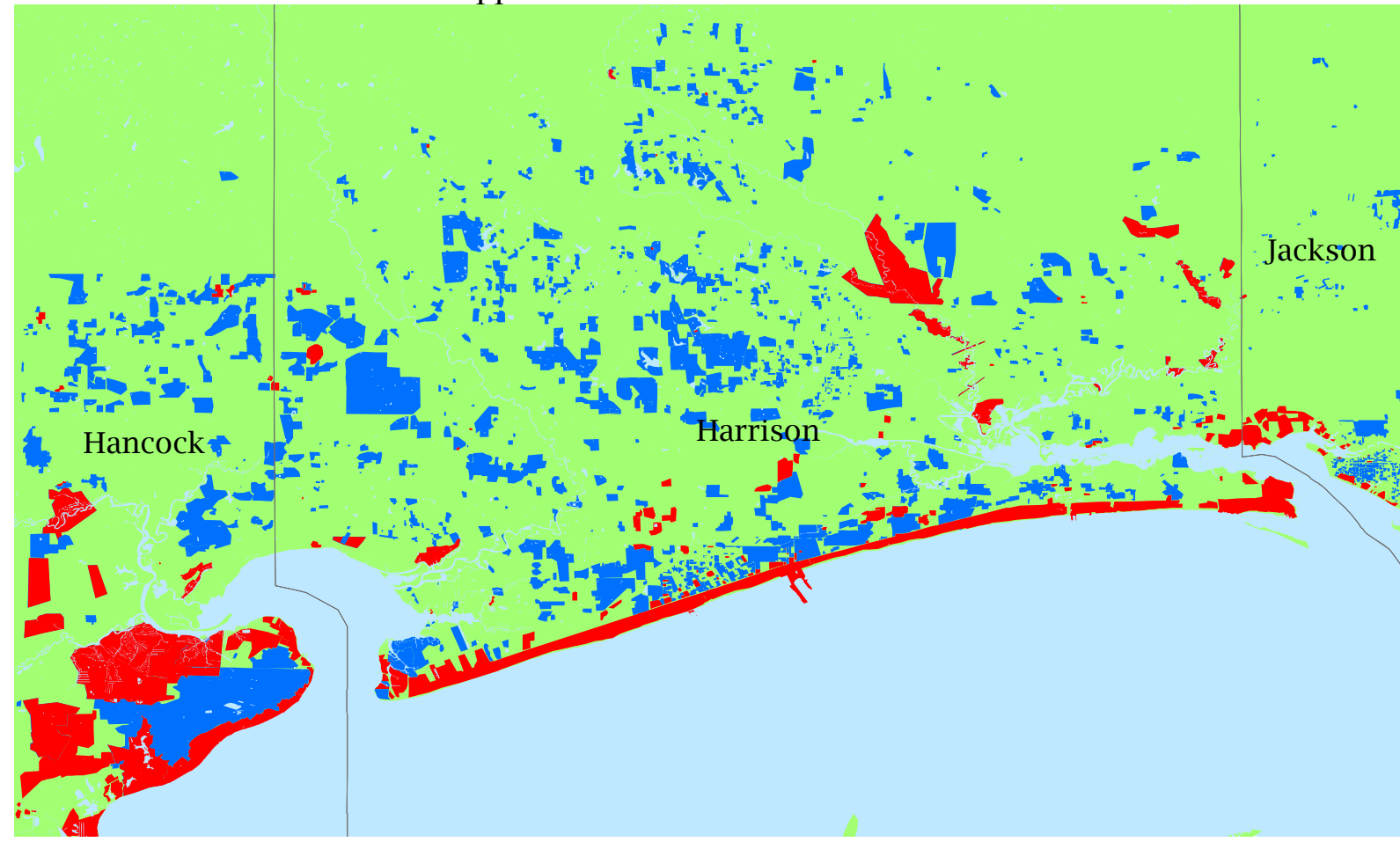

Source: Damage information from FEMA (2005).

Notes: Panels A and B depict damage from Hurricane Katrina, along with county names and boundaries. Red indicates major damage, dark blue indicates minor damage, green indicates undamaged land area, and light blue indicates bodies of water. Both maps are to the same scale and depict an area approximately 40 miles wide. 
Figure 3. Treatment and Control Areas

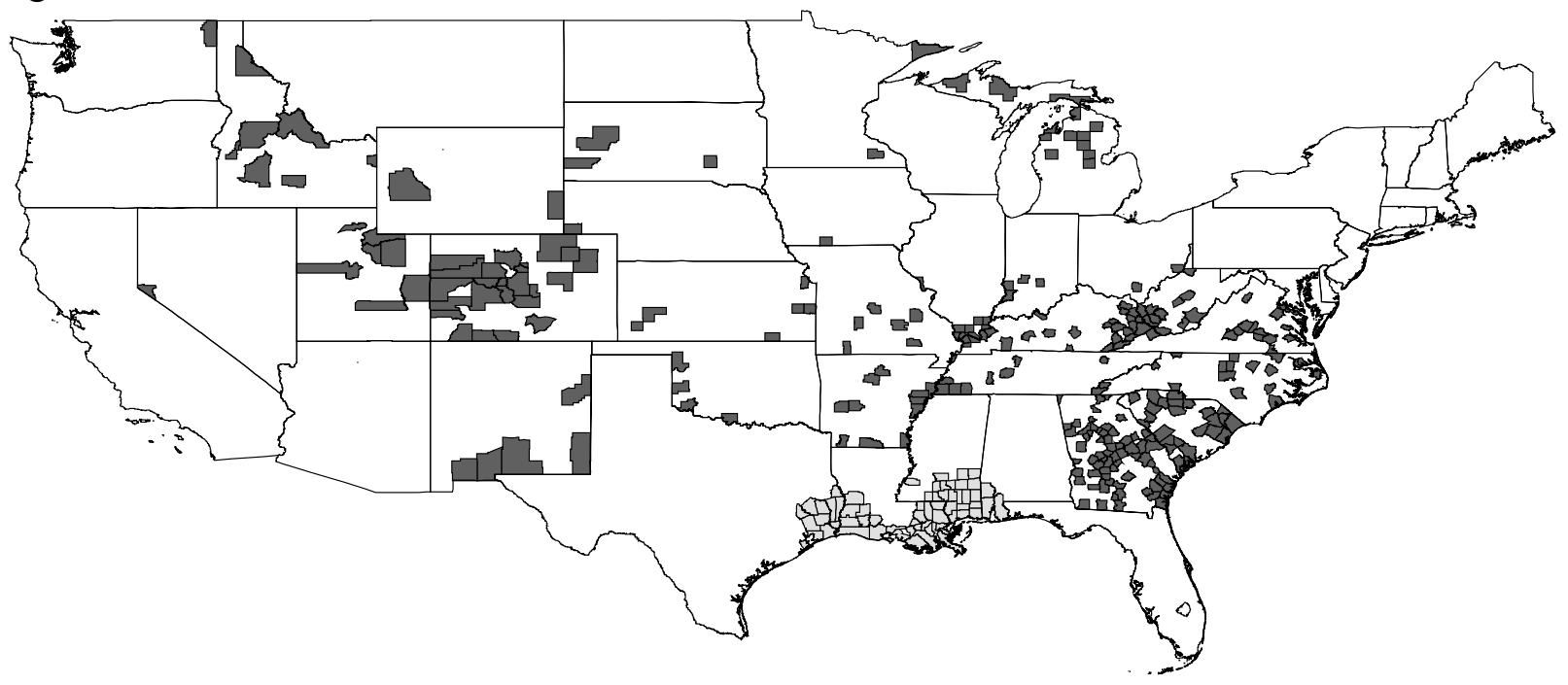

Notes: The estimation sample consists of workers who resided in treatment counties or control counties before the Hurricanes Katrina and Rita. Treatment counties (shaded lighter) are 63 counties in Texas, Louisiana, Mississippi, and Alabama. Control counties (shaded darker) are 286 counties in 26 states.

Figure 4. Average Earnings in Treatment and Control Samples

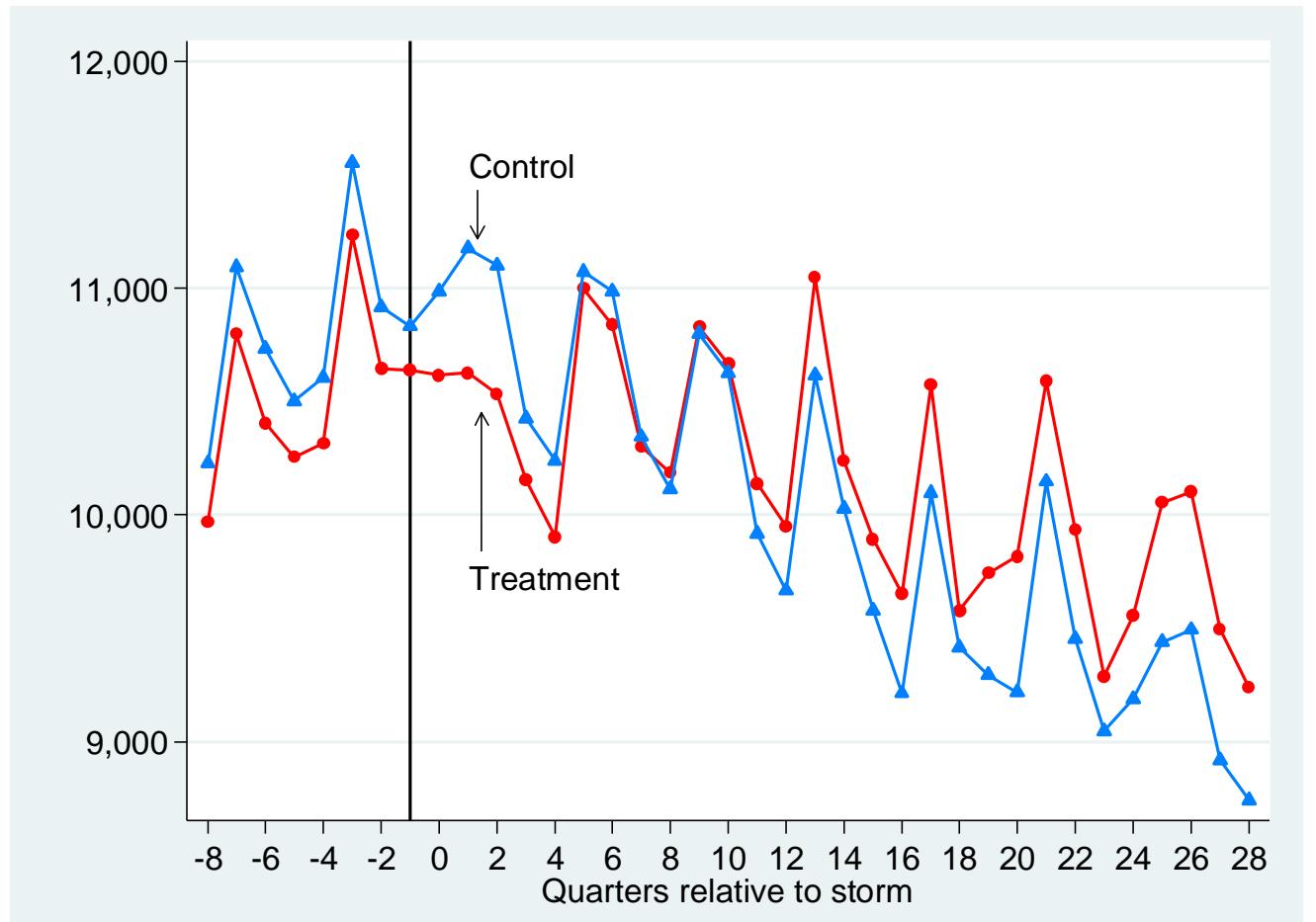

Notes: Average total earnings calculated from LEHD quarterly earnings records spanning 2003:3 to 2012:3. The storms struck in 2005:3, labeled zero. All earnings are adjusted to 2005:2 (marked by the vertical line) using the Consumer Price Index. All workers held a job at the beginning of 2005:2 as well as in each of the eight previous quarters. Sample includes 110,000 workers in the treatment sample and 355,000 in the control sample (Table 1). 
Figure 5. Effects on Earnings

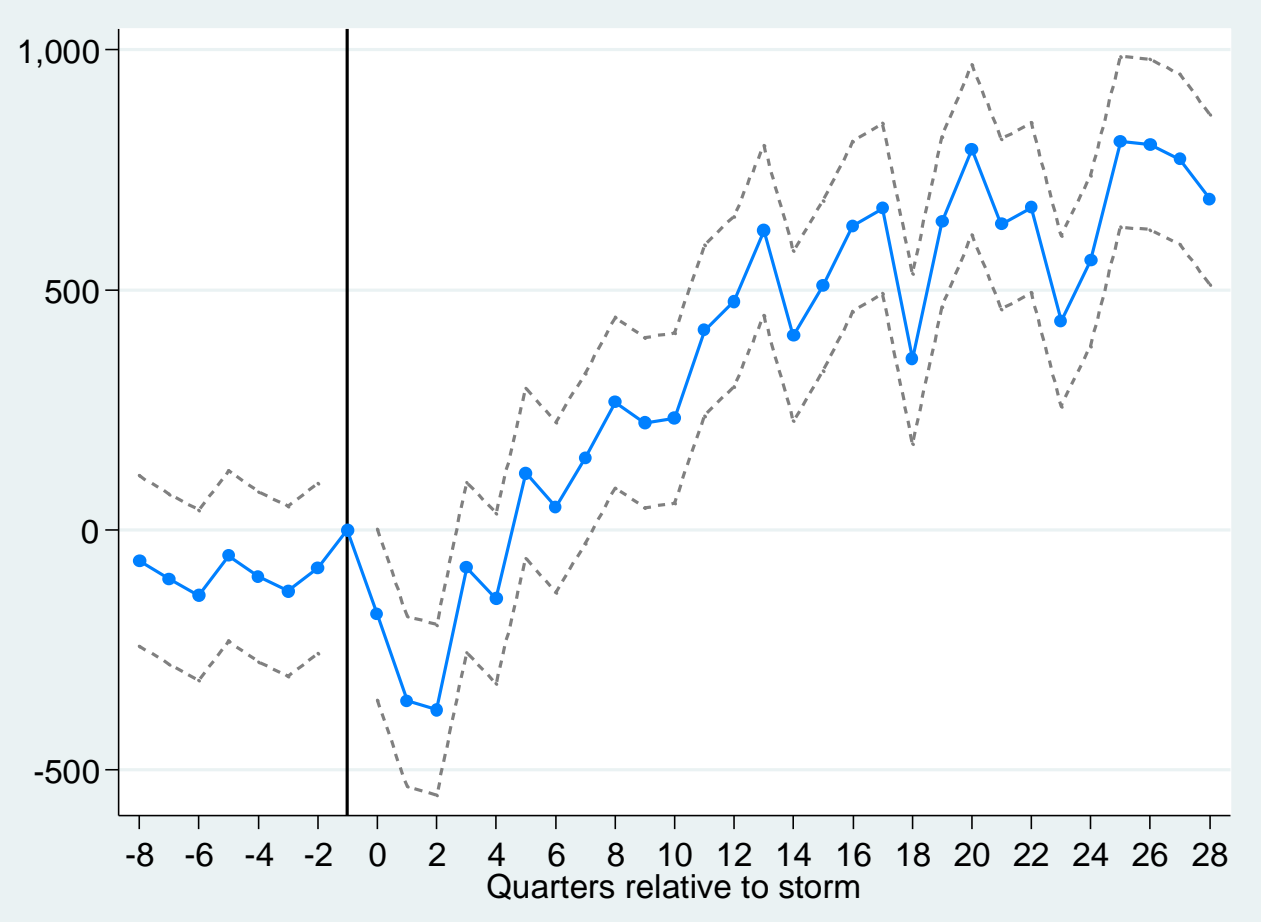

Notes: See Figure 4 for description of sample and earnings data. Equation (1) provides the model specification. Estimates capture the earnings difference between individuals in the treatment and control samples in each quarter before/after the storms, relative to this difference in the first quarter before the storm (2005:2). Person records are aggregated into cells defined by 2005 residence county and calendar quarter. Dashed lines show the upper and lower bounds of $95 \%$ confidence intervals. 
Figure 6. Channels of Effects on Earnings

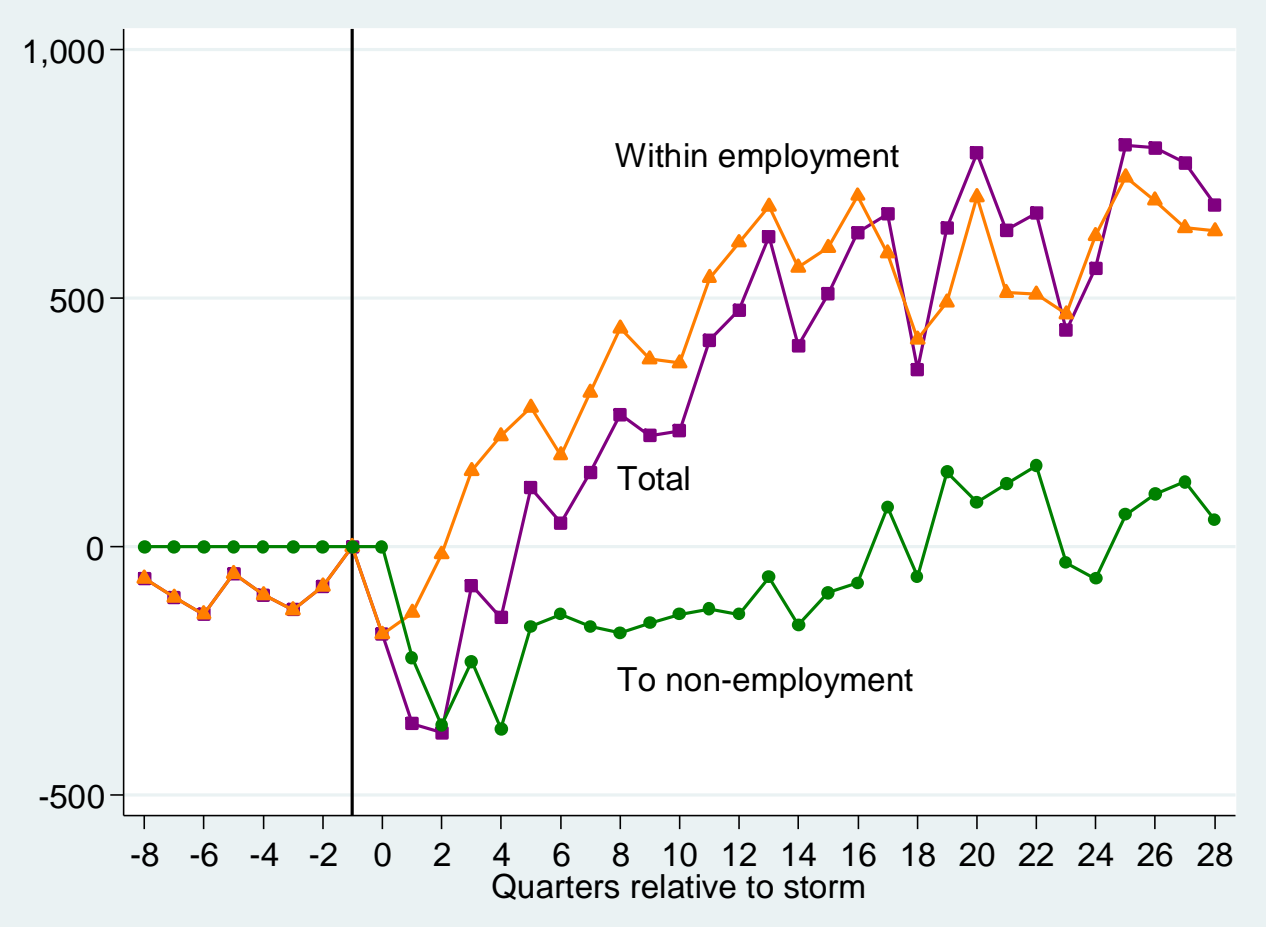

Notes: See Figure 4 for description of sample and earnings data. "Total" estimates are for Equation (1). The "within employment" and "to non-employment" estimates substitute alternate dependent variables that sum to total earnings. The "within employment" estimates isolate earnings changes for those employed in a quarter, while the "to non-employment" estimates isolate changes due to shifts to non-employment. 
Figure 7. Effects by Damage Type to a Workers' Residence or Workplace Residence Damage
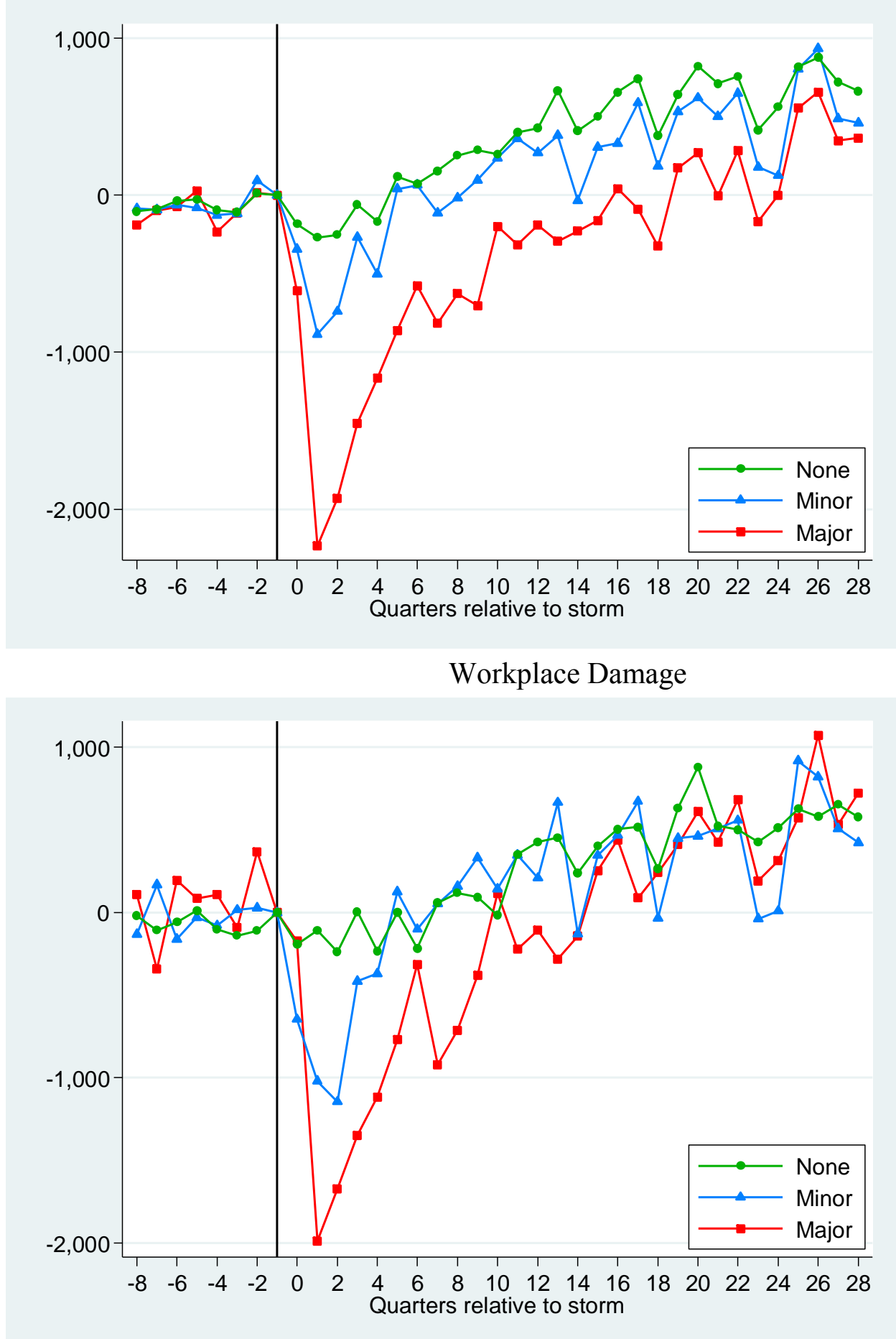

Notes: See Figure 4 for description of sample and earnings data. Equation (2) provides the model specification for the residence-damage estimates. The figure does not display estimates for uncertain damage (expected to be of lower frequency and intensity) and for working outside of the treatment area (in the workplace-damage model). See Table 2 for distribution of damage types in the treatment sample and Figure 2 for a mapping of the damage areas. 
Figure 8. Effects on Earnings by Subgroups based on Migration or Job Separation

\section{Movers and Non-movers}

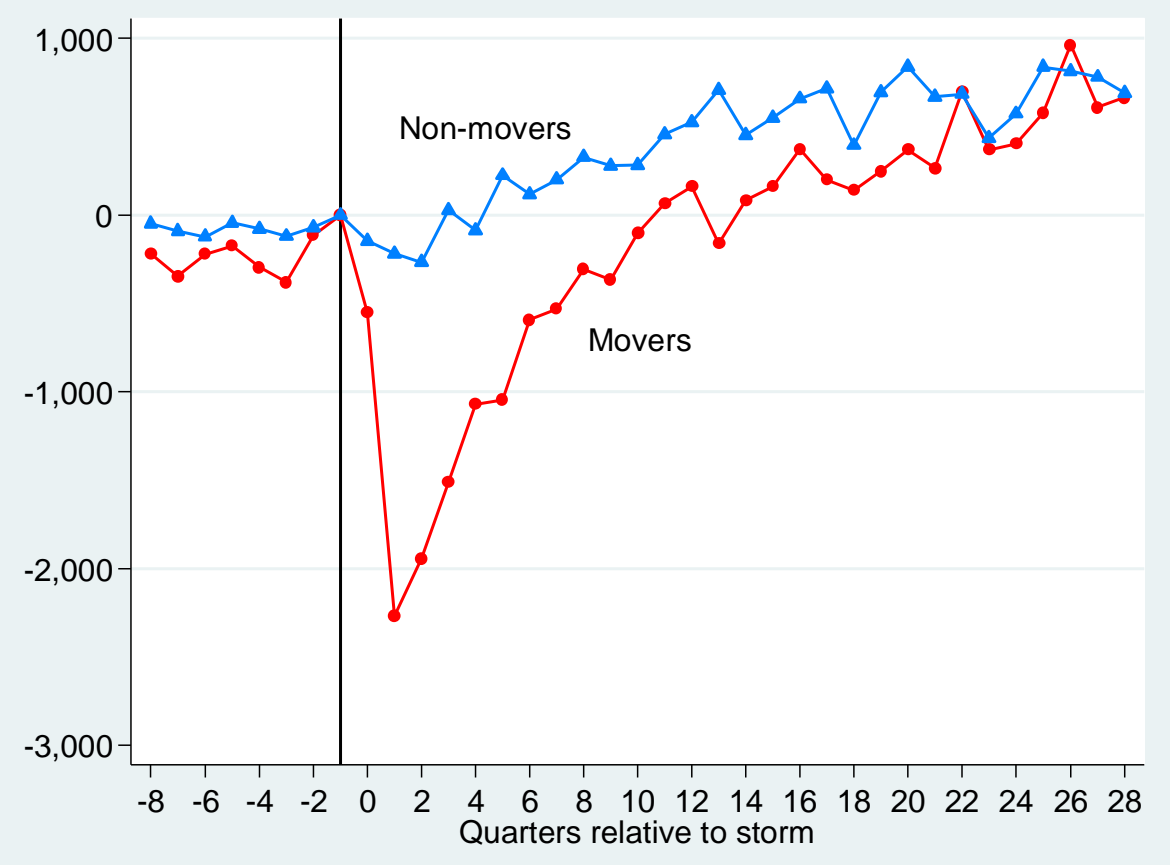

\section{Separators and Non-separators}

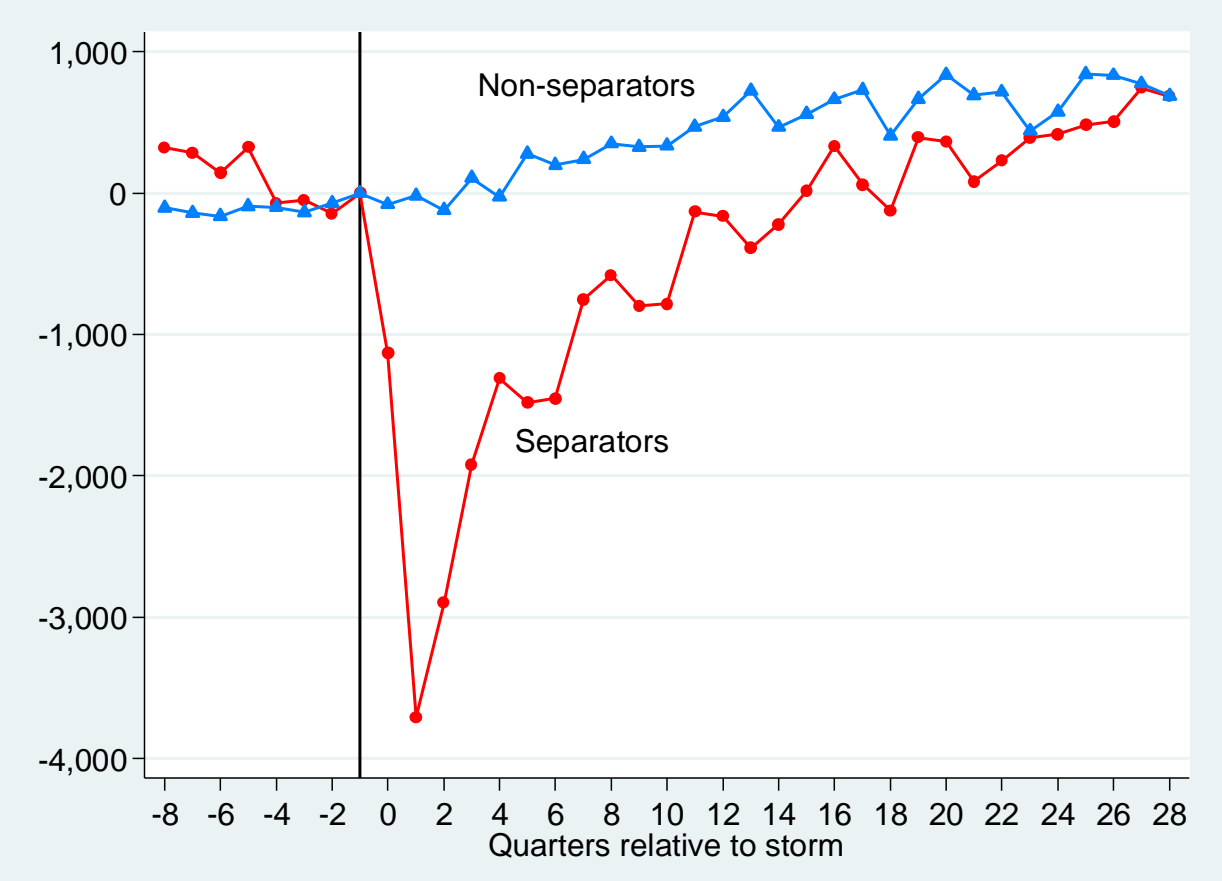

Notes: See Figure 4 for description of the separator sample and earnings data. See Table 3 for description of the migration sample. The model specification is analogous to Equation (2), with subgroups defined by migration or job separation rather than damage type. Movers are those in the treatment sample who were in a different commuting zone in 2005 and 2006; non-movers are the remainder of the treatment sample. Separators are those in the treatment sample who were not working for their pre-storm employer in the first four quarters after the storm; non-separators are the remainder of the treatment sample. 
Figure 9. Population and Employment in Treatment and Control Areas (\% of pre-storm level)

Population

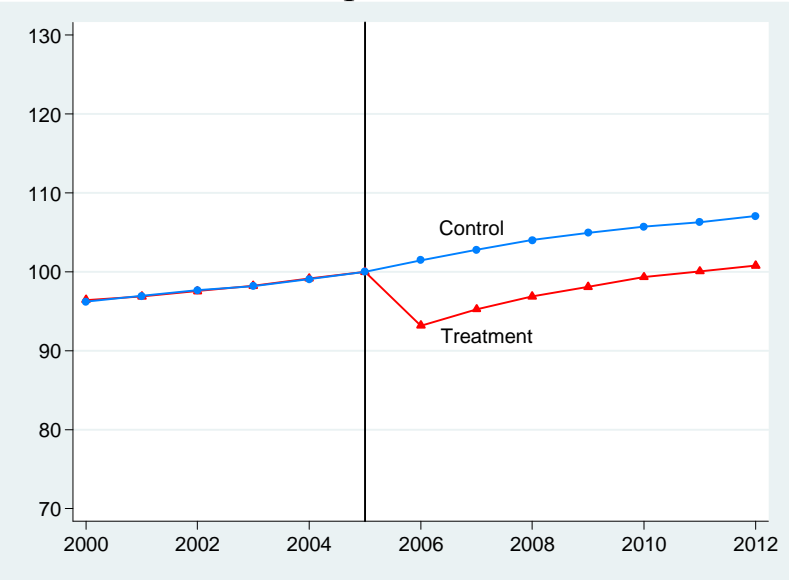

Employment-Construction

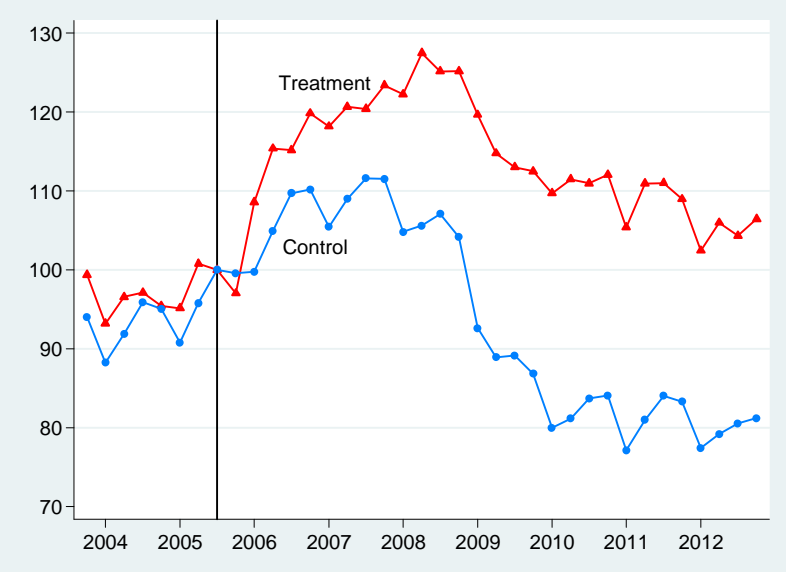

Employment—Leisure and Accommodations

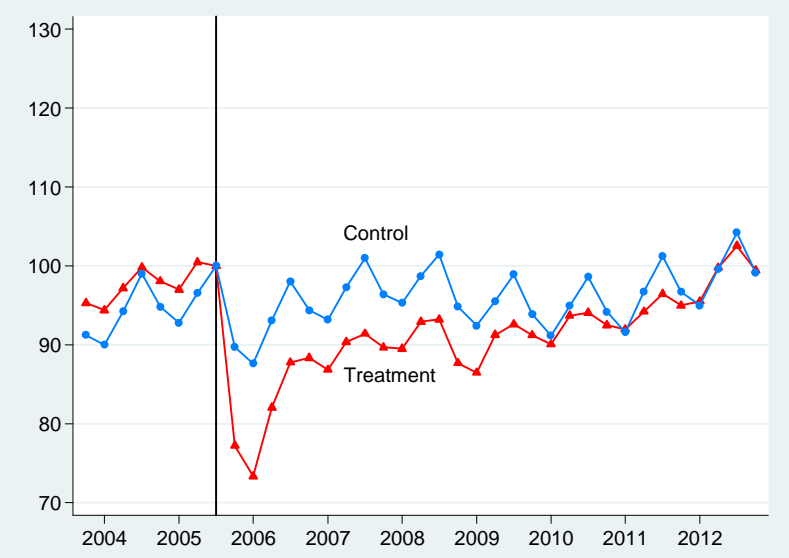

Employment-All Sectors

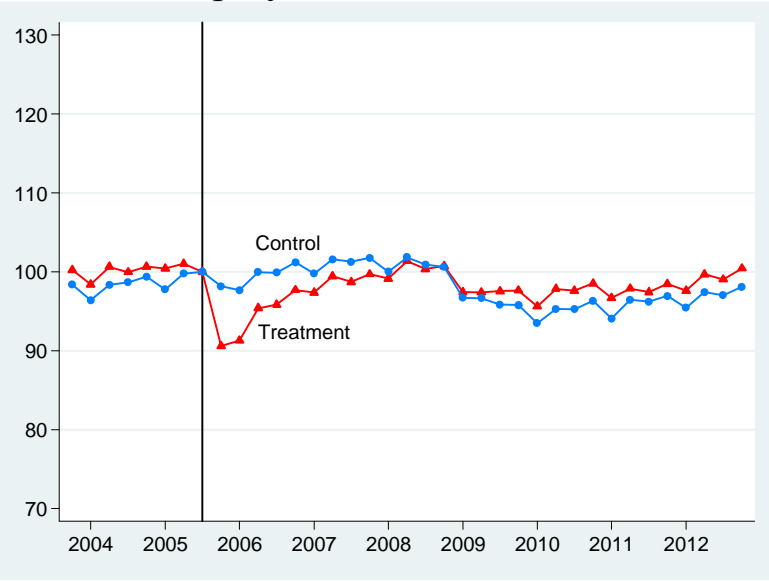

Employment-Manufacturing

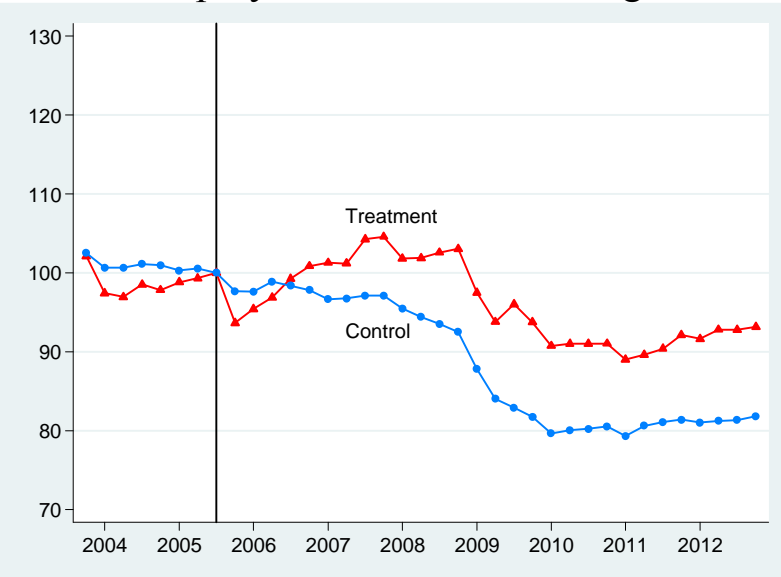

Employment-Healthcare

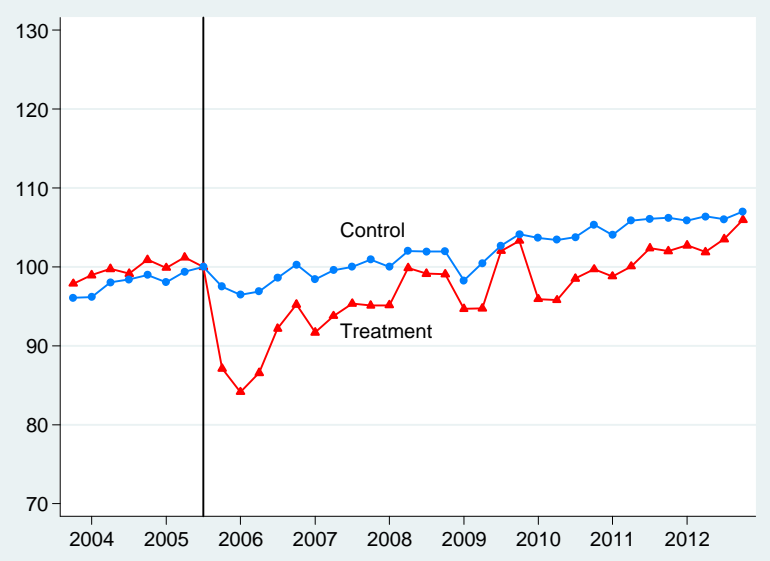

Source: Census Bureau County Population Estimates (public-use data) and Quarterly Workforce Indicators (authors' calculations; see Data Appendix). 
Figure 10. Local Labor-Market Dynamics over the Long Term

\section{$\underline{\text { Aggregate (all sectors combined) }}$}

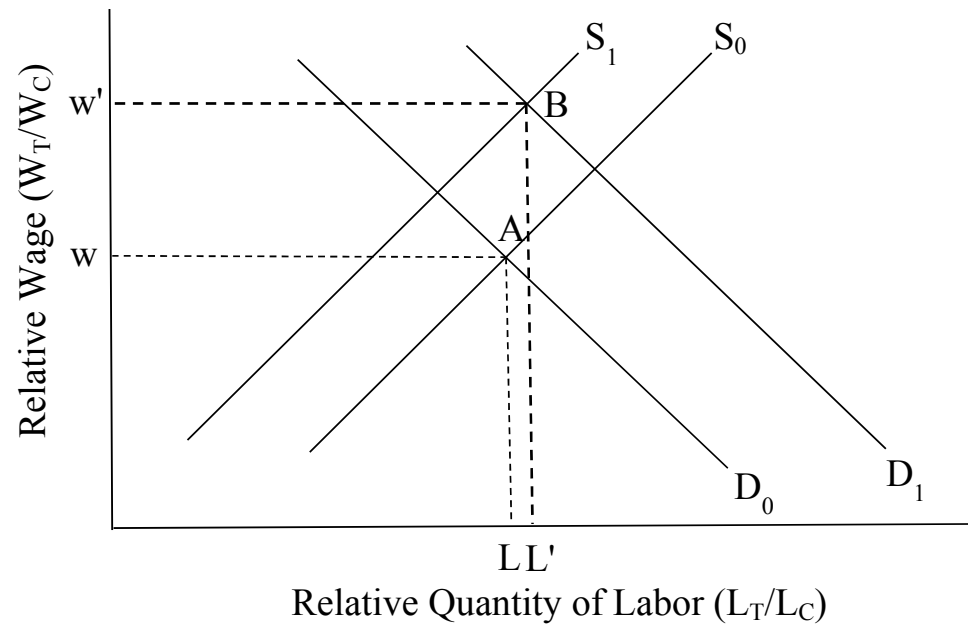

Construction (non-tradable sector tied to the reconstruction)

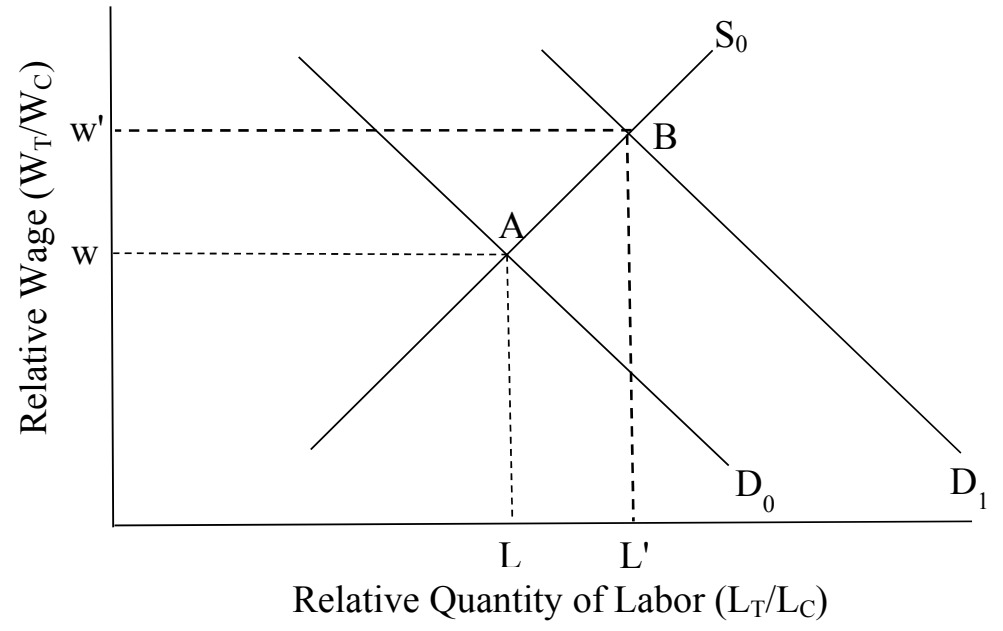

Healthcare (non-tradable sector tied to the local population)

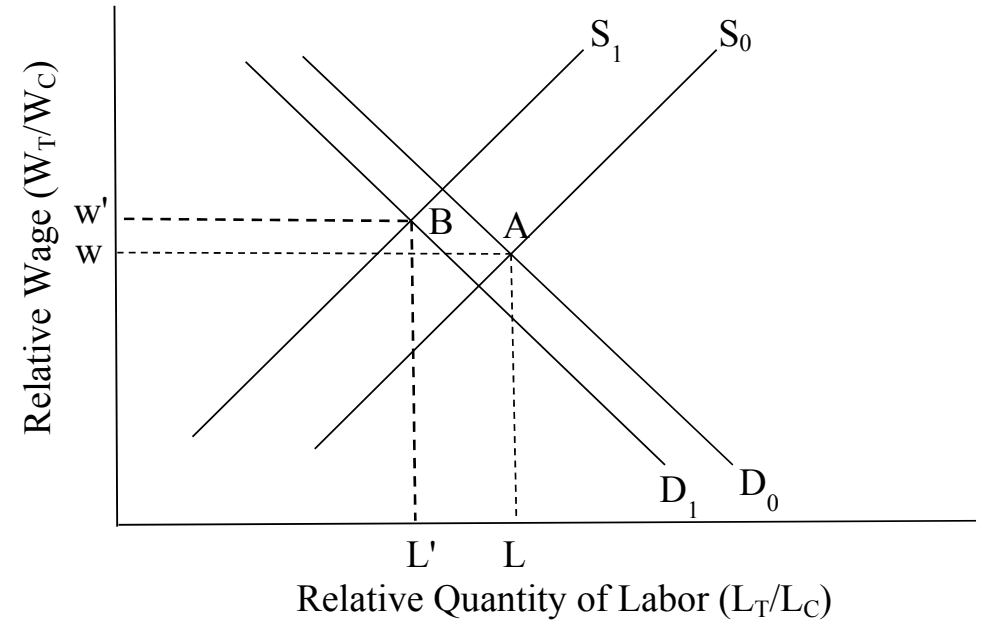

Note: " $\mathrm{T}$ " and "C" subscripts refer to the treatment area and control area, respectively. 
Figure 11. Wage Change in Local Areas and Earnings Effects of Storm, Long Term, by Sector

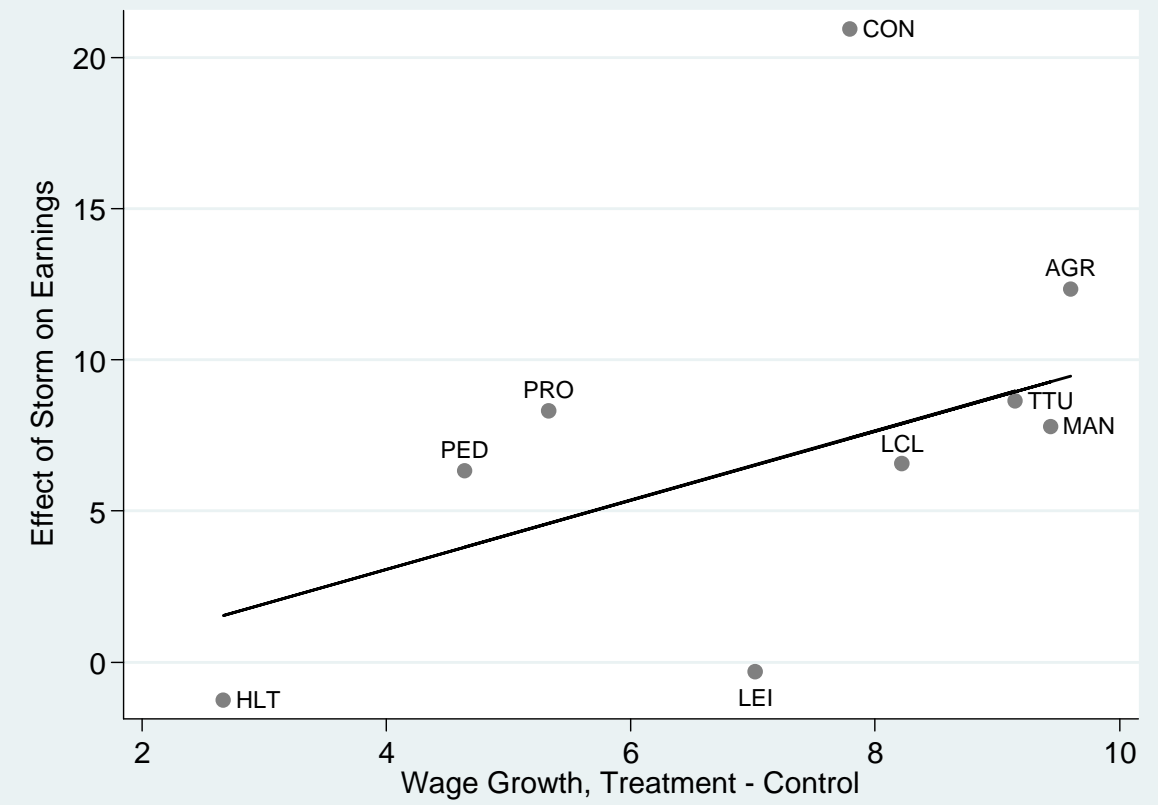

Notes: "Wage Growth, Treatment - Control" based on estimates from the Occupational Employment Statistics is defined as [\%change in average wage (2005 to 2012), relative to pre-storm, in treatment] - [\%change in average wage (2005 to 2012), relative to pre-storm, in control]. "Effect of Storm on Earnings" is long-term effect of the storm on earnings as a percent of average pre-storm earnings, taken from Table 5. Sectors: agriculture and natural resources (AGR); construction (CON); manufacturing (MAN); leisure and accommodations (LEI); healthcare (HLT); professional services (PRO); local services (LCL); trade, transportation, and utilities (TTU); and public and education (PED). The regression line is estimated by weighted least squares with the sector share of total employment before the storm in the treatment area as the weight. 


\section{Data Appendix}

\subsection{Worker Data}

In order to examine longitudinal outcomes for individuals potentially affected by Hurricanes Katrina and Rita, this paper makes use of restricted-access administrative and survey data brought together at the U.S. Census Bureau. The combined dataset tracks quarterly labormarket outcomes and includes a variety of demographic variables. The structure of the combined dataset permits us to examine individuals before and after the storms and to examine storm effects over a seven-year period. The large sample size also allows us to obtain precise parameter estimates and enables us to examine subsamples of the population.

We begin with an extract from the 2000 Census long-form microdata and ACS microdata (from January 2003 to July 2005) of persons who were aged 25 to 59 in 2005 and at least 25 when they responded to the survey. The 2000 long-form, or Sample Census Edited File (SCEF), contributes approximately 90 percent of the respondents overall, but the ACS provides all of the respondents under age 30 in 2005 . $^{40}$ The lower bound for age reduces the likelihood of nonemployment reflecting college attendance and improves the likelihood that reported educational attainment reflects attainment as of 2005. The upper bound for age reduces the likelihood of retirement within the study period. From the survey responses, we obtain demographic information (age, sex, race, and ethnicity) and educational attainment. In order to match the survey records to administrative data, we make use of a unique personal identifier, called a Protected Identification Key (PIK). The Census Bureau uses federal administrative data to probabilistically match survey responses to a PIK, based on a comparison of personally identifying information. ${ }^{41}$ For this combined survey sample, approximately 90 percent of records have a PIK match.

For each person in the survey sample, we determine a pre-hurricane residential location, using a PIK-linked address file based on federal administrative records. The Census Bureau produces an annual Composite Person Record (CPR) residence file, which provides a single residence location for a PIK in a given year. ${ }^{42}$ For the extract of survey respondents with a PIK, 96 percent match to a CPR record that provides at least county-level precision and 79 percent match to a Census tract and block location. Because the majority of CPR records are sourced from the addresses on federal income-tax returns (which are typically filed in the first four months of the year), the 2005 locations are a good representation of pre-storm location. We limit the sample to survey respondents with both a PIK and an administrative residence location in 2005 that is precise to the county level or better.

We reweight survey responses based on the relative prevalence of demographic characteristics at the national level in 2005 and based on the likelihood of a person having a link to the CPR with county-level geography or better. ${ }^{43}$ We use the new weights for computations reported in the paper, including summary statistics and regressions.

\footnotetext{
${ }^{40}$ The ACS expanded its sampling by threefold in 2005, so the majority of ACS responses are from that year, even though only the first seven months are used.

${ }^{41}$ In less than one percent of cases, multiple responses may be matched to the same PIK. In this event, we randomly retain the PIK of only one respondent.

${ }^{42}$ The LEHD program uses residences provided in the CPR for imputations and as a place of residence for jobs data in the LEHD Origin-Destination Employment Statistics, available in the Web tool OnTheMap.

${ }^{43}$ First, we estimate the number of 2005 persons that each survey respondent with a PIK in our age range represents (based on combinations of age, sex, and race/ethnicity categories). Then we estimate a logistic regression with the
} 
We then match the survey records, by PIK, to LEHD earnings records for jobs held between 2003 quarter 3 (also denoted as 2003:3) and 2012 quarter 3 (2012:3). The LEHD program produces a set of microdata Infrastructure Files using employment data provided by states along with federal administrative data and survey data (Abowd et al., 2009). States that have joined the Local Employment Dynamics (LED) Partnership provide the Census Bureau with two employment files each quarter. ${ }^{44}$ Unemployment Insurance (UI) earnings records list the quarterly earnings of each worker from each of his employers. The LEHD program compiles the records as an Employment History File, with a record in the file for each job, identified by the combination of a worker (PIK) and employer, which is identified by a State Employer Identification Number (SEIN). An SEIN may be further linked to the employer file, which is produced from the same source data that employers submit to the Bureau of Labor Statistics for the Quarterly Census of Employment and Wages. The employer file lists the industry, ownership, employment, and location of establishments.

To focus our study on workers with ties to the labor market covered by LEHD data, we require that survey respondents have LEHD earnings for each of nine quarters from 2003:3 to 2005:3. We also require that they have a job spanning July 1, 2005 (the beginning of the quarter in which the storms occurred). ${ }^{45}$ For that job (or the highest-earning one in 2005:2 if a worker has multiple such jobs), we link to the employer's industry (NAICS code) and establishment location. ${ }^{46}$ We link over 90 percent of workers to a workplace Census tract or block, and approximately 99 percent are linked to a workplace county. We use the industry and workplace information to examine differential effects of the storm on workers, given their pre-storm employment.

dependent variable indicating a match to a CPR residence at the county level or better and indicators for sex, age cohorts, and race/ethnicity as explanatory variables. Hispanics, younger respondents, and those with high school education or less are less likely to have a linked residence. We retain only the records with a PIK and linked residence, and we use the product of the inverse of the predicted retention probabilities from both reweighting schemes to reweight the remaining survey records. The resulting sample has very similar weighted characteristics as the original, unweighted extract.

${ }^{44}$ All 50 states, the District of Columbia, Puerto Rico, and the Virgin Islands joined the LED Partnership by 2012. The time series of LEHD earnings records begins in 1985, but not all states provide data in every year. By 2003 , there are data for 47 states. Jobs with earnings in Arizona and the District of Columbia were not available at the beginning of the series, but they are included in later years. Jobs with earnings in Massachusetts are not included in the study. These coverage issues should have only a small effect on our analysis because the treatment and control samples do not include any individuals whose 2005 residence was in Arizona, the District of Columbia, or Massachusetts. Because Mississippi first provided earnings records for 2003:3, that quarter is the first one used in the study.

${ }^{45}$ Using the LEHD data, we identify workers with earnings from the same employer in the adjacent quarters $2005: 2$ and 2005:3. The LEHD program uses this definition to tabulate beginning-of-quarter employment, with the reasoning that a worker with the same job in adjacent quarters is employed at the seam of those quarters. We use the Successor Predecessor File to span the adjacent quarters in cases where an employer identifier may have changed due to restructuring.

${ }^{46}$ We link earnings records by SEIN to the Employer Characteristics File. For jobs at single-unit employers, the link is straightforward. For jobs at multi-unit employers, we use the Unit-to-Worker imputation, applied by the LEHD program to assign establishments to workers when establishment assignments are unknown (for all states except Minnesota). The imputation only assigns an establishment to a worker if the establishment exists during the worker's tenure at the employer, and it uses establishment size and proximity to a worker's place of residence as explanatory factors. We use the first of ten implicates from the imputation model. In general, the use of imputed workplace data would be expected to attenuate any estimates relating to workplace-damage measures. 
In constructing the sample for our main analysis, the two-year attachment and July 1 job restriction reduce the sample to approximately 46 percent of all the survey respondents that link to LEHD earnings histories ever over the study period (after the restrictions based on age and residence data). Workers eliminated from the sample by this earnings restriction may be employed in sectors not covered by the LEHD data, including self-employment, the federal government, the postal service, the armed forces, agricultural or family work, and other noncovered sectors. ${ }^{47}$ Still, LEHD earnings records cover approximately 96 percent of privatesector, non-farm wage-and-salary employment. LEHD earnings include some high-earning records that can distort earnings measures in particular quarters. For this reason, and to focus on the earnings outcomes of typical workers, we top-code quarterly earnings levels to $\$ 500,000$ (in $\$ 2005: 2)$.

We define industries using 2007 NAICS Industry Sectors, as listed here by the first two digits of the code.

- Agriculture and resources: 11 and 21.

- Construction: 23.

- Manufacturing: 31-33.

- Leisure, Accommodations, Arts, Recreation, Food service: 71, 72.

- Public, Education: 61, 92.

- Healthcare: 62.

- Professional services, Information, Finance, Insurance, Real Estate, Management: 51-55.

- Local services, Retail: 44-45, 56, 81.

- Trade, Transportation, Warehousing, Wholesale, Utilities: 22, 42, 48-49.

\subsection{Damage Data}

FEMA (2005) carried out a remote-sensing analysis of areas affected by Hurricanes Katrina and Rita. ${ }^{48}$ The survey included areas in 22 of the 63 counties in our treatment area. FEMA assigned the following damage classifications applying to structures within geographic areas.

- Limited Damage: Generally superficial damage to solid structures (e.g., the loss of tiles or roof shingles); some mobile homes and light structures are damaged or displaced.

- Moderate Damage: Solid structures sustain exterior damage (e.g., missing roofs or roof segments); some mobile homes and light structures are destroyed, and many are damaged or displaced.

- Extensive Damage: Some solid structures are destroyed, most sustain exterior damage (e.g., roofs are missing, interior walls are exposed); most mobile homes and light structures are destroyed.

- Catastrophic Damage: Most solid and all light or mobile structures are destroyed.

- Flooded area: Area under water.

- Undamaged: Areas not covered by the above categories.

\footnotetext{
${ }^{47}$ See Stevens (2007) for a discussion of coverage in unemployment-insurance earnings records, which varies by state. The LEHD program is working to add data on the self-employed and on federal workers.

${ }^{48}$ Post-disaster reconnaissance includes several tiers of regional, neighborhood, and per-building assessment (Womble et al., 2006). Early stages made use of high-resolution satellite and aerial imagery.
} 
FEMA released several vintages of sub-county damage mapping in 2005. For this study, we use three vintages of geographic files. For Katrina, we use both the September 10 and September 11 files. For Rita, we use the September 29 file. ${ }^{49}$ We consider flooding in the September 10 and September 29 files to be minor damage and code the flooding in the September 11 file as major damage because only those locations had long-term flooding.

We use ArcMap 10.1 to intersect damage areas of these shape files with Census blocks in our treatment counties. ${ }^{50}$ A Census tract is a geographically compact and demographically homogeneous tabulation area with a target population of 4,000 residents, analogous to a neighborhood. Tracts consist of blocks, which are bounded by features such as streets, streams, and jurisdiction boundaries and often correspond with one or two city blocks in an urban area (there is no target population for a block, but there are typically dozens of people within a tract). Our residence addresses are geocoded to Census 2000 tabulation geography, while the workplace addresses are geocoded to Census 2010 tabulation geography. We use separate intersection files for each tabulation year to classify workers' residences and workplaces as damaged.

For the treatment sample, Table A5 gives the distribution of damage types associated with each worker, by 2005 residence block and workplace block. The top two rows indicate addresses with positive evidence of damage. Most instances of major damage are long-term flooding or Catastrophic Damage. Minor damage is split between short-term flooding and Moderate and Limited Damage. The middle two rows indicate addresses where damage is possible but uncertain - due to either an imprecise residence or workplace address in a surveyed county or an address in a county not surveyed. All addresses are precise to at least the county level. The lower two rows indicate addresses with no damage, which were either in a surveyed county or outside the treatment area altogether (workplace only). Overall, 70 percent of residences and 58 percent of workplaces were within surveyed counties of the treatment area.

Figure A4 presents more-detailed views of the maps in Figure 2, overlaid with boundaries of Census blocks. Panel A shows downtown New Orleans, including the French Quarter. Panel B shows an area of Gulfport, Mississippi, including beachside resorts, residential housing, and shipping terminals. Census-block boundaries are often consistent with city streets, so the maps also provide a good indication of the infrastructure layout in these areas and provide a scale for the extent of damage to urban areas. For this study, any address in a block including any minor or major damage is assumed to be subject to that damage, with major damage taking precedence over minor damage.

\subsection{Pre-storm Economic Conditions for Propensity-Score Model}

Our propensity-score model includes four county-level measures of pre-storm economic conditions.

\footnotetext{
${ }^{49}$ Our GIS files for these snapshots have the following names: damage_10sep05_1000 (Sept. 10), katrina_receded_flooding_11sep05 (Sept. 11), and damage_29sep05_1000 (Sept. 29). FEMA released these files as events unfolded but does not maintain them or provide additional information on the creation of the files. Ron Jarmin and Javier Miranda provided the copies used here based on the data used in Jarmin and Miranda (2009).

${ }^{50}$ Because addresses geocoded to Census blocks are already so spatially precise, we do not make a distinction of whether an address is located in the exact part of a block that intersects with the damage shape files. One concern with a coordinate-based measure is that some addresses can be geocoded to a street of a block but cannot be precisely located along the street. Another concern is that properties extend beyond the exact coordinates of an address. Furthermore, the exact extent of damage areas may be less certain than the shape files indicate.
} 
- Percent highly attached. This is the percent of individuals in the county who were employed for each of the nine quarters from 2003:3 to 2005:3 and continuously employed at a job from 2005:2 to 2005:3. The source of this measure is our matched survey-administrative worker data.

- Unemployment rate in 2004. The source of this measure is annual county-level estimates by the Bureau of Labor Statistics (Local Area Unemployment Statistics).

- Housing-price change from 2000:2 to 2005:2. This measure is based on Federal Housing Finance Agency (FHFA) All-Transactions House Price Indexes, which are derived from appraisal values and sales prices. These FHFA indexes are quarterly, not seasonally adjusted, and available for 401 metropolitan areas (or metropolitan divisions) and 47 nonmetropolitan balance-of-state areas (e.g., all nonmetropolitan counties in Iowa). For counties located in metropolitan areas, we use the FHFA index for that metropolitan area (or metropolitan division). For other counties, we use the FHFA index for the relevant nonmetropolitan area. The measure of change we use is $100 *($ hpi2005-hpi2000) / [(hpi2000+ hpi2005)/2], where hpi2000 and hpi2005 are the index values for 2000:2 and 2005:2, respectively.

- Population change from 2000 to 2005. This measure is based on Census Bureau population estimates at the county level, which have a reference date of July 1 . The measure of change we use is $100 *(\mathrm{p} 2005-\mathrm{p} 2000) /[(\mathrm{p} 2000+\mathrm{p} 2005) / 2]$, where $\mathrm{p} 2000$ and $\mathrm{p} 2005$ are the population estimates for 2000 and 2005 , respectively.

\subsection{Control Suitability}

While it is apparent from an inspection of Table 1 that the matched control sample improves upon the potential control sample in terms of alignment with the treatment sample, here we use standardized differences to quantify the improvement. Table A3 introduces the characteristics of the treatment sample, the matched control sample of counties, and three alternate sets of control counties. Figure A1 depicts the county composition of the three alternate control samples (described in Section 7.1). To quantify the dissimilarity of each control sample from the treatment sample, Table A4 presents a measure of how each of the control samples diverge from the treatment sample, both in aggregate and by characteristics (each defined by a single variable or a grouping of related variables).

The standardized difference (see Austin, 2009) of any variable that is continuous at the person level (e.g., earnings, county population change from 2000 to 2005, county unemployment rate in 2004) is calculated as

$$
d_{\text {continuous }}=\frac{\bar{x}_{\text {treatment }}-\bar{x}_{\text {control }}}{\sqrt{\frac{1}{2} \cdot\left(s_{\text {treatment }}^{2}+s_{\text {control }}^{2}\right)}},
$$

where $\bar{x}$ is the sample mean and $s^{2}$ is the sample variance. We calculate the sample mean and variance across persons in the sample, using person weights. Note that some characteristics, such as population change, are common to all persons in the same county. The standardized difference for a categorical variable (e.g., female, age bins, race/ethnicity categories) is calculated as

$$
d_{\text {categorical }}=\frac{\hat{p}_{\text {treatment }}-\hat{p}_{\text {control }}}{\sqrt{\frac{1}{2} \cdot\left(\hat{p}_{\text {treatment }}\left(1-\hat{p}_{\text {treatment }}\right)+\hat{p}_{\text {control }}\left(1-\hat{p}_{\text {control }}\right)\right)}},
$$

where $\hat{p}$ is the prevalence (or mean) of a categorical variable with a value between zero and one.

We compute an index of the standardized differences, a Root Mean Squared Error (RMSE), for each characteristic as 


$$
d(k)_{R M S E}=100 \cdot \sqrt{\frac{1}{M_{k}} \sum_{m=1}^{M_{k}}\left(d_{k m}\right)^{2}},
$$

where $k$ is a characteristic that takes on $M_{k}$ categorical values (or consists of a set of that many continuous variables), indexed $m=1$ to $M_{k}$. For measuring divergence, we treat the eight prestorm, quarterly-earnings variables as a single characteristic, with equal weight on each quarter. The index is always positive and treats each of the $M_{k}$ components with equal weight. For an aggregate difference measure for all characteristics combined, we index the characteristics by $k=1$ to $K$, assign equal weight to each characteristic, and compute the integrated index (RIMSE) as:

$$
d_{R I M S E}=100 \cdot \sqrt{\frac{1}{K} \sum_{k=1}^{K}\left[\frac{1}{M_{k}} \sum_{m=1}^{M_{k}}\left(d_{k m}\right)^{2}\right]} .
$$

The first row of Table A4 presents the integrated index, giving a divergence index of 23.9 for the set of potential control sample and 5.9 for the matched control sample. This drop in the index confirms that the matching process provides a control sample that is more similar to the treatment sample. The matched control sample also has a lower divergence index than the Coastal Plain, Upland South, and Weak Cities control samples. The matched control sample improves on the potential control sample on almost every characteristic. The biggest improvements were for race/ethnicity and housing-price growth.

\subsection{Employment and Wages in Local Labor Markets}

We construct estimates of quarterly employment totals (overall and by industry sector) for the treatment and control areas following the tabulation methods used in the Quarterly Workforce Indicators (QWI), an LEHD public-use data product. QWI includes local labormarket indicators of employment, earnings, hires, separations, turnover, and net employment growth. Confidentiality-protection methods, described in Abowd et al. (2009), allow the Census Bureau to release these data in cells defined by employer industry, ownership, and location and by worker characteristics with minimal suppression. Our study makes use of beginning-ofquarter employment, a point-in-time indicator of the count of jobs that had earnings records in two consecutive quarters. The logic of this employment measure is that a worker holding a job in both quarters was most likely employed there at the seam of the quarters (e.g., April 1 is the seam between the first and second quarters). In contrast, an employment measure that included all jobs held in a quarter would over-estimate employment at a point in time because some jobs are held one after the other.

Although it would be possible to construct aggregations of employment for the sets of counties in the treatment and control areas using the pubic-use QWI, there would be some undercount of employment due to suppression of some cells that do not meet Census Bureau publication standards. The undercount would be due to individual counties (or county-byindustry cells) having fewer than three persons or establishments. In addition, the noise infusion for some small cells may result in excessive distortion. These cells represent a small share of total jobs in the treatment and control areas.

Therefore, to provide a more-accurate representation of aggregate employment in treatment and control areas, we produce custom QWI tabulations where the suppression and distortion issues are not binding. We produce quarterly tabulations of employment in the treatment and control areas using confidentiality protection and suppression rules identical to those used in the QWI. By aggregating the county lists of the two areas, each as a single cell, we avoid the small-cell issues that can occur in single-county tabulations. 
Our estimates of average hourly wages in the treatment and control areas over time are derived from the Occupational Employment Statistics (OES) survey. The OES survey, which is a cooperative effort between the Bureau of Labor Statistics (BLS) and the State Workforce Agencies, is a semiannual mail survey measuring occupational employment and wage rates for wage-and-salary workers in nonfarm establishments. In the survey, establishments classify their employment by occupation and wage category. OES estimates are constructed from a sample of about 1.2 million establishments.

Each year, survey forms are mailed to two semiannual panels of approximately 200,000 sampled establishments, one panel in May and the other in November. Estimates for a given reference month are based on data collected from six semiannual panels over a three-year period ending in that month. In order to have wage estimates reflect current conditions, wages in the five previous panels are updated to the reference month using movements in occupational wages over time as measured by the BLS Employment Cost Index.

The starting point for our OES analysis is public-use estimates of average wages by metropolitan area for May 2005, May 2008, and May 2012. Estimates are made for each of 22 major occupation groups (e.g., management, sales, and production) and the total over all occupations. The May 2005 estimates are based on data collected between November 2002 and May 2005. The May 2008 estimates are based on data collected from November 2005 to May 2008, and the May 2012 estimates are based on data collected from November 2009 to May 2012. We use the Consumer Price Index to put all estimates of average wages in 2005:2 dollars.

We use the metropolitan-area estimates to construct estimates for the treatment and control areas. According to the definitions of metropolitan areas (MSAs), 31 of the treatment counties and 80 of the control counties are in metropolitan areas. There are 11 MSAs containing at least one treatment county and $41 \mathrm{MSAs}$ containing at least one control county. These counties represent a large share of employment in the treatment and control areas. In 2004, the 31 treatment counties in the OES analysis accounted for 80 percent of employment in the 63 treatment counties. The 80 control counties in the OES analysis accounted for 74 percent of employment in the 279 control counties.

When we aggregate estimates at the MSA level to estimates for treatment and control areas, we weight by MSA employment in the treatment/control counties. The OES estimates provide employment counts for the entire MSA (by occupation group), and we rescale these counts by the share of employment in each MSA that is in treatment/control counties. We derive these shares using county employment from the Quarterly Census of Employment and Wages (QCEW) for the calendar year preceding each OES reference month (e.g., calendar 2004 in QCEW for May 2005 in OES). QCEW employment for a given year is defined for this analysis as the average of employment for March, June, September, and December.

These procedures provide estimates of average wages by occupation for the treatment and control areas over time. To construct estimates of average wages by industry for the treatment and control areas, we make use of OES national estimates of employment by industry and occupation for each of the three time periods. These estimates allow us to construct, for each time period and industry sector, the share of employment that is in each occupation group. We then use these shares as weights for the occupational wage estimates in order to construct industry wage estimates. Specifically, the industry wage for a given area (treatment or control) is a weighted average of the occupational wage estimates, with the weights being the share of industry employment in each occupation group. 
The Census Bureau creates statistics on residential building permits (RBP), including annual totals by county for buildings, units, and value. We focus on the quantity of units, which is likely to apply equally to urban, suburban, and rural areas (building sizes may differ). The footnote in Section 6 refers to data from 1995 to 2013. The Census Bureau surveys local authorities on permit activity for new construction and renovations and imputes data based on local trends in the event of non-response in a particular year. Because some counties have never responded or do not issue permits, we focus on longitudinal changes among counties in the treatment and control areas that had RBP estimates in every year (including all counties in the treatment area and all but seven in the control area).

The National Center for Education Statistics provides the annual count of students enrolled in each public elementary and secondary school in the Common Core of Data. The footnote in Section 6 refers to data for 2002 to 2012, aggregated to the county level and then summarized for the treatment and control areas. 
Table A1. Propensity-score Model for Constructing Matched Control Sample

\begin{tabular}{lrr}
\hline \hline Variable & Coef. & Std. Err. \\
\hline White, not Hispanic & -- & \\
Black, not Hispanic & 0.063 & 0.017 \\
Hispanic & -0.047 & 0.038 \\
Other race, not Hispanic & -0.171 & 0.129 \\
\hline Less than high school & 0.390 & 0.129 \\
High school & -- & \\
Some college & 0.170 & 0.073 \\
College & -0.039 & 0.074 \\
\hline Agriculture & -0.322 & 0.295 \\
Natural resources & 0.046 & 0.093 \\
Construction & 0.384 & 0.136 \\
Manufacturing & -0.097 & 0.063 \\
Leisure, Accommodations & 0.130 & 0.075 \\
Healthcare & 0.066 & 0.068 \\
Professional services & -0.062 & 0.079 \\
Local services & -0.061 & 0.090 \\
Trade, Transport, Utilities & -0.091 & 0.090 \\
Public, Education & -- & \\
\hline Earnings 2003:3 & 5.342 & 1.358 \\
Earnings 2003:4 & -1.138 & 0.973 \\
Earnings 2004:1 & -1.137 & 1.238 \\
Earnings 2004:2 & -3.837 & 1.277 \\
Earnings 2004:3 & -2.218 & 1.301 \\
Earnings 2004:4 & -1.140 & 1.008 \\
Earnings 2005:1 & 1.601 & 0.931 \\
Earnings 2005:2 & 3.436 & 1.144 \\
\hline Percent highly attached & -0.211 & 0.054 \\
Unemployment rate, 2004 & 0.045 & 0.198 \\
Housing-price change, 2000:2-2005:2 & -0.166 & 0.043 \\
Population change, 2000-2005 & -0.003 & 0.047 \\
\hline Constant term & -6.007 & 6.277 \\
\hline Notes: Table shows cstims & & \\
\hline
\end{tabular}

Notes: Table shows estimated coefficients and standard errors from a logit model with the dependent variable being an indicator for a county being a treatment county. Number of observations is 2,456 . Counties are weighted by the sum of the person weights across individuals with high attachment to the labor market in the pre-storm period. For the model, the variables for race, education, industry, and share highly attached are percentages (0 to 100) and the earnings variables are coded in thousands of dollars (\$2005:2). Housing-price change and population change are rates of change (see text for definitions).

$* \mathrm{p}<0.05$. 
Table A2. Distribution of Treatment and Control Samples across Industries

\begin{tabular}{|c|c|c|c|c|c|c|c|c|}
\hline \multirow[b]{2}{*}{ Industry } & \multicolumn{4}{|c|}{ Treatment } & \multicolumn{4}{|c|}{ Control } \\
\hline & $2005: 2$ & $2006: 2$ & 2008:2 & 2012:2 & $2005: 2$ & 2006:2 & 2008:2 & 2012:2 \\
\hline Agriculture and resources & 2.96 & 2.52 & 2.67 & 2.27 & 1.88 & 1.71 & 1.69 & 1.54 \\
\hline Construction & 6.10 & 5.28 & 5.15 & 4.34 & 5.13 & 4.50 & 4.20 & 3.18 \\
\hline Manufacturing & 13.76 & 12.12 & 11.64 & 9.78 & 14.56 & 13.10 & 11.65 & 9.24 \\
\hline Leisure, Accommodations & 6.84 & 4.54 & 4.44 & 4.10 & 5.29 & 4.24 & 3.97 & 3.49 \\
\hline Healthcare & 14.78 & 12.28 & 12.08 & 11.45 & 14.51 & 12.98 & 12.42 & 11.53 \\
\hline Professional services & 12.70 & 10.68 & 10.62 & 9.74 & 13.76 & 12.55 & 11.73 & 10.41 \\
\hline Local services & 15.53 & 13.02 & 12.41 & 10.89 & 15.92 & 13.62 & 12.79 & 11.41 \\
\hline Trade, Transport, Utilities & 9.80 & 8.30 & 8.39 & 7.52 & 10.51 & 9.45 & 9.12 & 8.09 \\
\hline Public, Education & 17.53 & 14.72 & 14.11 & 13.28 & 18.45 & 16.66 & 16.54 & 14.49 \\
\hline \multirow[t]{2}{*}{ Not employed } & 0.00 & 16.53 & 18.48 & 26.63 & 0.00 & 11.20 & 15.89 & 26.62 \\
\hline & \multicolumn{4}{|c|}{ Treatment - Control } & & & & \\
\hline Industry & $2005: 2$ & $2006: 2$ & 2008:2 & $2012: 2$ & & & & \\
\hline Agriculture and resources & 1.08 & 0.81 & 0.98 & 0.73 & & & & \\
\hline Construction & 0.97 & 0.78 & 0.95 & 1.16 & & & & \\
\hline Manufacturing & -0.80 & -0.98 & -0.01 & 0.54 & & & & \\
\hline Leisure, Accommodations & 1.55 & 0.30 & 0.47 & 0.61 & & & & \\
\hline Healthcare & 0.27 & -0.70 & -0.34 & -0.08 & & & & \\
\hline Professional services & -1.06 & -1.87 & -1.11 & -0.67 & & & & \\
\hline Local services & -0.39 & -0.60 & -0.38 & -0.52 & & & & \\
\hline Trade, Transport, Utilities & -0.71 & -1.15 & -0.73 & -0.57 & & & & \\
\hline Public, Education & -0.92 & -1.94 & -2.43 & -1.21 & & & & \\
\hline Not employed & 0.00 & 5.33 & 2.59 & 0.01 & & & & \\
\hline
\end{tabular}

Notes: Columns in the upper panel provide the distribution (in percentages) across industry sectors of the treatment and matched control samples at the beginning of each quarter listed. Industry assignments are for the highestearning job in that quarter, among those held in the listed quarter and in the following quarter (referred to in QWI as an end-of-quarter job). The lower panel provides differences between the industry distributions of the treatment and matched control samples in each quarter. 
Table A3. Summary Statistics for Alternate Control Samples and Broader Sample

\begin{tabular}{|c|c|c|c|c|c|c|c|}
\hline \multirow[b]{3}{*}{ Variable } & \multicolumn{5}{|c|}{ High-attachment Sample } & \multicolumn{2}{|c|}{ Broader Sample } \\
\hline & \multirow[b]{2}{*}{ Treatment } & \multirow[b]{2}{*}{$\begin{array}{r}\text { Matched } \\
\text { Control } \\
\end{array}$} & \multicolumn{3}{|c|}{ Alternate Control Samples } & \multirow[b]{2}{*}{ Treatment } & \multirow[b]{2}{*}{$\begin{array}{l}\text { Matched } \\
\text { Control }\end{array}$} \\
\hline & & & $\begin{array}{r}\text { Coastal } \\
\text { Plain } \\
\end{array}$ & $\begin{array}{r}\text { Upland } \\
\text { South } \\
\end{array}$ & $\begin{array}{r}\text { Weak } \\
\text { Cities } \\
\end{array}$ & & \\
\hline Male & 50.2 & 49.1 & 47.1 & 50.3 & 51.0 & 48.1 & 48.2 \\
\hline Female & 49.8 & 50.9 & 52.9 & 49.7 & 49.0 & 52.0 & 51.8 \\
\hline $25 \leq$ Age $<30$ & 11.4 & 11.5 & 11.4 & 11.0 & 13.1 & 12.6 & 12.6 \\
\hline $30 \leq$ Age $<40$ & 28.9 & 29.5 & 28.3 & 29.4 & 28.9 & 28.1 & 28.6 \\
\hline $40 \leq$ Age $<50$ & 34.5 & 33.7 & 34.2 & 33.8 & 33.4 & 32.3 & 31.8 \\
\hline $50 \leq$ Age $<60$ & 25.2 & 25.3 & 26.1 & 25.8 & 24.7 & 27.0 & 27.0 \\
\hline White, not Hispanic & 65.3 & 65.4 & 60.7 & 77.0 & 67.8 & 64.2 & 64.7 \\
\hline Black, not Hispanic & 26.8 & 26.6 & 32.1 & 13.7 & 10.3 & 27.4 & 26.4 \\
\hline Hispanic & 5.3 & 5.2 & 3.2 & 3.4 & 15.2 & 5.2 & 5.7 \\
\hline Other race, not Hispanic & 2.6 & 2.8 & 4.0 & 5.9 & 6.7 & 3.2 & 3.2 \\
\hline Less than high school & 11.4 & 10.2 & 9.8 & 10.0 & 9.9 & 16.4 & 14.1 \\
\hline High school & 32.0 & 30.1 & 31.0 & 32.8 & 25.9 & 32.5 & 31.1 \\
\hline Some college & 33.2 & 33.0 & 34.3 & 31.6 & 32.3 & 31.3 & 31.6 \\
\hline College & 23.4 & 26.7 & 24.9 & 25.6 & 31.9 & 19.8 & 23.3 \\
\hline Ann'l earnings $<\$ 28.5 \mathrm{~K}$ & 38.7 & 37.8 & 41.0 & 39.1 & 30.4 & 69.5 & 68.9 \\
\hline$\$ 28.5 \mathrm{~K} \leq$ Ann'l earnings $<\$ 50 \mathrm{~K}$ & 34.5 & 36.4 & 36.7 & 38.3 & 35.4 & 17.8 & 18.7 \\
\hline Ann'l earnings $\geq \$ 50 \mathrm{~K}$ & 26.8 & 25.8 & 22.3 & 22.6 & 34.2 & 12.7 & 12.4 \\
\hline Agriculture and resources & 3.0 & 1.9 & 0.9 & 1.7 & 0.4 & 1.5 & 1.1 \\
\hline Construction & 6.1 & 5.1 & 5.1 & 4.2 & 4.2 & 3.4 & 3.1 \\
\hline Manufacturing & 13.8 & 14.6 & 14.7 & 20.0 & 15.1 & 6.4 & 7.1 \\
\hline Leisure, Accommodations & 6.8 & 5.3 & 5.6 & 3.9 & 5.0 & 3.8 & 3.2 \\
\hline Healthcare & 14.8 & 14.5 & 14.1 & 13.9 & 14.0 & 7.3 & 7.6 \\
\hline Professional services & 12.7 & 13.8 & 14.5 & 13.4 & 18.6 & 6.4 & 7.2 \\
\hline Local services & 15.5 & 15.9 & 17.0 & 14.5 & 15.7 & 8.6 & 9.3 \\
\hline Trade, Transport, Utilities & 9.8 & 10.5 & 8.8 & 10.6 & 10.2 & 4.9 & 5.4 \\
\hline Public, Education & 17.5 & 18.5 & 19.3 & 17.8 & 16.8 & 8.2 & 9.3 \\
\hline Not employed on July 1, 2005 & 0.0 & 0.0 & 0.0 & 0.0 & 0.0 & 49.7 & 46.7 \\
\hline Same county last year & 94.5 & 93.5 & 93.0 & 94.2 & 96.4 & 90.8 & 89.8 \\
\hline Other county last year & 5.5 & 6.6 & 7.0 & 5.8 & 3.6 & 9.2 & 10.2 \\
\hline Earnings 2003:3 & 9,970 & 10,228 & 9,388 & 9,564 & 11,481 & 5,346 & 5,568 \\
\hline Earnings 2003:4 & 10,799 & 11,095 & 10,368 & 10,649 & 12,745 & 5,760 & 5,992 \\
\hline Earnings 2004:1 & 10,405 & 10,734 & 9,812 & 10,129 & 12,292 & 5,509 & 5,715 \\
\hline Earnings 2004:2 & 10,255 & 10,503 & 9,842 & 10,156 & 12,013 & 5,420 & 5,598 \\
\hline Earnings 2004:3 & 10,315 & 10,606 & 9,831 & 10,032 & 11,983 & 5,400 & 5,656 \\
\hline Earnings 2004:4 & 11,234 & 11,555 & 10,788 & 11,140 & 13,384 & 5,863 & 6,056 \\
\hline Earnings 2005:1 & 10,646 & 10,918 & 9,896 & 10,257 & 12,446 & 5,589 & 5,688 \\
\hline Earnings 2005:2 & 10,640 & 10,833 & 10,069 & 10,440 & 12,415 & 5,483 & 5,709 \\
\hline Percent highly attached & 40.0 & 42.4 & 40.5 & 44.9 & 48.9 & 39.3 & 41.6 \\
\hline Unemployment rate, 2004 & 6.2 & 6.1 & 5.6 & 5.4 & 5.9 & 6.2 & 6.1 \\
\hline Housing-price change, 2000:2-2005:2 & 23.7 & 23.4 & 37.9 & 21.5 & 42.9 & 23.9 & 23.7 \\
\hline Population change, 2000-2005 & 3.7 & 4.1 & 6.2 & 4.1 & 1.3 & 3.6 & 4.0 \\
\hline Observations & 110,000 & 335,000 & 179,000 & 367,000 & 936,000 & 275,000 & 795,000 \\
\hline
\end{tabular}

Note: See notes to Table 1. 
Table A4. Index of Standardized Differences of Control Samples from Treatment Sample

\begin{tabular}{|c|c|c|c|c|c|c|c|}
\hline Characteristic & $\begin{array}{l}\text { Variable } \\
\text { type }\end{array}$ & $\begin{array}{r}\text { Categories/ } \\
\text { variables }\end{array}$ & $\begin{array}{r}\text { Potential } \\
\text { Control } \\
\end{array}$ & $\begin{array}{r}\text { Matched } \\
\text { Control } \\
\end{array}$ & $\begin{array}{r}\text { Coastal } \\
\text { Plain } \\
\end{array}$ & $\begin{array}{r}\text { Upland } \\
\text { South } \\
\end{array}$ & $\begin{array}{l}\text { Weak } \\
\text { Cities }\end{array}$ \\
\hline Integrated index & Both & 35 & 23.89 & 5.93 & 17.89 & 18.05 & 29.77 \\
\hline Sex & Categorical & 2 & 2.10 & 2.25 & 6.16 & 0.15 & 1.62 \\
\hline Age & Categorical & 4 & 2.78 & 1.08 & 1.21 & 1.24 & 2.87 \\
\hline Race/ethnicity & Categorical & 4 & 28.28 & 0.53 & 10.07 & 23.16 & 29.12 \\
\hline Educational attainment & Categorical & 4 & 10.92 & 4.76 & 3.54 & 3.85 & 11.93 \\
\hline Industry $(2005: 3)$ & Categorical & 9 & 7.80 & 3.91 & 6.27 & 8.31 & 9.59 \\
\hline $\begin{array}{l}\text { Quarterly earnings } \\
(2003: 3-2005: 2)\end{array}$ & Continuous & 8 & 5.06 & 0.87 & 1.96 & 0.90 & 5.18 \\
\hline $\begin{array}{l}\text { Population change, } \\
2000-2005\end{array}$ & Continuous & 1 & 0.32 & 1.97 & 14.76 & 2.23 & 20.03 \\
\hline $\begin{array}{l}\text { Housing-price change } \\
\text { 2000:2-2005:2 }\end{array}$ & Continuous & 1 & 35.50 & 1.60 & 50.56 & 18.53 & 41.98 \\
\hline Percent highly attached & Continuous & 1 & 56.11 & 16.94 & 4.12 & 40.65 & 73.91 \\
\hline $\begin{array}{l}\text { Unemployment rate, } \\
2004\end{array}$ & Continuous & 1 & 16.78 & 3.61 & 14.60 & 25.19 & 10.80 \\
\hline
\end{tabular}

Notes: See Section 10.4. Each characteristic gives the RMSE of the control sample compared to the treatment sample, where standardized differences serve as the error measure. Each characteristic consists of a set of categorical variables, one continuous variable, or a set of continuous variables. The integrated index, or RIMSE, integrates the divergence measures across all characteristics, with an equal weight on each characteristic. See Table 1 and Table A3 for the complete list of sample means.

Table A5. Damage Incidence by Residence and Workplace (in percent)

\begin{tabular}{lrr}
\hline \hline Type of Damage & Residence & Workplace \\
\hline Major damage & 5.4 & 6.6 \\
Minor damage & 11.9 & 18.2 \\
Imprecise address (Uncertain) & 10.8 & 3.7 \\
Not surveyed (Uncertain) & 30.0 & 19.4 \\
No damage (None) & 41.9 & 29.2 \\
Outside treatment area & N.A. & 23.0 \\
\hline \hline
\end{tabular}

Notes: Residence and workplace determined by 2005 locations. Residence location is from linked CPR address. Workplace location is from Employer Characteristics File, linked to earnings record at the time of the storm in the Employment History File. Damage labels in parentheses correspond to the labels in Table 2. 
Figure A1. Alternate Control Areas

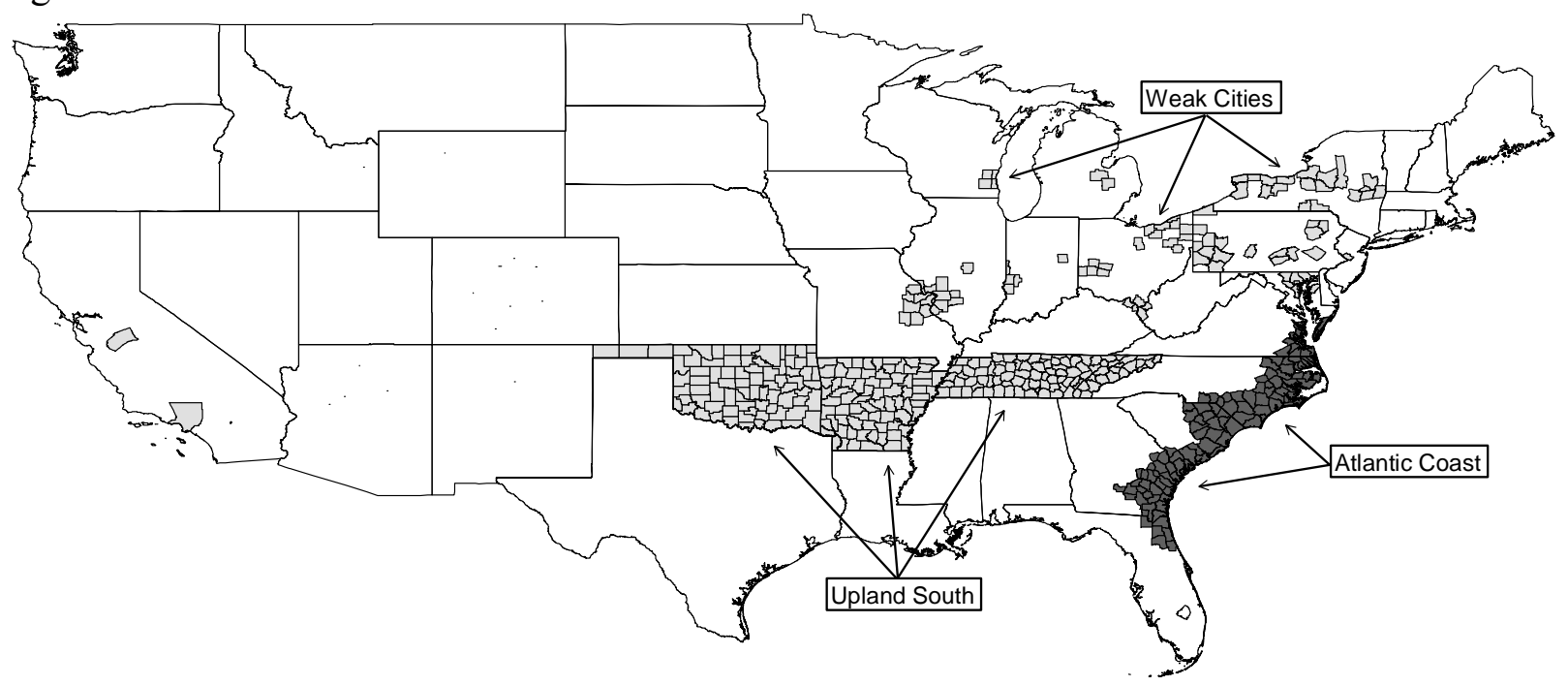

Notes: Map depicts the residence location of workers in alternate control samples. The Atlantic Coast (darker shading) control is in Florida, Georgia, South Carolina, North Carolina, and Virginia. The Upland South (lighter shading) control is in Oklahoma, Arkansas, and Tennessee. The Weak Cities (lighter shading) control is in California, Missouri, Illinois, Wisconsin, Indiana, Michigan, Ohio, Kentucky, West Virginia, Pennsylvania, Maryland, New Jersey, and New York. 
Figure A2. Effects on Earnings with Alternate Control Samples

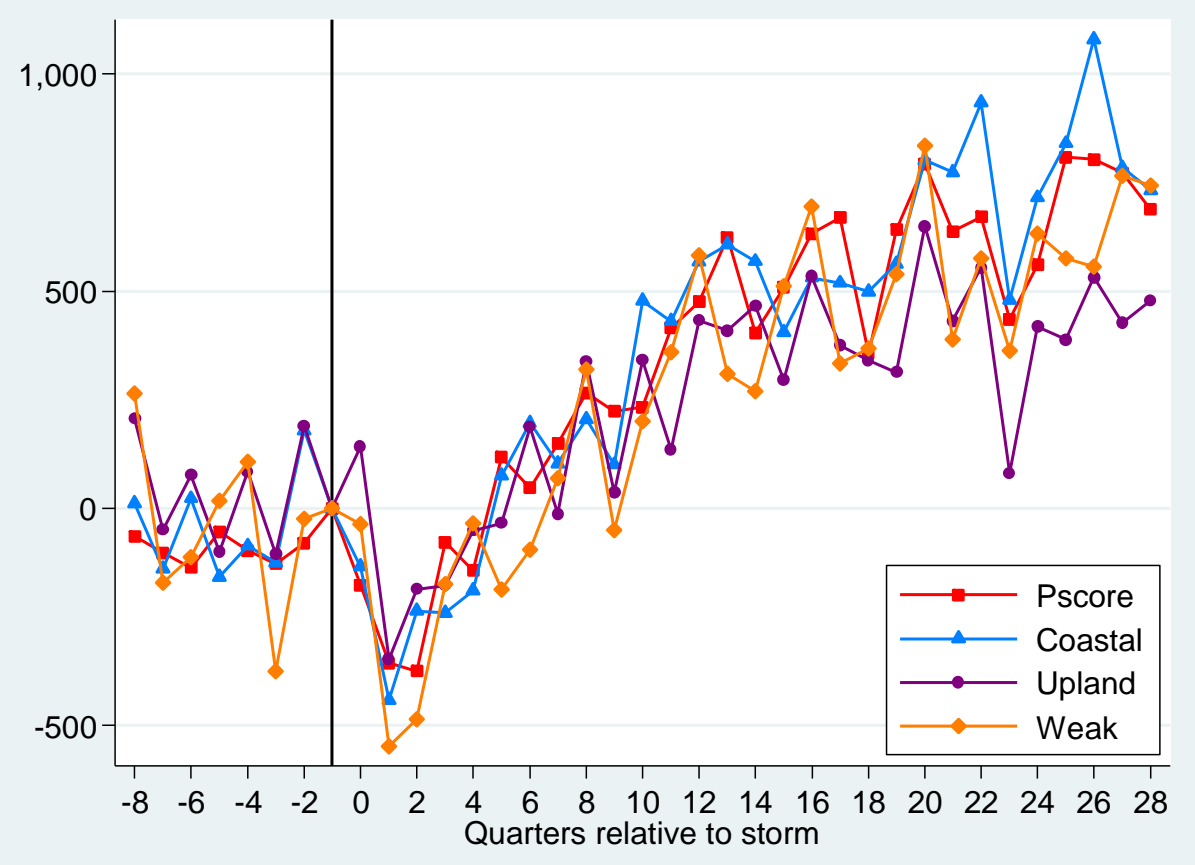

Notes: See Figure 4 for description of earnings data. Equation (1) provides the model specification. The sample for this analysis is the treatment sample paired with the either the matched (labeled "Pscore"), Coastal Plain, Upland South, or Weak Cities control sample. See Table A3 for sample sizes.

Figure A3. Effects on Earnings, Broader Sample

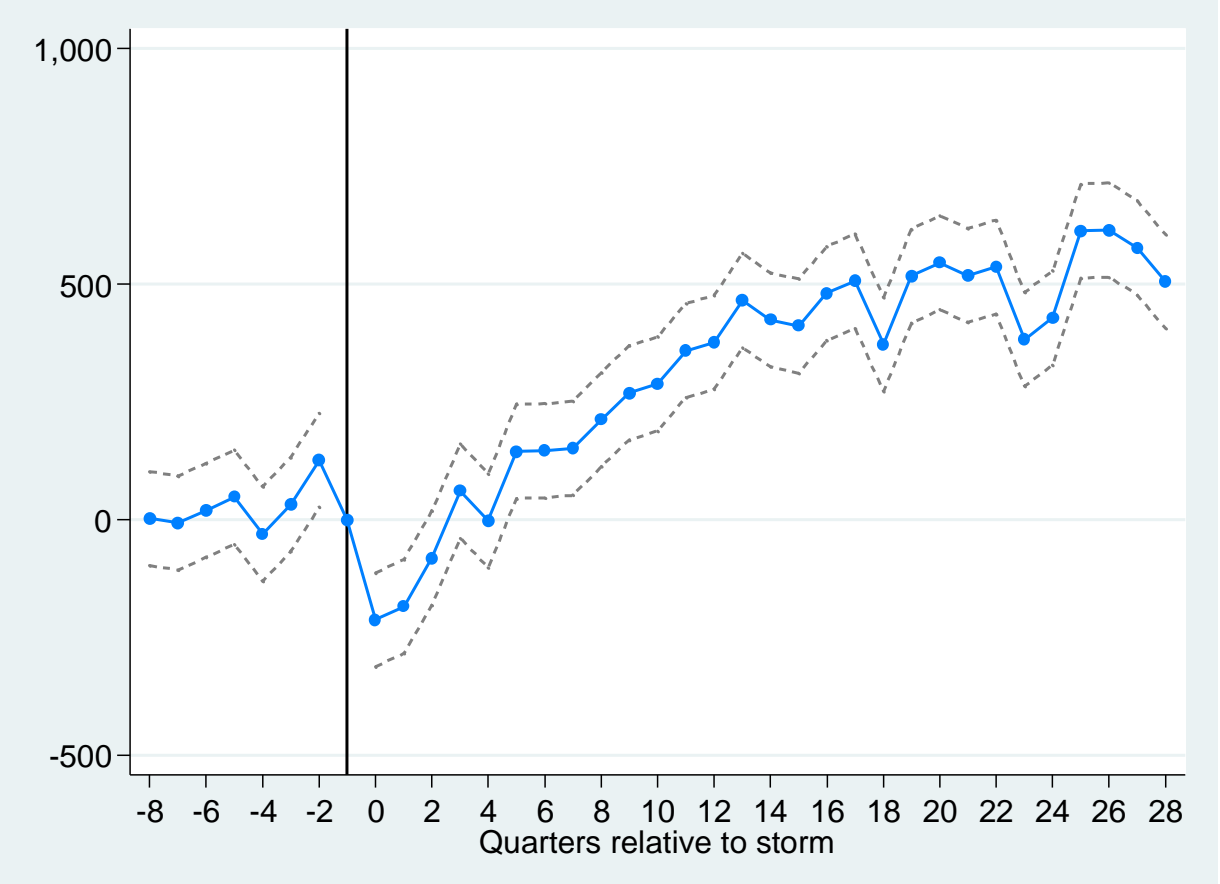

Notes: See Figure 4 for description of earnings data. Equation (1) provides the model specification. See Table A3 for sample sizes for the broader sample. Dashed lines show the upper and lower bounds of $95 \%$ confidence intervals. 
Figure A4. Major and Minor Damage Overlaid with Census Blocks
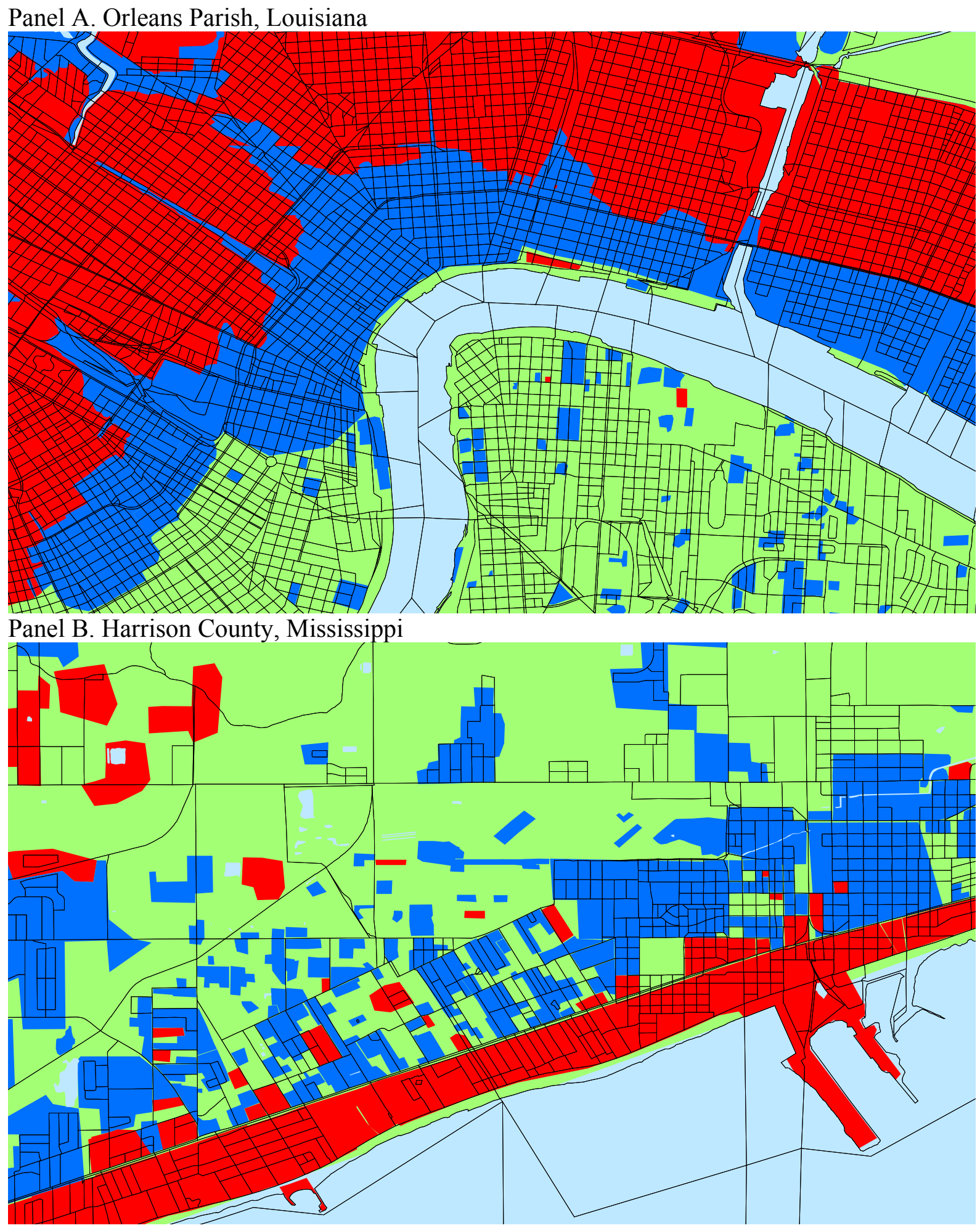

Source: Damage information from FEMA (2005).

Notes: Panels A and B depict damage from Hurricane Katrina, along with boundaries of Census blocks. Red indicates major damage, dark blue indicates minor damage, green indicates undamaged land area, and light blue indicates bodies of water. Both maps are to the same scale and depict an area approximately 5.5 miles wide. 